Supplementary Information:

\title{
Electrophilic sulfonium promoted peptide and protein amidation in aqueous media
}

Chuan Wan ${ }^{+, \#}$, Yuan Feng ${ }^{+, \#}$, Zhanfeng Hou ${ }^{\dagger, \#}$, Chenshan Lian', Liang Zhang ${ }^{\ddagger, \boldsymbol{q}}$, Yuhao An ${ }^{\dagger}$, Jinming Sun ${ }^{+}$, Dongyan Yang ${ }^{£}$, Chenran Jiang $^{\dagger}$, Feng Yin ${ }^{\dagger, *}$, Rui Wang †,, Zigang $\mathrm{Li}^{+,,, \text {, }}$

+State Key Laboratory of Chemical Oncogenomics, School of Chemical Biology and Biotechnology, Peking University Shenzhen Graduate School, Shenzhen, 518055, P. R. China.

$\nmid$ Pingshan translational medicine center, Shenzhen Bay Laboratory, Shenzhen, 518118, P. R. China. $£$ College of Chemistry and Chemical Engineering, Zhongkai University of Agriculture and Engineering, Guangzhou, 510225, P. R. China.

$\ddagger$ Key Laboratory of Biochip Technology, Biotech and Health Centre, Shenzhen Research Institute of City University of Hong Kong, Shenzhen, 518057, China.

IDepartment of Biomedical Sciences, College of Veterinary Medicine and Life Sciences, City University of Hong Kong, 83 Tat Chee Avenue, Kowloon, Hong Kong, China.

\#Contributed equally to this work.

*Address correspondence to yinfeng@szbl.ac.cn, wangrui@szbl.ac.cn, $\underline{\text { lizg.sz@pku.edu.cn, }}$ lizg@szbl.ac.cn 


\section{Table of Contents}

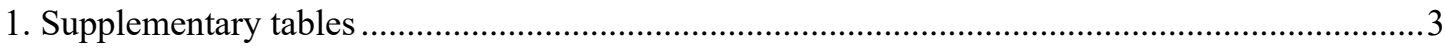

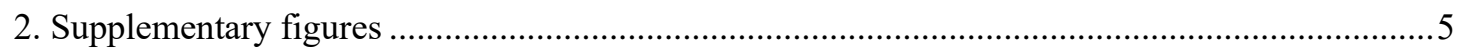

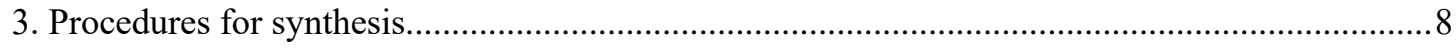

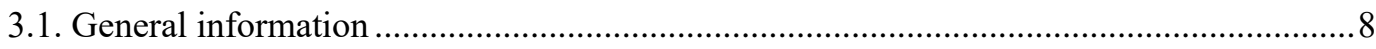

3.2. General procedure A for the propargyl sulfonium 3 promoted amidation in aqueous

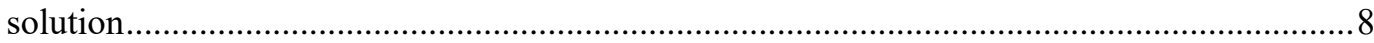

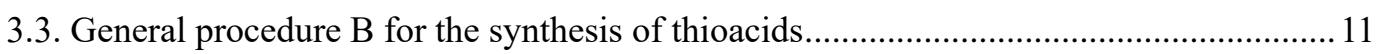

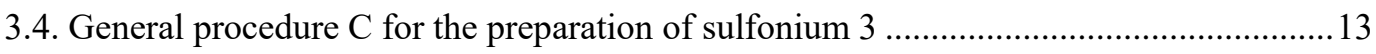

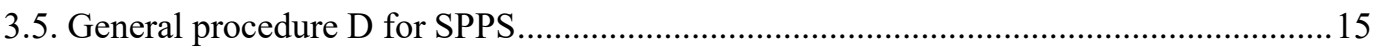

3.6. General procedure $\mathrm{E}$ for the synthesis of sulfonium intermediates..................................15

3.7. General procedure F for the synthesis of control probes (NHS esters) ............................17

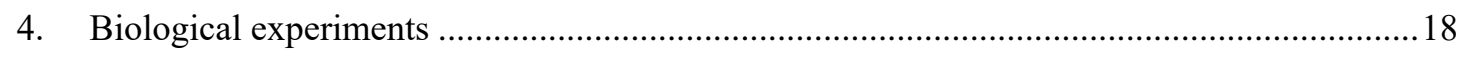

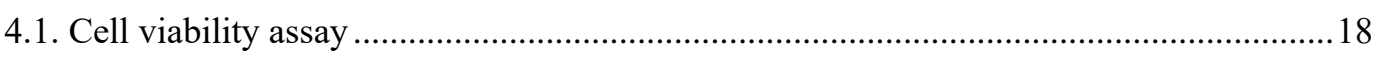

4.2. Western blot to identify the covalent reaction efficiency of activated ester and protein.. 18

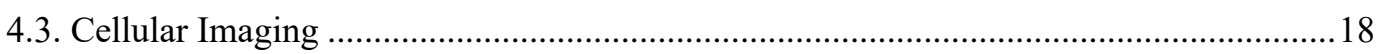

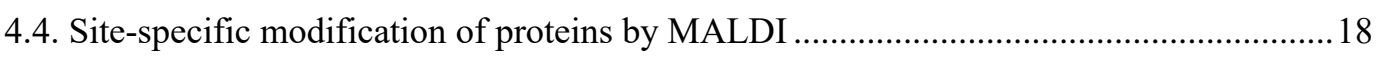

4.5. Sample preparation for modification site analysis by MS/MS spectrum ..........................18

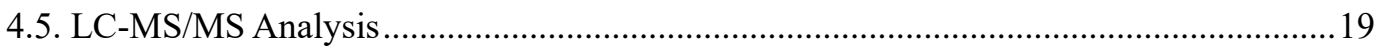

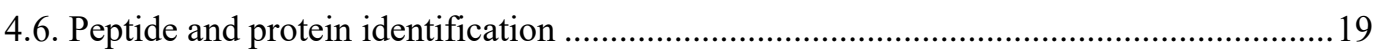

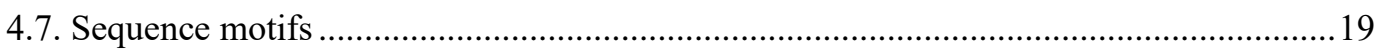

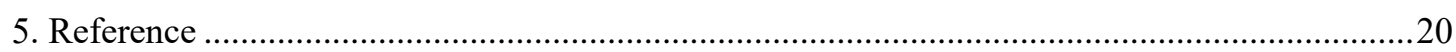

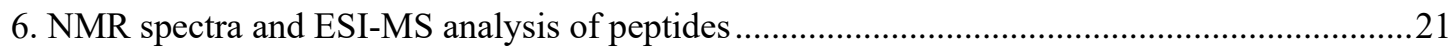




\section{Supplementary tables}

Table S1. Optimization of the equivalent of substrate, sulfonium and base for SPSS

\begin{tabular}{ccccc} 
& & & \\
\hline
\end{tabular}


Table S2. Optimization of solvent and amount of solvent for SPSS

\begin{tabular}{|c|c|c|c|}
\hline Entry & Solvent & $\begin{array}{l}\text { Amount of } \\
\text { solvent }(\mu L)\end{array}$ & Yield (\%) \\
\hline 1 & DMF & 300 & 25 \\
\hline 2 & DMF & 400 & 44 \\
\hline 3 & DMF & 500 & 65 \\
\hline 4 & DMF & 600 & 64 \\
\hline 5 & DMF & 700 & 60 \\
\hline 6 & DMF & 800 & 62 \\
\hline 7 & DMF & 1000 & 57 \\
\hline 8 & THF & 800 & 81 \\
\hline 9 & 1,4-Dioxane & 800 & 61 \\
\hline 10 & DCM & 800 & 11 \\
\hline 11 & $\mathrm{CH}_{3} \mathrm{OH}$ & 800 & 4 \\
\hline 12 & DMSO & 800 & 11 \\
\hline 13 & Chloroform & 800 & 4 \\
\hline 14 & Pyridine & 800 & 6 \\
\hline
\end{tabular}

Table S3. Optimization of base for SPSS
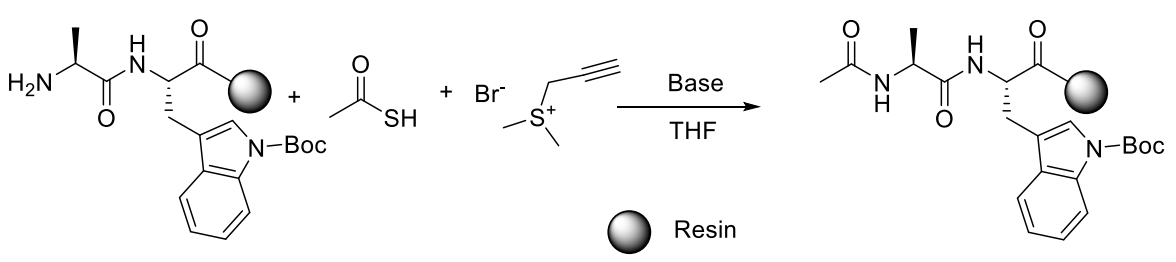

\begin{tabular}{cccccc}
\hline Entry & $\begin{array}{c}\text { AcSH } \\
\text { (equiv.) }\end{array}$ & $\begin{array}{c}\text { Sulfonium } \\
\text { (equiv.) }\end{array}$ & Base & $\begin{array}{c}\text { Amount of } \\
\text { base(equiv.) }\end{array}$ & $\begin{array}{c}\text { Yield } \\
(\%)\end{array}$ \\
\hline 1 & 2 & 2 & DIPEA & 3 & 81 \\
2 & 2 & 2 & Pyridine & 3 & 36 \\
3 & 2 & 2 & TEA & 3 & 67 \\
4 & 2 & 2 & DBU & 3 & 69 \\
5 & 2 & 2 & NMM & 3 & 94 \\
6 & 2 & 2 & - & 3 & 38 \\
\hline
\end{tabular}




\section{Supplementary figures}
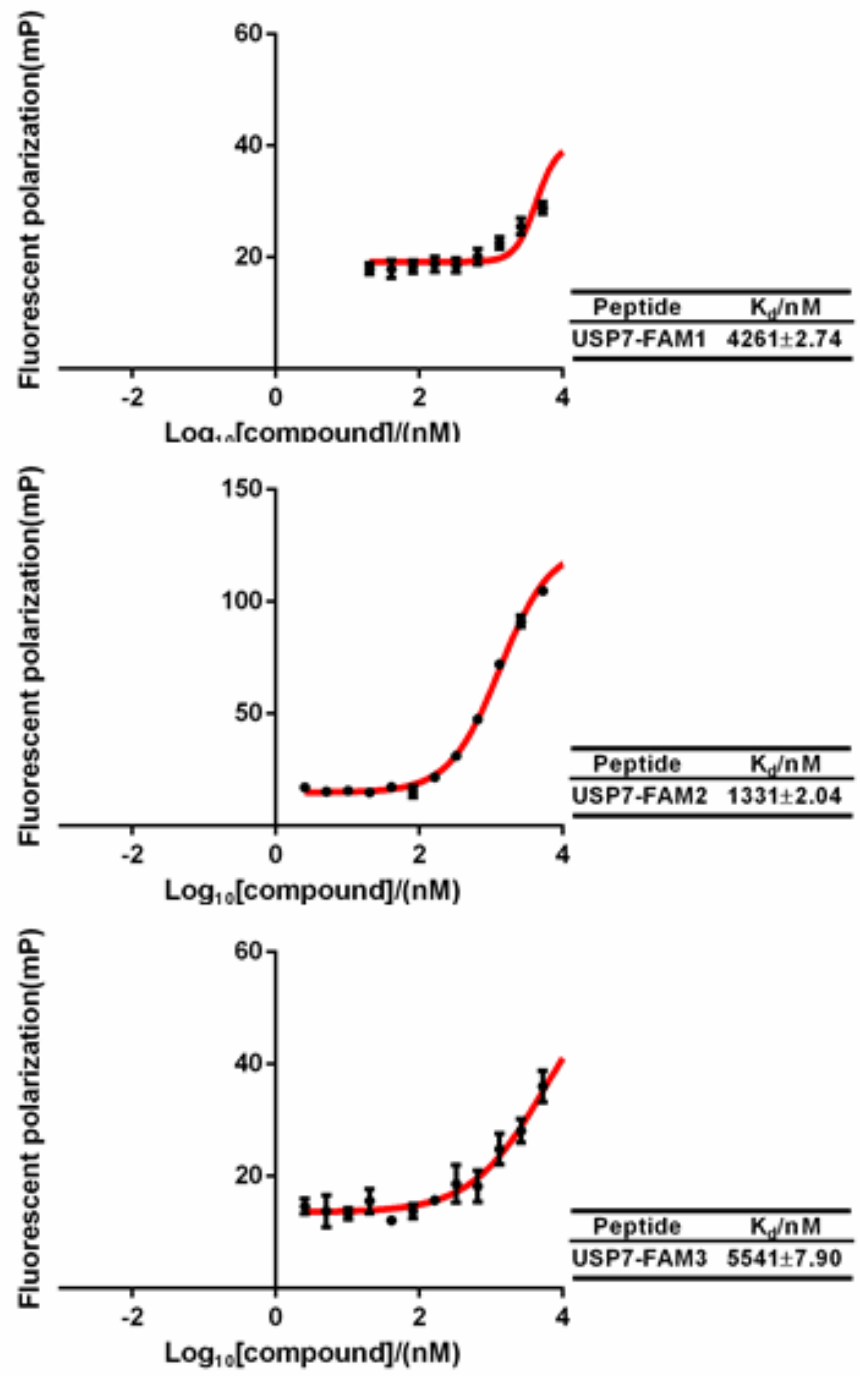

Figure S1. FP assays of usp7-1 usp7-3 peptides with USP7-UBL domain proteins.

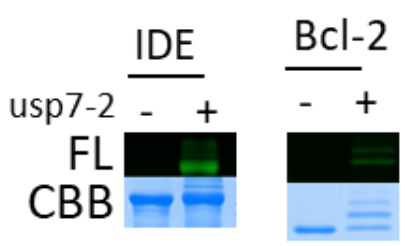

Figure S2. Gel fluorescent scanning of usp7-2 peptides bound USP7-UBL domain proteins. 

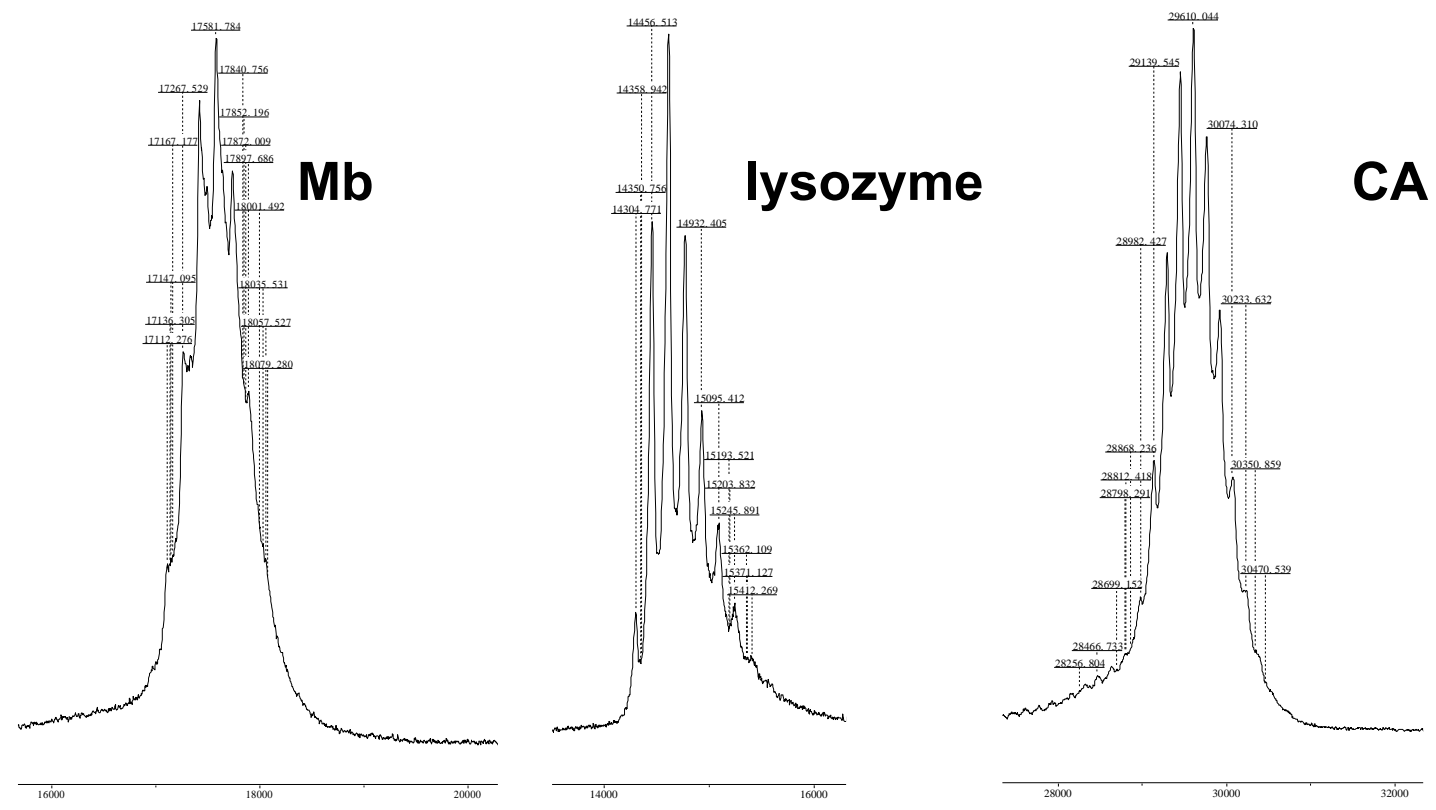

Figure S3. MALDI spectrum of alkyne-modified $\mathbf{P 4}$ probe on lysozyme and carbonic anhydrase (CA) with Myoglobin (Mb) using RapifleX MALDI-TOF/TOF Mass Spectrometer (Bruker).
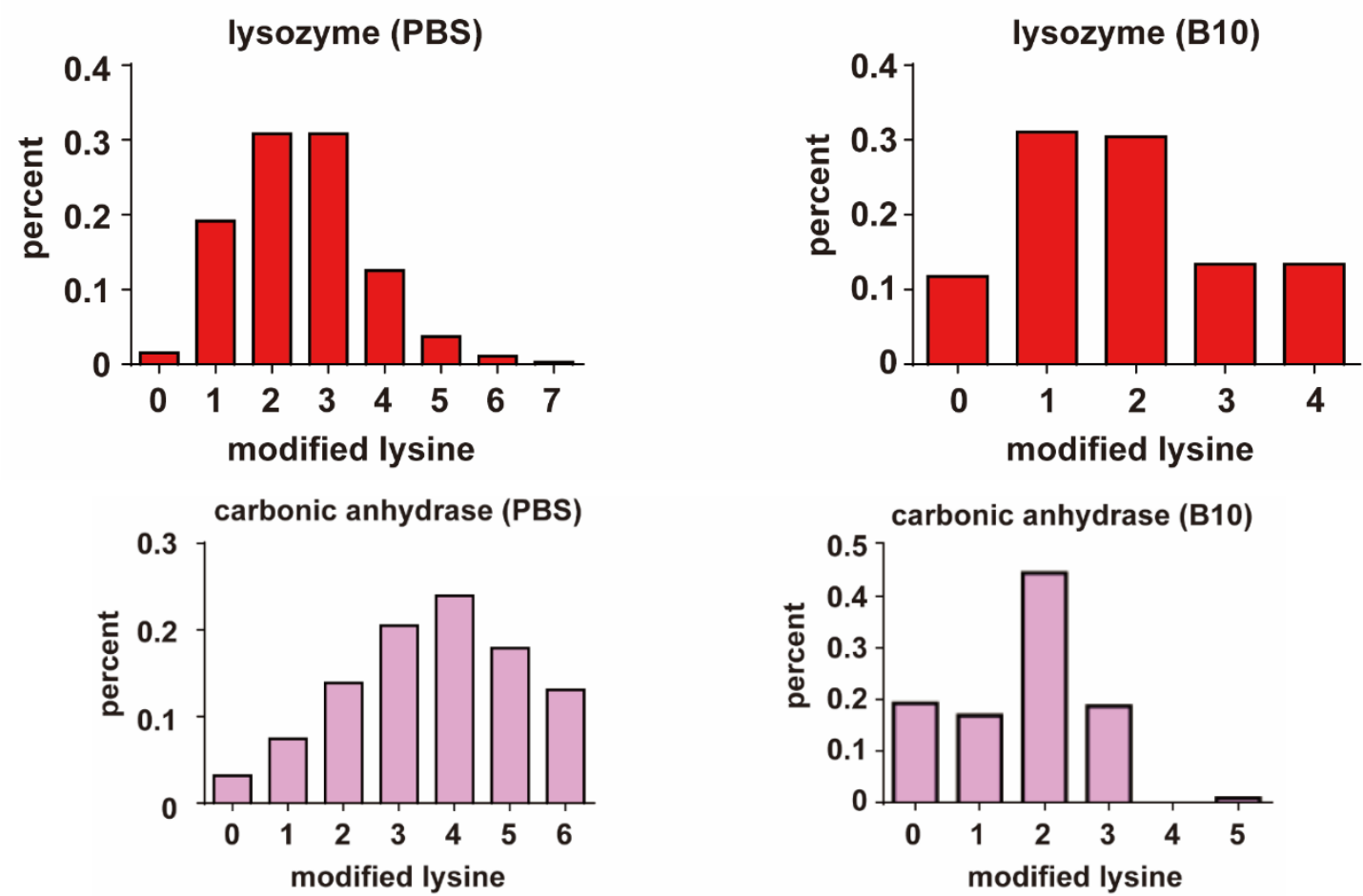

Figure S4. Modification efficiency of alkyne-modified $\mathbf{P 4}$ probe on lysozyme and carbonic anhydrase (CA) using RapifleX MALDI-TOF/TOF Mass Spectrometer (Bruker). 


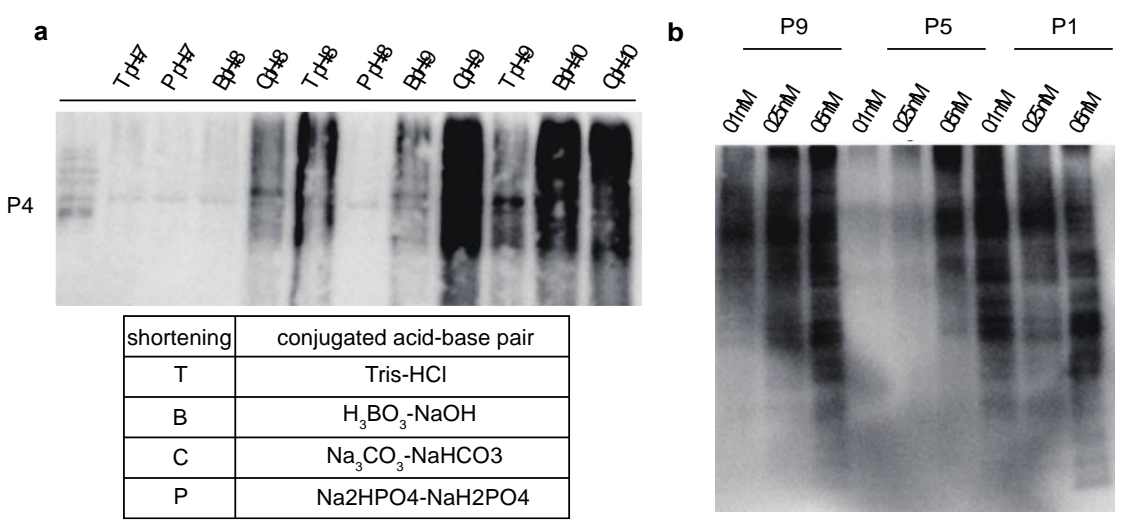

Figure S5. (a)P4 probe labeling human proteome under different basic buffer; (b)P1/P5/P9 probe labeling human proteome under different concentration.
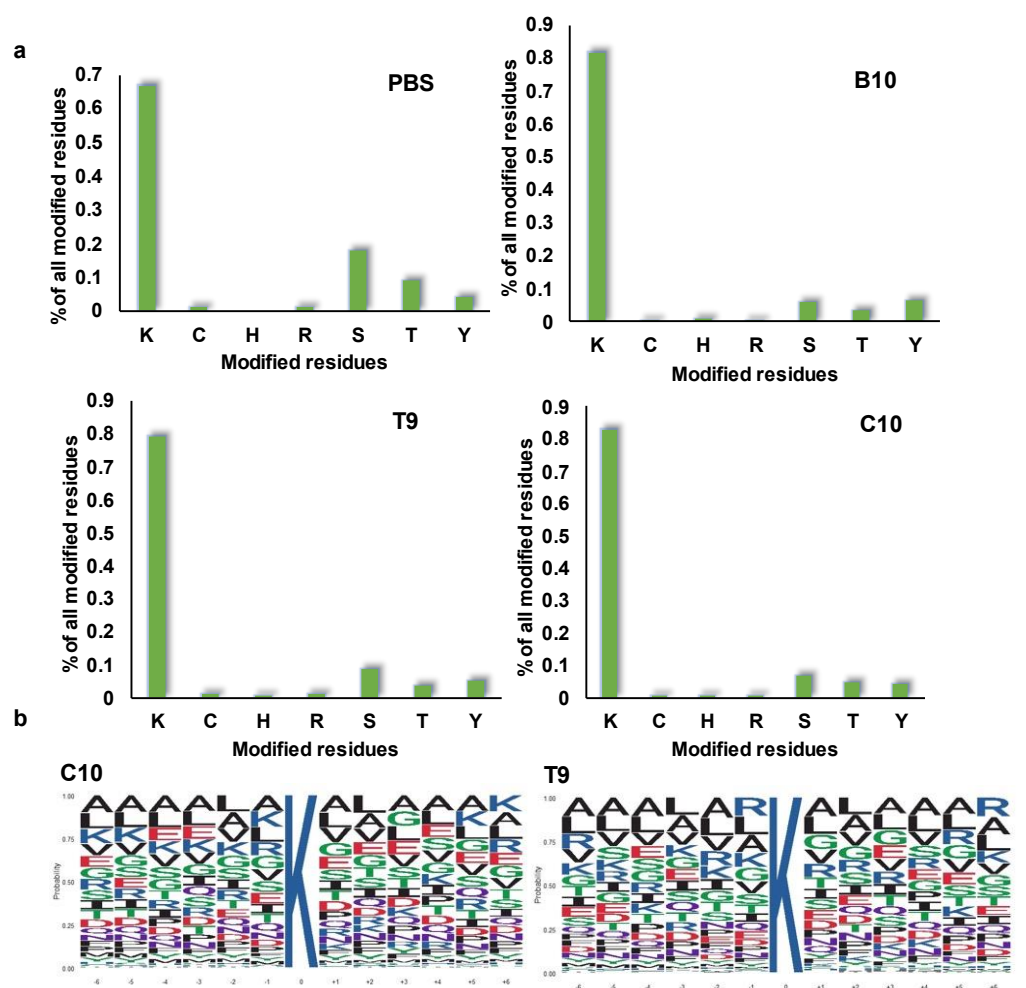

Figure S6. (a) P4 probe preferentially labels lysine residues in A549 cell proteomes under PBS/B10/T9/C10 buffers; (b) Frequency plots showing the conserved motifs for lysine with A549 cells from probe P4-labeled lysine residue sites. 

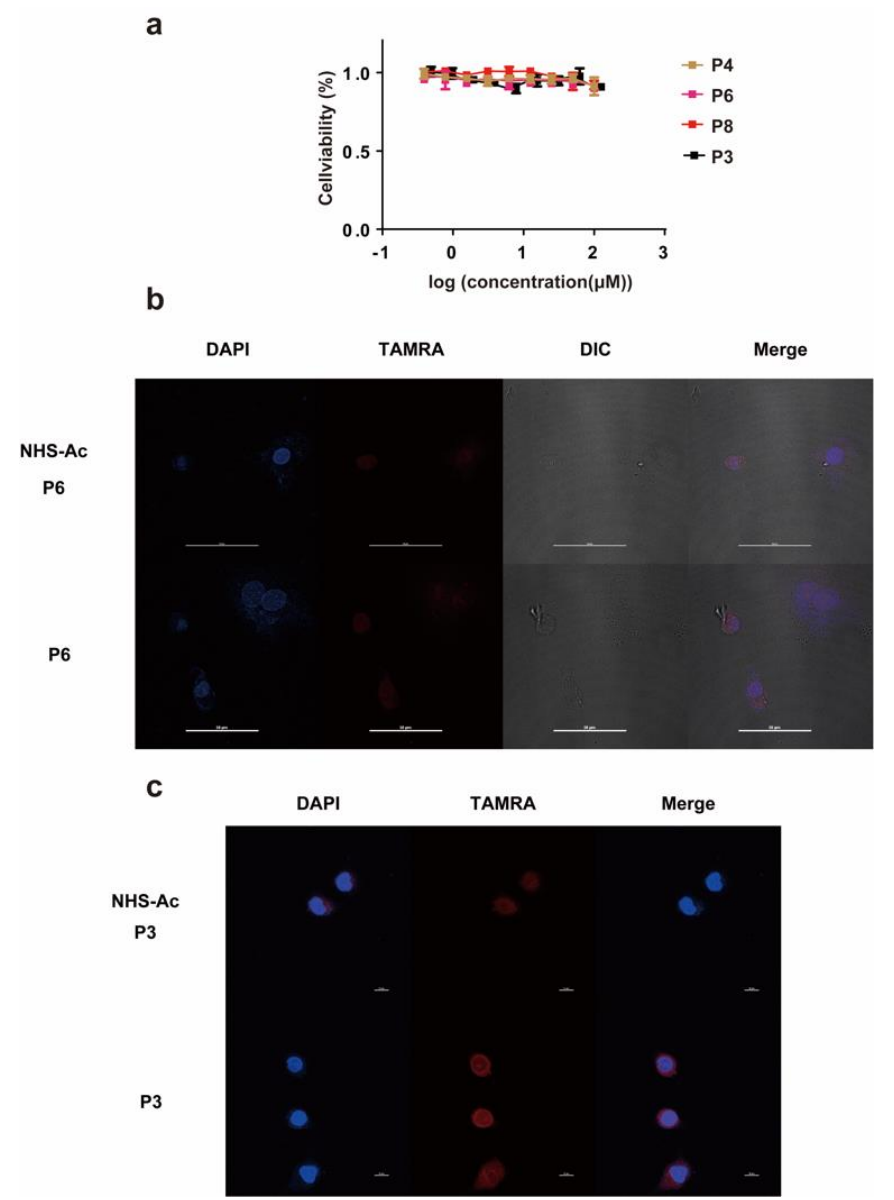

Figure S7. (a)A549 Cell viability under different kinds of probes; (b-c) Cellular imaging of P3/P6 probe $(2.5 \mu \mathrm{M})$ with A549 cells.

\section{Procedures for synthesis}

\subsection{General information}

All chemical reagents are commercially available from Energy Chemical without purification. The reactions were monitored by TLC (silica gel-G). Nuclear Magnetic Resonance (NMR) spectra were recorded on Bruker $300 \mathrm{MHz}, 400 \mathrm{MHz}$ or $500 \mathrm{MHz}$ spectrometer using trimethylsilane (TMS) as internal standard under ambient temperature $\left(20^{\circ} \mathrm{C}\right)$. High-Resolution Mass Spectrometry (HRMS) were measured on a Q_Exactive_Focus. Reverse Phase High Performance Liquid Chromatography (HPLC) was performed on SHIMAZU prominence LC-20AT instrument equipped with Kromasil 1005-C18 column $(4.6 \times 250 \mathrm{~mm}, 5 \mu \mathrm{m}) . \mathrm{H}_{2} \mathrm{O}$ (containing $0.1 \% \mathrm{TFA}$ ) and pure $\mathrm{CH}_{3} \mathrm{CN}$ were used as solvents in linear gradient mixtures. Mass Spectrometry (MS) to screen the molecular weight of HPLC fractions were carried out on SHIMAZU LC-MS 8030 in positive ion mode.

3.2. General procedure A for the propargyl sulfonium 3 promoted amidation in aqueous

solution 


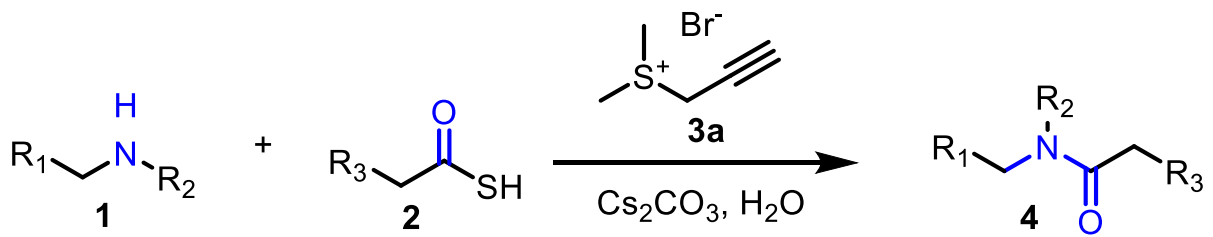

Take the synthesis of $\mathbf{4 b}$ as one example. To a $100 \mathrm{~mL}$ round-bottomed flask was added thioacetic acid 2a (0.31 g, 4 mmol, 2.0 equiv.), propargyl sulfonium 3a (0.72 g, 4 mmol, 2.0 equiv.), $\mathrm{Cs}_{2} \mathrm{CO}_{3}(1.31 \mathrm{~g}, 4$ mmol, 2.0 equiv. ) and water solvent $(30 \mathrm{~mL})$. The mixture was stirred for $10 \mathrm{~min}$, and aniline $(0.19 \mathrm{~g}, 2$ mmol, 1.0 equiv.) was added. The flask was then sealed and stirred at rt. The reaction completion was monitored by TLC. The aqueous solution was extracted successively with $\mathrm{CH}_{2} \mathrm{Cl}_{2}(3 \times 50 \mathrm{~mL})$ for three times, and the organic phase was collected and dried over $\mathrm{Na}_{2} \mathrm{SO}_{4}$. The solvent was then removed in vacuum to afford the crude product, which was purified by flash column chromatography on silica gel using hexane/EA (10:1) to afford the desired product $\mathbf{4 b}$.<smiles>CC(=O)NCC(=O)O</smiles>

4a was synthesized using thioacetic acid 2a (0.31 g, 4 mmol, 2.0 equiv.), propargyl sulfonium 3a (0.72 g, 4 mmol, 2.0 equiv.), $\mathrm{Cs}_{2} \mathrm{CO}_{3}(1.31 \mathrm{~g}, 4 \mathrm{mmol}, 2.0$ equiv.) and glycine $1 \mathrm{a}(0.15 \mathrm{~g}$, $2 \mathrm{mmol}, 1.0$ equiv.) in accordance with the general procedure A. The product $\mathbf{4 a}$ was obtained by HPLC as a white solid (0.21 g, 90\%). ${ }^{1} \mathrm{H}$ NMR (400 MHz, DMSO- $\left.d_{6}\right) \delta 12.50(\mathrm{~s}, 1 \mathrm{H}), 8.16(\mathrm{~s}, 1 \mathrm{H}), 3.71(\mathrm{~d}, J$ $=6.0 \mathrm{~Hz}, 2 \mathrm{H}), 1.84(\mathrm{~s}, 3 \mathrm{H}) .{ }^{13} \mathrm{C}$ NMR (101 MHz, DMSO) $\delta 171.9,170.3,41.0,22.6$. The NMR spectra are consistant with the reported literature. ${ }^{1}$<smiles>CC(=O)Nc1ccccc1</smiles>

4b was synthesized using thioacetic acid 2a (0.31 g, 4 mmol, 2.0 equiv.), propargyl sulfonium 3a (0.72 g, 4 mmol, 2.0 equiv.), $\mathrm{Cs}_{2} \mathrm{CO}_{3}$ (1.31 g, 4 mmol, 2.0 equiv.) and aniline (0.19 g, $2 \mathrm{mmol}, 1.0$ equiv.) in accordance with the general procedure $A$. The product $\mathbf{4 b}$ was obtained by flash chromatography on silica gel using hexane/EA (10:1) as a yellow oil (0.24 g, 90\%). ${ }^{1} \mathrm{H}$ NMR (400 MHz, $\left.\mathrm{CDCl}_{3}\right) \delta 7.73(\mathrm{~s}, 1 \mathrm{H}), 7.54(\mathrm{~d}, J=8.4 \mathrm{~Hz}, 2 \mathrm{H}), 7.38-7.27(\mathrm{~m}, 2 \mathrm{H}), 7.13(\mathrm{dt}, J=8.3,4.2 \mathrm{~Hz}, 1 \mathrm{H}), 2.19$ (s, 3H). ${ }^{13} \mathrm{C} \mathrm{NMR}\left(101 \mathrm{MHz}, \mathrm{CDCl}_{3}\right) \delta 168.8,138.1,129.1,124.4,120.1,24.6$. The NMR spectra are consistant with the reported literature. ${ }^{2}$<smiles>CC(=O)NCc1ccccc1</smiles>

4c was synthesized using thioacetic acid $\mathbf{2 a}(0.31 \mathrm{~g}, 4 \mathrm{mmol}, 2.0$ equiv.), propargyl sulfonium $3 \mathrm{a}$ (0.72 g, $4 \mathrm{mmol}, 2.0$ equiv.), $\mathrm{Cs}_{2} \mathrm{CO}_{3}$ (1.31 g, 4 mmol, 2.0 equiv.) and benzylamine (0.22 $\mathrm{g}, 2 \mathrm{mmol}, 1.0$ equiv.) in accordance with the general procedure A. The product $\mathbf{4 c}$ was obtained by flash chromatography on silica gel using hexane/EA (10:1) as a yellow oil $(0.27 \mathrm{~g}, 91 \%) .{ }^{1} \mathrm{H} \mathrm{NMR}(400 \mathrm{MHz}$, $\left.\mathrm{CDCl}_{3}\right) \delta 7.31-7.17(\mathrm{~m}, 5 \mathrm{H}), 6.98(\mathrm{~s}, 1 \mathrm{H}), 4.30(\mathrm{~d}, J=5.8 \mathrm{~Hz}, 2 \mathrm{H}), 1.90(\mathrm{~s}, 3 \mathrm{H}) .{ }^{13} \mathrm{C} \mathrm{NMR}(101 \mathrm{MHz}$, $\left.\mathrm{CDCl}_{3}\right) \delta 170.6,138.3,128.5,127.6,127.2,43.4,22.8$. The NMR spectra are consistant with the reported literature. $^{2}$ 
4d was synthesized using thioacetic acid $2 \mathbf{a}(0.31 \mathrm{~g}, 4 \mathrm{mmol}, 2.0$ equiv.), propargyl sulfonium 3a (0.72 g, 4 mmol, 2.0 equiv.), $\mathrm{Cs}_{2} \mathrm{CO}_{3}$ (1.31 g, 4 mmol, 2.0 equiv.) and morpholine ( $0.17 \mathrm{~g}, 2 \mathrm{mmol}, 1.0$ equiv.) in accordance with the general procedure A. The product 4d was obtained by flash chromatography on silica gel using hexane/EA (2:1) as a yellow oil ( $0.24 \mathrm{~g}, 91 \%) .{ }^{1} \mathrm{H}$ NMR (400 MHz, $\left.\mathrm{CDCl}_{3}\right) \delta 3.63-3.55(\mathrm{~m}, 4 \mathrm{H}), 3.53(\mathrm{dd}, J=6.2,4.2 \mathrm{~Hz}, 2 \mathrm{H}), 3.42-3.35(\mathrm{~m}, 2 \mathrm{H}), 2.02(\mathrm{~s}, 3 \mathrm{H}) .{ }^{13} \mathrm{C} \mathrm{NMR}$ $\left(101 \mathrm{MHz}, \mathrm{CDCl}_{3}\right) \delta 169.1,66.8,66.5,46.6,41.7,21.1$. The NMR spectra are consistant with the reported literature. $^{3}$<smiles>O=C(NC(Cc1ccccc1)C(=O)O)c1ccccc1</smiles>

4e was synthesized using thiobenzoic acid ( $0.55 \mathrm{~g}, 4 \mathrm{mmol}, 2.0$ equiv.), propargyl

sulfonium 3a ( $0.72 \mathrm{~g}, 4 \mathrm{mmol}, 2.0$ equiv.), $\mathrm{Cs}_{2} \mathrm{CO}_{3}(1.31 \mathrm{~g}, 4 \mathrm{mmol}, 2.0$ equiv.) and phenylalanine ( 0.33 $\mathrm{g}, 2 \mathrm{mmol}, 1.0$ equiv.) in accordance with the general procedure $\mathrm{A}$. The product $4 \mathbf{e}$ was obtained by flash chromatography on silica gel using $\mathrm{CH}_{2} \mathrm{Cl}_{2} / \mathrm{MeOH}$ (5:1) as a white powder $(0.47 \mathrm{~g}, 87 \%)$. ${ }^{1} \mathrm{H}$ NMR (400 MHz, DMSO- $\left.d_{6}\right) \delta 8.70(\mathrm{~d}, J=8.2 \mathrm{~Hz}, 1 \mathrm{H}), 7.86-7.74(\mathrm{~m}, 2 \mathrm{H}), 7.55-7.40(\mathrm{~m}, 3 \mathrm{H}), 7.38-7.22(\mathrm{~m}$, 4H), 7.17 (t, $J=7.2 \mathrm{~Hz}, 1 \mathrm{H}), 4.63$ (ddd, $J=10.4,8.0,4.3 \mathrm{~Hz}, 1 \mathrm{H}$ ), 3.22 (dd, $J=13.8,4.4 \mathrm{~Hz}, 1 \mathrm{H}), 3.09$ (dd, $J=13.8,10.6 \mathrm{~Hz}, 1 \mathrm{H}) .{ }^{13} \mathrm{C}$ NMR $\left(101 \mathrm{MHz}\right.$, DMSO- $\left.d_{6}\right) \delta 173.5,166.4,138.4,134.1,131.5,129.2$, $128.4,128.3,127.4,126.4,54.5,36.4$. The NMR spectra are consistant with the reported literature. ${ }^{4}$<smiles>O=C(NC(CCCCNC(=O)c1ccccc1)C(=O)O)OCc1ccccc1</smiles>

$4 \mathbf{f}$ was synthesized using thiobenzoic acid ( $0.55 \mathrm{~g}, 4 \mathrm{mmol}, 2.0$ equiv.), propargyl sulfonium 3a ( $0.72 \mathrm{~g}, 4 \mathrm{mmol}, 2.0$ equiv.), $\mathrm{Cs}_{2} \mathrm{CO}_{3}$ (1.31 g, $4 \mathrm{mmol}, 2.0$ equiv.) and Boc-Lys$\mathrm{OH}(0.49 \mathrm{~g}, 2 \mathrm{mmol}, 1.0$ equiv. $)$ in accordance with the general procedure $\mathrm{A}$. The product $\mathbf{4} \mathbf{f}$ was obtained by flash chromatography on silica gel using $\mathrm{CH}_{2} \mathrm{Cl}_{2} / \mathrm{MeOH}(5: 1)$ as a white powder $(0.53 \mathrm{~g}, 76 \%) .{ }^{1} \mathrm{H}$ NMR (500 MHz, $\left.\mathrm{CDCl}_{3}\right) \delta 8.10(\mathrm{~s}, 2 \mathrm{H}), 7.72(\mathrm{t}, J=8.5 \mathrm{~Hz}, 2 \mathrm{H}), 7.45(\mathrm{t}, J=7.3 \mathrm{~Hz}, 1 \mathrm{H}), 7.37(\mathrm{t}, J=7.5$ $\mathrm{Hz}, 2 \mathrm{H}), 5.38(\mathrm{~d}, J=6.9 \mathrm{~Hz}, 1 \mathrm{H}), 4.32-4.14(\mathrm{~m}, 1 \mathrm{H}), 3.39$ (q, $J=6.5 \mathrm{~Hz}, 2 \mathrm{H}), 1.87-1.65(\mathrm{~m}, 2 \mathrm{H})$, $1.66-1.56(\mathrm{~m}, 2 \mathrm{H}), 1.38(\mathrm{~d}, J=7.1 \mathrm{~Hz}, 11 \mathrm{H}) .{ }^{13} \mathrm{C} \mathrm{NMR}\left(126 \mathrm{MHz}, \mathrm{CDCl}_{3}\right) \delta$ 175.6, 168.9, 156.1, 134.0, 131.8, 128.6, 127.1, 80.4, 53.2, 39.9, 32.0, 28.8, 28.3, 22.5. HRMS m/z (ESI-TOF): $[\mathrm{M}+\mathrm{Na}]^{+}$calcd for $\mathrm{C}_{18} \mathrm{H}_{26} \mathrm{~N}_{2} \mathrm{O}_{5} \mathrm{Na} 373.1734$, found 373.1734 .<smiles>C#CCOc1ccc(C(=O)NCCCCC(NC(=O)O)C(=O)O)cc1</smiles>

4g was synthesized using intermediate 5 (P4) $(0.081 \mathrm{~g}, 0.2$ mmol, 2.0 equiv.), propargyl sulfonium 3a ( $0.036 \mathrm{~g}, 0.2 \mathrm{mmol}, 2.0$ equiv.) and Boc-Lys-OH ( $0.49 \mathrm{~g}, 0.2$ mmol, 1.0 equiv.) in a $\mathrm{pH} 8.0$ PBS buffer. The product $\mathbf{4 g}$ was obtained by flash chromatography on silica gel using $\mathrm{CH}_{2} \mathrm{Cl}_{2} / \mathrm{MeOH}$ (5:1) as a white powder (0.058 g, 72\%). ${ }^{1} \mathrm{H}$ NMR (500 MHz, $\left.\mathrm{CDCl}_{3}\right) \delta$ $7.74(\mathrm{~d}, J=8.7 \mathrm{~Hz}, 2 \mathrm{H}), 6.95(\mathrm{~d}, J=8.5 \mathrm{~Hz}, 2 \mathrm{H}), 6.63(\mathrm{~s}, 1 \mathrm{H}), 5.36(\mathrm{~d}, J=7.7 \mathrm{~Hz}, 1 \mathrm{H}), 5.21(\mathrm{~s}, 1 \mathrm{H})$, $4.70(\mathrm{~d}, J=2.2 \mathrm{~Hz}, 2 \mathrm{H}), 4.34-4.21(\mathrm{~m}, 1 \mathrm{H}), 3.39$ (d, $J=6.3 \mathrm{~Hz}, 2 \mathrm{H}), 2.53(\mathrm{t}, J=2.4 \mathrm{~Hz}, 1 \mathrm{H}), 1.89-$ $1.66(\mathrm{~m}, 2 \mathrm{H}), 1.63-1.55(\mathrm{~m}, 2 \mathrm{H}), 1.40(\mathrm{~s}, 11 \mathrm{H}) .{ }^{13} \mathrm{C} \mathrm{NMR}\left(101 \mathrm{MHz}, \mathrm{CDCl}_{3}\right) \delta 175.4,167.9,160.1$, 
156.0, 129.0, 127.4, 114.7, 80.3, 78.0, 76.1, 55.9, 53.2, 39.8, 32.0, 29.0, 28.4, 22.5. HRMS m/z (ESITOF): [M-H] $]^{-}$calcd for $\mathrm{C}_{21} \mathrm{H}_{27} \mathrm{~N}_{2} \mathrm{O}_{6} 403.1875$, found 403.1876 .<smiles>CC(=O)NC(C(=O)N[C@H]1C(=O)N2[C@@H]1SC(C)(C)[C@H]2C(=O)O)c1ccc(O)cc1</smiles>

4h was synthesized using thioacetic acid $2 \mathbf{a}(0.031 \mathrm{~g}, 0.4 \mathrm{mmol}, 2.0$ equiv.), propargyl sulfonium 3a (0.072 g, 0.4 mmol, 2.0 equiv.), $\mathrm{Cs}_{2} \mathrm{CO}_{3}$ (1.31 g, 0.4 mmol, 2.0 equiv.) and amoxicillin ( $0.084 \mathrm{~g}, 0.2 \mathrm{mmol}, 1.0$ equiv.) in accordance with the general procedure $\mathrm{A}$. The product 4h was obtained by HPLC as a white powder $(70 \mathrm{mg}, 83 \%) .{ }^{1} \mathrm{H}$ NMR $\left(400 \mathrm{MHz}\right.$, Methanol- $\left.d_{4}\right) \delta 7.30(\mathrm{~d}$, $J=8.6 \mathrm{~Hz}, 2 \mathrm{H}), 6.80(\mathrm{~d}, J=8.6 \mathrm{~Hz}, 2 \mathrm{H}), 5.46(\mathrm{~s}, 1 \mathrm{H}), 5.02(\mathrm{~s}, 1 \mathrm{H}), 4.45(\mathrm{~d}, J=5.8 \mathrm{~Hz}, 1 \mathrm{H}), 3.39$ (s, 1H), $2.00(\mathrm{~s}, 3 \mathrm{H}), 1.44(\mathrm{~s}, 3 \mathrm{H}), 1.21(\mathrm{~s}, 3 \mathrm{H}) .{ }^{13} \mathrm{C}$ NMR (101 MHz, Methanol-d 4 ) $\delta 175.6,173.2,172.8$, $172.3,158.4,130.3,128.8,116.5,76.7,74.8,66.2,60.2,59.2,58.3,53.0,27.7,27.4,22.5$. HRMS m/z (ESI-TOF): [M-H] $]^{-}$calcd for $\mathrm{C}_{18} \mathrm{H}_{20} \mathrm{~N}_{3} \mathrm{O}_{6} \mathrm{~S} 406.1078$, found 406.1080 .

\subsection{General procedure $B$ for the synthesis of thioacids}

The preparation of thioacids were followed the similar procedure of the reported literatures. ${ }^{5}$ Take the preparation of TA1 as one example. To a $100 \mathrm{~mL}$ round-bottomed flask was added Fmoc-Trp(Boc)-OH ( $0.53 \mathrm{~g}, 1 \mathrm{mmol}, 1$ equiv.), carbonyl diimidazole ( $0.49 \mathrm{~g}, 3 \mathrm{mmol}, 3$ equiv.) and $50 \mathrm{~mL} \mathrm{CH}_{2} \mathrm{Cl}_{2}$ solvent. The mixture was stirred for $1 \mathrm{~h}$ under ice bath, and $\mathrm{NaSH}$ monohydrate $(0.22 \mathrm{~g}, 3 \mathrm{mmol}, 3$ equiv. $)$ was added by one portion. The reaction was then stirred at rt, and the completion was monitored by TLC. The solution was washed successively with brine $(3 \times 30 \mathrm{~mL})$, and the organic phase was dried over $\mathrm{Na}_{2} \mathrm{SO}_{4}$. The solvent was then removed in vacuum to afford the crude product, which was purified by flash column chromatography on silica gel using $\mathrm{CH}_{2} \mathrm{Cl}_{2} / \mathrm{MeOH}(10: 1)$.<smiles>CC(C)(C)OC(=O)NC(Cc1cn(C(F)(F)F)c2ccccc12)C(=O)O</smiles>

TA1 is known compound, yellow solid, $0.44 \mathrm{~g}, 81 \%$, purified by flash column chromatography on silica gel using $\mathrm{CH}_{2} \mathrm{Cl}_{2} / \mathrm{MeOH}(10: 1) .{ }^{5 \mathrm{c}}{ }^{1} \mathrm{H}$ NMR $\left(300 \mathrm{MHz}, \mathrm{CDCl}_{3}\right) \delta 8.27(\mathrm{~s}, 1 \mathrm{H})$, $7.78(\mathrm{~d}, J=7.4 \mathrm{~Hz}, 2 \mathrm{H}), 7.67-7.50(\mathrm{~m}, 4 \mathrm{H}), 7.43(\mathrm{t}, J=7.4 \mathrm{~Hz}, 4 \mathrm{H}), 7.32(\mathrm{dd}, J=9.9,5.2 \mathrm{~Hz}, 3 \mathrm{H})$, $5.95(\mathrm{~d}, J=8.2 \mathrm{~Hz}, 1 \mathrm{H}), 4.89(\mathrm{~s}, 1 \mathrm{H}), 4.45(\mathrm{dq}, J=20.2,10.3,8.9 \mathrm{~Hz}, 2 \mathrm{H}), 4.21(\mathrm{t}, J=7.1 \mathrm{~Hz}, 1 \mathrm{H}), 3.44$ $-3.31(\mathrm{~m}, 1 \mathrm{H}), 3.21(\mathrm{dd}, J=14.9,7.8 \mathrm{~Hz}, 1 \mathrm{H}), 1.72(\mathrm{~s}, 9 \mathrm{H}) .{ }^{13} \mathrm{C} \mathrm{NMR}\left(75 \mathrm{MHz}, \mathrm{CDCl}_{3}\right) \delta 200.1,156.1$, $149.6,143.7,141.3,135.5,130.3,127.8,127.2$, 125.1 124.9, 124.5, 123.0, 120.1, 118.9, 115.6, 114.8, $84.0,67.4,61.7,55.6,47.1,28.2$.<smiles>CC(NC(F)F)C(=O)S</smiles>

TA2 is known compound, yellow solid, $0.29 \mathrm{~g}$, 89\%, purified by flash column chromatography on silica gel using $\mathrm{CH}_{2} \mathrm{Cl}_{2} / \mathrm{MeOH}(10: 1) .{ }^{5 \mathrm{c}}{ }^{1} \mathrm{H} \mathrm{NMR}\left(300 \mathrm{MHz}, \mathrm{CDCl}_{3}\right) \delta 7.78(\mathrm{~d}, J=$ $7.4 \mathrm{~Hz}, 2 \mathrm{H}), 7.73-7.51(\mathrm{~m}, 2 \mathrm{H}), 7.51-7.27(\mathrm{~m}, 4 \mathrm{H}), 5.60(\mathrm{~d}, J=7.5 \mathrm{~Hz}, 1 \mathrm{H}), 4.55(\mathrm{dd}, J=10.2,6.9$ $\mathrm{Hz}, 1 \mathrm{H}), 4.44$ (p, $J=10.3,8.8 \mathrm{~Hz}, 2 \mathrm{H}), 4.24$ (t, $J=6.7 \mathrm{~Hz}, 1 \mathrm{H}), 1.42$ (d, $J=7.1 \mathrm{~Hz}, 3 \mathrm{H}) .{ }^{13} \mathrm{C}$ NMR $(75$ 
$\left.\mathrm{MHz}, \mathrm{CDCl}_{3}\right) \delta 200.8,155.8,143.6,141.3,127.8,127.2,125.0,120.1,67.2,57.7,47.1,18.0$.<smiles>CCCOC(=O)C[C@H](NC(F)F)C(=O)S</smiles>

TA3 is known compound, yellow oil, $0.32 \mathrm{~g}, 76 \%$, purified by flash column chromatography on silica gel using $\mathrm{CH}_{2} \mathrm{Cl}_{2} / \mathrm{MeOH}(10: 1) .{ }^{\text {c }}{ }^{1} \mathrm{H}$ NMR $\left(300 \mathrm{MHz}, \mathrm{CDCl}_{3}\right) \delta 7.77$ (d, $J=$ $7.4 \mathrm{~Hz}, 2 \mathrm{H}), 7.71-7.56(\mathrm{~m}, 2 \mathrm{H}), 7.52-7.27$ (m, 4H), 6.29 (d, J=9.5 Hz, 1H), $4.82-4.50(\mathrm{~m}, 2 \mathrm{H})$, $4.41(\mathrm{dd}, J=10.3,7.1 \mathrm{~Hz}, 1 \mathrm{H}), 4.26(\mathrm{t}, J=6.7 \mathrm{~Hz}, 1 \mathrm{H}), 2.97(\mathrm{dd}, J=17.0,4.9 \mathrm{~Hz}, 1 \mathrm{H}), 2.79-2.63(\mathrm{~m}$, $1 \mathrm{H}), 1.49$ (s, 9H). ${ }^{13} \mathrm{C} \mathrm{NMR}\left(75 \mathrm{MHz}, \mathrm{CDCl}_{3}\right) \delta 199.7,170.1,156.0,143.6,141.4,127.8,127.2,125.1$, $120.1,82.3,67.4,58.2,47.2,37.0,28.1$.

Fmoc ${ }_{\mathrm{H}}^{\mathrm{H}} \overbrace{\mathrm{O}}^{\mathrm{SH}}$

TA4 is known compound, white solid, $0.28 \mathrm{~g}$, 91\%, purified by flash column chromatography on silica gel using $\mathrm{CH}_{2} \mathrm{Cl}_{2} / \mathrm{MeOH}(5: 1) .{ }^{5 c}{ }^{1} \mathrm{NMR}\left(300 \mathrm{MHz}, \mathrm{CDCl}_{3}\right) \delta 7.78(\mathrm{~d}, J=$ $7.5 \mathrm{~Hz}, 2 \mathrm{H}), 7.61$ (d, J=7.3 Hz, 2H), $7.48-7.28(\mathrm{~m}, 4 \mathrm{H}), 5.66(\mathrm{~s}, 1 \mathrm{H}), 4.48(\mathrm{~d}, J=6.8 \mathrm{~Hz}, 2 \mathrm{H}), 4.24$ (t, $J=6.5 \mathrm{~Hz}, 1 \mathrm{H}), 4.09(\mathrm{~d}, J=5.8 \mathrm{~Hz}, 1 \mathrm{H}) .{ }^{13} \mathrm{C} \mathrm{NMR}\left(75 \mathrm{MHz}, \mathrm{CDCl}_{3}\right) \delta 196.7,156.3,143.7,141.3,127.8$, 127.2, 125.0, 120.1, 67.3, 51.8, 47.1.<smiles>CCCNC(=O)CC[C@H](NC(=O)O)C(=O)S</smiles>

TA5 is known compound, yellow oil, $0.50 \mathrm{~g}, 80 \%$, purified by flash column

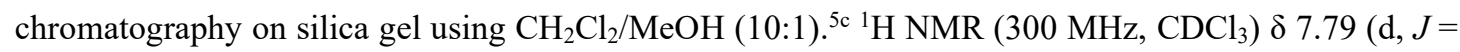
$7.4 \mathrm{~Hz}, 2 \mathrm{H}), 7.65(\mathrm{~d}, J=6.8 \mathrm{~Hz}, 2 \mathrm{H}), 7.46-7.17(\mathrm{~m}, 21 \mathrm{H}), 6.39(\mathrm{~d}, J=6.5 \mathrm{~Hz}, 1 \mathrm{H}), 4.67-4.47(\mathrm{~m}$, $1 \mathrm{H}), 4.29$ (ddd, $J=32.0,21.1,7.2 \mathrm{~Hz}, 3 \mathrm{H}), 2.33$ (d, $J=24.8 \mathrm{~Hz}, 2 \mathrm{H}), 2.19-1.79(\mathrm{~m}, 2 \mathrm{H}) .{ }^{13} \mathrm{C}$ NMR $(75$ $\left.\mathrm{MHz}, \mathrm{CDCl}_{3}\right) \delta 201.4,171.6,156.5,144.4,143.7,141.4,128.7,128.1,127.8,127.2,125.3,125.2,120.1$, $70.8,67.1,61.9,47.2,33.0,27.0$.<smiles>CC(C)COC(C)C(NC(F)F)C(=O)S</smiles>

TA6, yellow oil, $0.34 \mathrm{~g}, 83 \%$, purified by flash column chromatography on silica gel using $\mathrm{CH}_{2} \mathrm{Cl}_{2} / \mathrm{MeOH}(10: 1) .{ }^{1} \mathrm{H}$ NMR $\left(300 \mathrm{MHz}, \mathrm{CDCl}_{3}\right) \delta 7.80(\mathrm{~d}, J=7.2 \mathrm{~Hz}, 2 \mathrm{H}), 7.68(\mathrm{dd}, J=6.7$, $3.7 \mathrm{~Hz}, 2 \mathrm{H}), 7.40(\mathrm{dt}, J=23.6,7.2 \mathrm{~Hz}, 4 \mathrm{H}), 4.60$ (dd, $J=10.7,6.9 \mathrm{~Hz}, 1 \mathrm{H}), 4.46$ (ddt, $J=10.4,7.5,3.8$ $\mathrm{Hz}, 1 \mathrm{H}), 4.31$ (ddt, $J=19.4,13.3,6.6 \mathrm{~Hz}, 3 \mathrm{H}), 1.28-1.11(\mathrm{~m}, 12 \mathrm{H}) .{ }^{13} \mathrm{C} \mathrm{NMR}\left(75 \mathrm{MHz}, \mathrm{CDCl}_{3}\right) \delta$ 201.1, 156.4, 143.7, 141.4, 127.8, 127.1, 125.1, 120.1, 74.5, 74.3, 67.3, 67.0, 47.3, 28.5, 20.7. HRMS $\mathrm{m} / \mathrm{z}$ (ESI-TOF): [M-H] $]^{+}$calcd for $\mathrm{C}_{23} \mathrm{H}_{26} \mathrm{NO}_{4} \mathrm{~S} 412.1588$, found 412.1587 .<smiles>CC(C)[C@H](NC(F)F)C(=O)S</smiles>

TA7 is known compound, white solid, $0.31 \mathrm{~g}, 88 \%$, purified by flash column chromatography on silica gel using $\mathrm{CH}_{2} \mathrm{Cl}_{2} / \mathrm{MeOH}(10: 1) .{ }^{5 \mathrm{c}}{ }^{1} \mathrm{H} \mathrm{NMR}\left(300 \mathrm{MHz}, \mathrm{CDCl}_{3}\right) \delta 7.79(\mathrm{~d}, J=$ $7.4 \mathrm{~Hz}, 2 \mathrm{H}), 7.62(\mathrm{~s}, 2 \mathrm{H}), 7.38(\mathrm{dt}, J=25.9,7.3 \mathrm{~Hz}, 4 \mathrm{H}), 5.27(\mathrm{~d}, J=8.9 \mathrm{~Hz}, 1 \mathrm{H}), 4.51$ (dq, $J=17.4$, $10.4 \mathrm{~Hz}, 2 \mathrm{H}), 4.34$ (dd, $J=8.6,4.3 \mathrm{~Hz}, 1 \mathrm{H}), 4.27$ (t, $J=6.6 \mathrm{~Hz}, 1 \mathrm{H}), 2.32$ (dd, $J=12.3,6.3 \mathrm{~Hz}, 1 \mathrm{H})$, $1.02(\mathrm{~d}, J=6.6 \mathrm{~Hz}, 3 \mathrm{H}), 0.93(\mathrm{~d}, J=6.8 \mathrm{~Hz}, 3 \mathrm{H}) .{ }^{13} \mathrm{C} \mathrm{NMR}\left(75 \mathrm{MHz}, \mathrm{CDCl}_{3}\right) \delta 199.9,156.2,143.6$, $141.3,127.8$, 127.1, 125.0, 120.0, 67.1, 66.7, 50.8, 47.2, 30.6, 19.4, 16.8. 
<smiles>O=C(S)C(Cc1ccccc1)NCCF</smiles>

TA8 is known compound, white solid, $0.36 \mathrm{~g}, 89 \%$, purified by flash column chromatography on silica gel using $\mathrm{CH}_{2} \mathrm{Cl}_{2} / \mathrm{MeOH}(10: 1) .{ }^{5 \mathrm{c}}{ }^{1} \mathrm{H} \mathrm{NMR}\left(300 \mathrm{MHz}, \mathrm{CDCl}_{3}\right) \delta 7.80(\mathrm{~d}, J=$ $7.5 \mathrm{~Hz}, 2 \mathrm{H}), 7.55(\mathrm{t}, J=8.1 \mathrm{~Hz}, 2 \mathrm{H}), 7.44(\mathrm{t}, J=7.3 \mathrm{~Hz}, 2 \mathrm{H}), 7.34(\mathrm{~d}, J=7.6 \mathrm{~Hz}, 5 \mathrm{H}), 7.20(\mathrm{~d}, J=6.5$ $\mathrm{Hz}, 2 \mathrm{H}), 5.36(\mathrm{~d}, J=8.3 \mathrm{~Hz}, 1 \mathrm{H}), 4.70(\mathrm{q}, J=7.6 \mathrm{~Hz}, 1 \mathrm{H}), 4.45(\mathrm{~d}, J=7.0 \mathrm{~Hz}, 2 \mathrm{H}), 4.22(\mathrm{t}, J=6.6 \mathrm{~Hz}$, $2 \mathrm{H}), 3.20(\mathrm{dd}, J=14.1,5.3 \mathrm{~Hz}, 1 \mathrm{H}), 3.07(\mathrm{dd}, J=14.1,7.6 \mathrm{~Hz}, 1 \mathrm{H}) .{ }^{13} \mathrm{C} \mathrm{NMR}\left(75 \mathrm{MHz}, \mathrm{CDCl}_{3}\right) \delta 199.5$, 155.7, 143.6, 141.3, 135.2, 129.3, 128.9, 127.8, 127.4, 127.1, 125.0, 120.1, 67.2, 62.4, 47.1, 37.5.<smiles>O=C(NCCCC(NCC(F)F)C(=O)S)NC(=O)c1ccccc1</smiles>

TA9 is known compound, yellow solid, $0.35 \mathrm{~g}, 75 \%$, purified by flash column chromatography on silica gel using $\mathrm{CH}_{2} \mathrm{Cl}_{2} / \mathrm{MeOH}(10: 1) .{ }^{5 \mathrm{c}}{ }^{1} \mathrm{H}$ NMR $\left(300 \mathrm{MHz}, \mathrm{CDCl}_{3}\right) \delta 7.77(\mathrm{~d}, J=$ $7.4 \mathrm{~Hz}, 2 \mathrm{H}), 7.61(\mathrm{t}, J=7.1 \mathrm{~Hz}, 2 \mathrm{H}), 7.48-7.28(\mathrm{~m}, 4 \mathrm{H}), 5.77(\mathrm{~s}, 1 \mathrm{H}), 5.26(\mathrm{~s}, 1 \mathrm{H}), 4.56(\mathrm{dd}, J=10.3$, $6.9 \mathrm{~Hz}, 1 \mathrm{H}), 4.50-4.29(\mathrm{~m}, 2 \mathrm{H}), 4.24$ (t, $J=6.8 \mathrm{~Hz}, 1 \mathrm{H}), 3.12(\mathrm{~s}, 2 \mathrm{H}), 2.02-1.59(\mathrm{~m}, 2 \mathrm{H}), 1.47$ (d, $J=$ $6.6 \mathrm{~Hz}, 13 \mathrm{H}) .{ }^{13} \mathrm{C} \mathrm{NMR}\left(75 \mathrm{MHz}, \mathrm{CDCl}_{3}\right) \delta 200.3,156.1,143.7,143.6,141.3,127.8,127.1,125.0,120.0$, $73.5,67.2,61.8,47.2,39.6,31.2,29.6,28.4,22.3$.<smiles>O=C(S)CCCC[C@H]1SC[C@H]2NC(=O)N[C]21</smiles>

P1, yellow oil, $0.18 \mathrm{~g}, 68 \%$, purified by flash column chromatography on silica gel using $\mathrm{CH}_{2} \mathrm{Cl}_{2} / \mathrm{MeOH}(5: 1) .{ }^{1} \mathrm{H}$ NMR (300 MHz, DMSO- $\left.d_{6}\right) \delta 7.28(\mathrm{~s}, 1 \mathrm{H}), 4.30$ (dd, $J=7.5$, $4.9 \mathrm{~Hz}, 1 \mathrm{H}), 4.13(\mathrm{dd}, J=7.6,4.4 \mathrm{~Hz}, 1 \mathrm{H}), 3.14-3.06(\mathrm{~m}, 1 \mathrm{H}), 2.83(\mathrm{dt}, J=12.3,6.3 \mathrm{~Hz}, 2 \mathrm{H}), 2.73-$ 2.53 (m, 2H), 1.53 (ddd, $J=48.9,16.6,8.7 \mathrm{~Hz}, 4 \mathrm{H}), 1.38-1.22$ (m, 2H). ${ }^{13} \mathrm{C}$ NMR (75 MHz, DMSO$\left.d_{6}\right) \delta 193.8,163.2,61.4,59.6,55.7,42.4,33.9,28.3,28.1,25.4$. HRMS m/z (ESI-TOF): [M-H] ${ }^{-}$calcd for $\mathrm{C}_{10} \mathrm{H}_{15} \mathrm{~N}_{2} \mathrm{O}_{2} \mathrm{~S}_{2} 259.0580$, found 259.0582 .<smiles>C#CCOc1ccc(C(=O)O)cc1</smiles>

TA10, yellow oil, $0.16 \mathrm{~g}, 82 \%$, purified by flash column chromatography on silica gel using $\mathrm{CH}_{2} \mathrm{Cl}_{2} / \mathrm{MeOH}(50: 1) .{ }^{1} \mathrm{H}$ NMR $\left(300 \mathrm{MHz}, \mathrm{CDCl}_{3}\right) \delta 7.98-7.82(\mathrm{~m}, 2 \mathrm{H}), 7.12-6.94$ (m, 2H), $4.76(\mathrm{~d}, J=2.4 \mathrm{~Hz}, 2 \mathrm{H}), 2.56(\mathrm{t}, J=2.4 \mathrm{~Hz}, 1 \mathrm{H}) .{ }^{13} \mathrm{C} \mathrm{NMR}\left(75 \mathrm{MHz}, \mathrm{CDCl}_{3}\right) \delta$ 188.6, 162.0, 130.2, 130.1, 114.8, 77.5, 76.4, 55.9. HRMS m/z (ESI-TOF): [M-H]' calcd for $\mathrm{C}_{10} \mathrm{H}_{7} \mathrm{O}_{2} \mathrm{~S}$ 191.0172, found 191.0175 .

\subsection{General procedure $\mathrm{C}$ for the preparation of sulfonium 3}

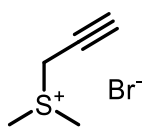

$3 a$

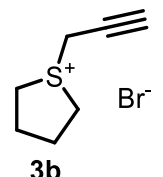

$3 b$

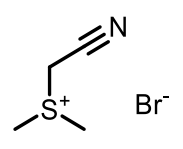

$3 \mathrm{~h}$

The preparation of sulfonium $\mathbf{3 a}, \mathbf{3 b}$ and $\mathbf{3 h}$ was achieved by following the reported procedures. ${ }^{6}$ 


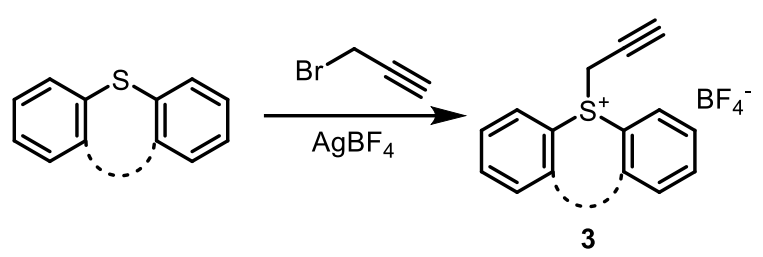

Take the synthesis of $\mathbf{3 c}$ as one example. To a $100 \mathrm{~mL}$ round-bottomed flask was added diphenyl sulfide (0.19 g, 1 mmol, 1 equiv.), 3-bromoprop-1-yne (0.24 g, 2 mmol, 2 equiv.), $\operatorname{AgBF}_{4}$ (0.2 g, 1 mmol, 1 equiv.) and $30 \mathrm{~mL} \mathrm{CH}_{2} \mathrm{Cl}_{2}$ solvent. The mixture was protected from light and stirred at $\mathrm{rt}$ under nitrogen atmosphere, and the completion was monitored by TLC. The solution was filtered through celite, and the solvent was then removed in vacuum to afford the crude product, which was purified by flash column chromatography on silica gel using $\mathrm{CH}_{2} \mathrm{Cl}_{2} / \mathrm{MeOH}$ (50:1).<smiles>C#CC[S+](c1ccccc1)c1ccc([Te])cc1</smiles>

3c, white powder, $0.26 \mathrm{~g}, 85 \%$, purified by flash column chromatography on silica gel using $\mathrm{CH}_{2} \mathrm{Cl}_{2} / \mathrm{MeOH}(40: 1) .{ }^{1} \mathrm{H}$ NMR $\left(400 \mathrm{MHz}\right.$, Methanol- $\left.d_{4}\right) \delta 8.02-7.94(\mathrm{~m}, 4 \mathrm{H}), 7.88-7.81(\mathrm{~m}$, $2 \mathrm{H}), 7.78-7.72(\mathrm{~m}, 4 \mathrm{H}), 7.30(\mathrm{~d}, J=3.8 \mathrm{~Hz}, 5 \mathrm{H}), 5.25(\mathrm{~d}, J=2.7 \mathrm{~Hz}, 2 \mathrm{H}), 3.29(\mathrm{t}, J=2.6 \mathrm{~Hz}, 1 \mathrm{H}) .{ }^{13} \mathrm{C}$ NMR $\left(101 \mathrm{MHz}\right.$, Methanol- $\left.d_{4}\right) \delta 134.8,131.2,131.1,130.8,130.7,129.1,127.0,124.1,80.9,70.4,35.9$. HRMS m/z (ESI-TOF): [M] $]^{+}$calcd for $\mathrm{C}_{15} \mathrm{H}_{13} \mathrm{~S} 225.0733$, found 225.0732 .<smiles>C#CC[s+]1c2ccccc2c2ccccc21</smiles>

3d, yellow powder, $0.12 \mathrm{~g}, 40 \%$, purified by flash column chromatography on silica gel using $\mathrm{CH}_{2} \mathrm{Cl}_{2} / \mathrm{MeOH}(40: 1) . \quad{ }^{1} \mathrm{H} \mathrm{NMR}\left(400 \mathrm{MHz}, \mathrm{CD}_{3} \mathrm{CN}\right) \delta 8.30-8.15(\mathrm{~m}, 4 \mathrm{H}), 7.92(\mathrm{t}, J=7.8 \mathrm{~Hz}$, $2 \mathrm{H}), 7.75(\mathrm{td}, J=7.9,1.3 \mathrm{~Hz}, 2 \mathrm{H}), 4.83(\mathrm{~d}, J=2.5 \mathrm{~Hz}, 2 \mathrm{H}), 2.58(\mathrm{t}, J=2.5 \mathrm{~Hz}, 1 \mathrm{H}) . \quad{ }^{13} \mathrm{C} \mathrm{NMR}(101$ $\left.\mathrm{MHz}, \mathrm{CD}_{3} \mathrm{CN}\right) \delta 142.2,135.6,132.1,129.2,128.0,125.0,118.5,82.4,69.5,42.5$. HRMS m/z (ESI-TOF): $[\mathrm{M}]^{+}$calcd for $\mathrm{C}_{15} \mathrm{H}_{11} \mathrm{~S} 223.0576$, found 223.0575.<smiles>C#CC[S+]1c2ccccc2Sc2ccccc21</smiles>

3e, white powder, $0.27 \mathrm{~g}, 79 \%$, purified by flash column chromatography on silica gel using $\mathrm{CH}_{2} \mathrm{Cl}_{2} / \mathrm{MeOH}(40: 1)$. ${ }^{1} \mathrm{H}$ NMR (400 MHz, DMSO- $\left.d_{6}\right) \delta 8.20$ (dd, $\left.J=7.9,1.4 \mathrm{~Hz}, 2 \mathrm{H}\right), 8.05$ (dd, $J=7.9,1.3 \mathrm{~Hz}, 2 \mathrm{H}), 7.83(\mathrm{td}, J=7.7,1.4 \mathrm{~Hz}, 2 \mathrm{H}), 7.74(\mathrm{td}, J=7.7,1.3 \mathrm{~Hz}, 2 \mathrm{H}), 5.13(\mathrm{~s}, 2 \mathrm{H}), 5.04(\mathrm{~d}, J$ $=2.5 \mathrm{~Hz}, 1 \mathrm{H}) .{ }^{13} \mathrm{C}$ NMR $\left(101 \mathrm{MHz}, \mathrm{DMSO}-d_{6}\right) \delta 136.5,135.5,134.8,134.6,130.4,129.9,128.8,127.8$, 117.0, 70.2, 51.8. HRMS m/z (ESI-TOF): [M] $]^{+}$calcd for $\mathrm{C}_{15} \mathrm{H}_{11} \mathrm{~S}_{2} 255.0297$, found 255.0297 .<smiles>C#CC[S+]1c2ccccc2Oc2ccccc21</smiles>

3f, white powder, $0.23 \mathrm{~g}, 71 \%$ purified by flash column chromatography on silica gel using $\mathrm{CH}_{2} \mathrm{Cl}_{2} / \mathrm{MeOH}(40: 1) .{ }^{1} \mathrm{H}$ NMR (400 MHz, DMSO- $\left.d_{6}\right) \delta 7.29-7.16(\mathrm{~m}, 4 \mathrm{H}), 7.09$ (ddd, $J=8.2$, $5.6,1.5 \mathrm{~Hz}, 4 \mathrm{H}), 5.04$ (d, $J=2.4 \mathrm{~Hz}, 2 \mathrm{H}), 4.09$ (t, $J=2.4 \mathrm{~Hz}, 1 \mathrm{H}) .{ }^{13} \mathrm{C}$ NMR $\left(101 \mathrm{MHz}, \mathrm{DMSO}-d_{6}\right) \delta$ 151.4, 128.3, 127.1, 125.1, 119.3, 117.8, 82.8, 76.9, 62.9. HRMS m/z (ESI-TOF): $[\mathrm{M}]^{+}$calcd for $\mathrm{C}_{15} \mathrm{H}_{11} \mathrm{OS} 239.0525$, found 239.0529. 

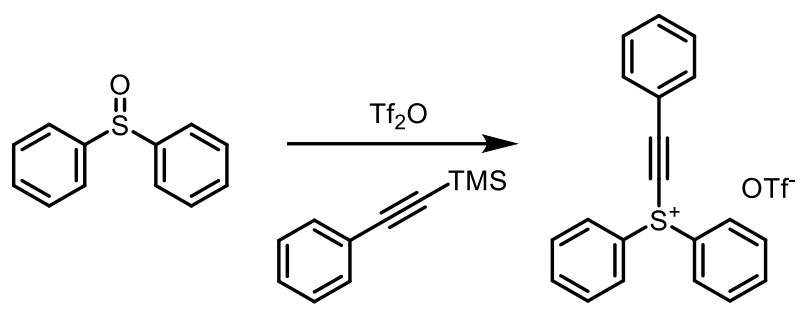

$3 g$

Triflic anhydride ( $0.84 \mathrm{~mL}, 5 \mathrm{mmol}, 1.0$ equiv.) was slowly added at $-50{ }^{\circ} \mathrm{C}$ to a solution of diphenyl sulfoxide (1.01 g, $5 \mathrm{mmol}, 1.0$ equiv.) in dry DCM $(8 \mathrm{~mL} / \mathrm{mmol})$. The reaction was stirred for 1 hour at that temperature and then a solution of the desired 1-phenyl-2-trimethylsilylacetylene $(872 \mathrm{mg}, 5 \mathrm{mmol}$, 1.0 equiv. $)$ in DCM $(1 \mathrm{~mL} / \mathrm{mmol})$ was dropwise added. After this, the reaction was slowly warmed to $15{ }^{\circ} \mathrm{C}$ and stirred for another 6 hours at this temperature. The solvents were removed in vacuo. The crude product was purified by flash column chromatography.

3g, white powder, $1.17 \mathrm{~g}, 82 \%$, purified by flash column chromatography on silica gel using $\mathrm{CH}_{2} \mathrm{Cl}_{2} / \mathrm{MeOH}(40: 1) .{ }^{1} \mathrm{H}$ NMR (500 MHz, Methanol- $\left.d_{4}\right) \delta 8.25-8.19(\mathrm{~m}, 4 \mathrm{H}), 7.93-7.89(\mathrm{~m}, 2 \mathrm{H})$, $7.76-7.69(\mathrm{~m}, 6 \mathrm{H}), 7.62-7.57(\mathrm{~m}, 1 \mathrm{H}), 7.49(\mathrm{dd}, J=8.6,7.1 \mathrm{~Hz}, 2 \mathrm{H}) .{ }^{13} \mathrm{C}$ NMR $(126 \mathrm{MHz}$, Methanol$\left.d_{4}\right) \delta 135.8,134.6,134.1,132.7,130.3,130.1,129.8,118.2,64.2$. HRMS m/z (ESI-TOF): [M] ${ }^{+}$calcd for $\mathrm{C}_{20} \mathrm{H}_{15} \mathrm{~S} 287.0889$, found 287.0884 .

\subsection{General procedure $D$ for SPPS}

Peptides were synthesized on Rink Amide MBHA resin or Fmoc-Wang resin by Fmoc solid-phase synthesis (SPPS). Rink-amide resin was pre-swelled with DCM for 30min, filtered, the Fmoc (9fluorenylmethyloxycarbonyl) group was removed with $50 \%$ (vol $/ \mathrm{vol}$ ) morpholine for $30 \mathrm{~min} * 2$; the resin was sequentially washed with DCM and DMF for three times. For natural amino acids coupling, Fmocprotected amino acids or acids (2.0 equiv.) and HATU (2.0 equiv.) were dissolved in DMF, followed by DIPEA (3.0 equiv.). The mixture was pre-activated for $1 \mathrm{~min}$ and added to the resin for 1 hour with $\mathrm{N}_{2}$ bubbling, repeat once. The resin was washed sequentially with DCM, DMF for three times, then dried under a stream of nitrogen for next step. For cleavage of resin, the final resin was treated with TFA/DCM/TIS/water (90:5:2.5:2.5) at room temperature for $3 \mathrm{~h}$ and concentrated under a stream of nitrogen. The crude peptides were precipitated and washed with cold hexane/diehyl ether $(1: 2, \mathrm{v} / \mathrm{v})$ at $4^{\circ} \mathrm{C}$, redissolved in $50 \%$ acetonitrile in water. Crude peptides were purified by HPLC.

\subsection{General procedure $\mathbf{E}$ for the synthesis of sulfonium intermediates}

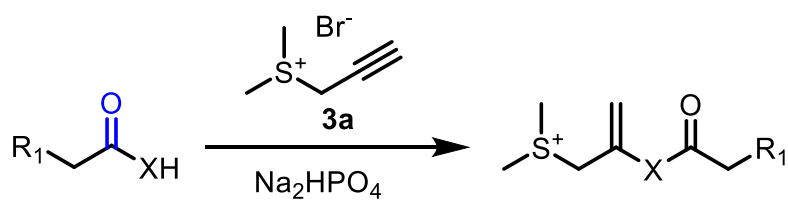

Take the synthesis of $\mathbf{S 1}$ as one example. To a $50 \mathrm{~mL}$ EP tube was added benzoic acid $(0.12 \mathrm{~g}, 1 \mathrm{mmol}$, 1 equiv.), propargyl sulfonium 3a ( $0.36 \mathrm{~g}, 2 \mathrm{mmol}, 2$ equiv.), $\mathrm{Na}_{2} \mathrm{HPO}_{4} 12 \mathrm{H}_{2} \mathrm{O}$ (1.43 g, 4 mmol, 4 equiv.) and $\mathrm{MeCN} / \mathrm{H}_{2} \mathrm{O}=1 / 1$ solvent $(20 \mathrm{~mL})$. The tube was then sealed and shook on a shaker at $37^{\circ} \mathrm{C}$ for $1 \mathrm{~h}$. After filtration, the resulting reaction mixture was then purified directly via HPLC. Desired distillates were identified by MS and lyophilized to obtain target products. 
<smiles>C=C(C[Si](C)C)OC(=O)c1ccccc1</smiles>

S1, yellow oil, $0.28 \mathrm{~g}, 93 \%$. After filtration, the resulting reaction mixture was then purified directly via HPLC. Desired distillates were identified by MS and lyophilized to obtain target products. ${ }^{1} \mathrm{H}$ NMR $\left(400 \mathrm{MHz}\right.$, Methanol- $\left.d_{4}\right) \delta 8.18-8.11(\mathrm{~m}, 2 \mathrm{H}), 7.75(\mathrm{t}, J=7.5 \mathrm{~Hz}, 1 \mathrm{H}), 7.62-7.56$ $(\mathrm{m}, 2 \mathrm{H}), 5.61(\mathrm{~d}, J=2.4 \mathrm{~Hz}, 1 \mathrm{H}), 5.55(\mathrm{~d}, J=2.4 \mathrm{~Hz}, 1 \mathrm{H}), 4.42(\mathrm{~s}, 2 \mathrm{H}), 3.02(\mathrm{~s}, 6 \mathrm{H}) .{ }^{13} \mathrm{C}$ NMR $(101$ MHz, Methanol- $\left.d_{4}\right) \delta 165.2,143.8,134.2,132.7,129.9,128.65,113.0,46.5,23.8$. HRMS m/z (ESITOF): [M] calcd for $\mathrm{C}_{12} \mathrm{H}_{15} \mathrm{O}_{2} \mathrm{~S} 223.0787$, found 223.0791.<smiles>C#CCOc1ccc(C(=O)OC(=C)C[Si](C)C)cc1</smiles>

P3, yellow oil, $0.31 \mathrm{~g}, 87 \%$. After filtration, the resulting reaction mixture was then purified directly via HPLC. Desired distillates were identified by MS and lyophilized to obtain target products. ${ }^{1} \mathrm{H}$ NMR (400 MHz, Methanol- $\left.d_{4}\right) \delta 8.07-8.01(\mathrm{~m}, 2 \mathrm{H}), 7.12-7.07(\mathrm{~m}, 2 \mathrm{H})$, $5.55(\mathrm{~d}, J=2.4 \mathrm{~Hz}, 1 \mathrm{H}), 5.45(\mathrm{~d}, J=2.3 \mathrm{~Hz}, 1 \mathrm{H}), 4.83(\mathrm{~d}, J=2.4 \mathrm{~Hz}, 2 \mathrm{H}), 4.37(\mathrm{~s}, 2 \mathrm{H}), 3.02-3.00(\mathrm{~m}$, $1 \mathrm{H}), 2.97(\mathrm{~s}, 6 \mathrm{H}) .{ }^{13} \mathrm{C}$ NMR (101 MHz, Methanol- $\left.d_{4}\right) \delta 164.8,162.6,143.8,132.0,120.9,114.8,112.8$, 77.6, 76.2, 55.5, 46.5, 23.8. HRMS m/z (ESI-TOF): [M] $]^{+}$calcd for $\mathrm{C}_{15} \mathrm{H}_{17} \mathrm{O}_{3} \mathrm{~S} 277.0893$, found 277.0890.<smiles>C#CCOc1ccc(C(=O)SC(=C)C[Si](C)C)cc1</smiles>

P4, yellow oil, $24 \mathrm{mg}, 65 \%$. After filtration, the resulting reaction mixture was then purified directly via HPLC. Desired distillates were identified by MS and lyophilized to obtain target products. ${ }^{1} \mathrm{H}$ NMR $\left(400 \mathrm{MHz}, \mathrm{CDCl}_{3}\right) \delta 7.93(\mathrm{~d}, J=8.5 \mathrm{~Hz}, 2 \mathrm{H}), 7.08(\mathrm{~d}, J=8.4 \mathrm{~Hz}$, 2H), $6.61(\mathrm{~s}, 1 \mathrm{H}), 6.09(\mathrm{~s}, 1 \mathrm{H}), 4.82(\mathrm{~s}, 2 \mathrm{H}), 4.81(\mathrm{~s}, 2 \mathrm{H}), 3.24(\mathrm{~s}, 6 \mathrm{H}), 2.61$ (d, $J=2.5 \mathrm{~Hz}, 1 \mathrm{H}) .{ }^{13} \mathrm{C}$ NMR $\left(101 \mathrm{MHz}, \mathrm{CDCl}_{3}\right) \delta 189.1,162.6,139.2,130.0,128.9,125.6,115.2,77.3,76.6,56.1,52.0,24.8$. HRMS $\mathrm{m} / \mathrm{z}$ (ESI-TOF): [M] $]^{+}$calcd for $\mathrm{C}_{15} \mathrm{H}_{17} \mathrm{O}_{2} \mathrm{~S}_{2} 293.0665$, found 293.0670.<smiles>C=C(C[Si](C)C)OC(=O)CCCC[C@H]1SCC2NC(=O)NC21</smiles>

P5, yellow oil, $0.31 \mathrm{~g}, 73 \%$. After filtration, the resulting reaction mixture was then purified directly via HPLC. Desired distillates were identified by MS and lyophilized to obtain target products. ${ }^{1} \mathrm{H}$ NMR $\left(400 \mathrm{MHz}, \mathrm{D}_{2} \mathrm{O}\right) \delta 5.38(\mathrm{~d}, J=2.6 \mathrm{~Hz}, 1 \mathrm{H}), 5.30(\mathrm{~d}, J=2.6 \mathrm{~Hz}, 1 \mathrm{H})$, 4.49 (dd, $J=7.7,4.3 \mathrm{~Hz}, 1 \mathrm{H}), 4.33-4.29$ (m, 1H), 4.12 (s, 2H), 3.24 (dt, $J=9.4,4.8 \mathrm{~Hz}, 1 \mathrm{H}), 2.90-$ $2.86(\mathrm{~m}, 1 \mathrm{H}), 2.82(\mathrm{~s}, 6 \mathrm{H}), 2.66(\mathrm{~d}, J=9.3 \mathrm{~Hz}, 1 \mathrm{H}), 2.47(\mathrm{~d}, J=7.2 \mathrm{~Hz}, 1 \mathrm{H}), 2.29(\mathrm{~d}, J=7.3 \mathrm{~Hz}, 1 \mathrm{H})$, 1.55 (dtd, $J=23.5,9.4,8.6,5.8 \mathrm{~Hz}, 4 \mathrm{H}), 1.36-1.30(\mathrm{~m}, 2 \mathrm{H}) .{ }^{13} \mathrm{C}$ NMR $\left(101 \mathrm{MHz}, \mathrm{D}_{2} \mathrm{O}\right) \delta 174.4,165.2$, 142.0, 113.7, 61.9, 60.1, 55.2, 45.8, 39.5, 33.3, 33.0, 27.6, 24.0, 23.5. HRMS m/z (ESI-TOF): $[\mathrm{M}]^{+}$calcd for $\mathrm{C}_{15} \mathrm{H}_{25} \mathrm{~N}_{2} \mathrm{O}_{3} \mathrm{~S}_{2} 345.1301$, found 345.1304 .

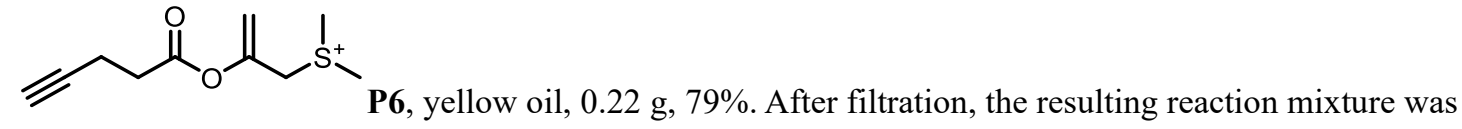
then purified directly via HPLC. Desired distillates were identified by MS and lyophilized to obtain target products. ${ }^{1} \mathrm{H}$ NMR $\left(300 \mathrm{MHz}\right.$, Methanol- $\left.d_{4}\right) \delta 5.48(\mathrm{~d}, J=2.3 \mathrm{~Hz}, 1 \mathrm{H}), 5.39(\mathrm{~d}, J=2.4 \mathrm{~Hz}, 1 \mathrm{H}), 4.29(\mathrm{~s}$, 2H), $2.94(\mathrm{~d}, J=9.8 \mathrm{~Hz}, 7 \mathrm{H}), 2.79-2.68(\mathrm{~m}, 2 \mathrm{H}), 2.57-2.49(\mathrm{~m}, 2 \mathrm{H}) .{ }^{13} \mathrm{C}$ NMR $(75 \mathrm{MHz}$, Methanol$\left.d_{4}\right) \delta 170.6,143.4,112.6,81.5,69.3,46.1,32.7,23.7,13.4$. HRMS m/z (ESI-TOF): [M] ${ }^{+}$calcd for 


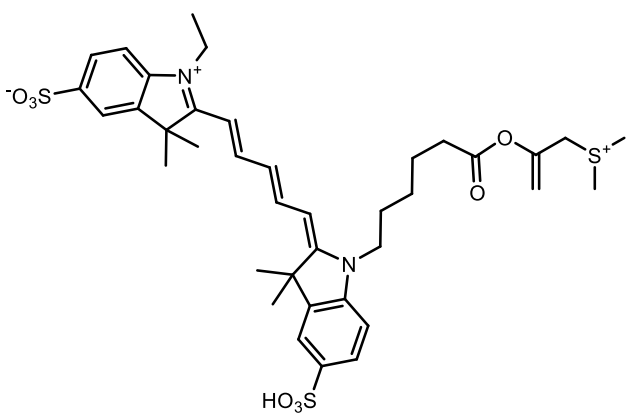

P7, blue oil, $0.5 \mathrm{mg}, 19 \%$. After filtration, the resulting reaction mixture was then purified directly via HPLC. Desired distillates were identified by MS and lyophilized to obtain target products. ${ }^{1} \mathrm{H}$ NMR $\left(400 \mathrm{MHz}, \mathrm{D}_{2} \mathrm{O}\right) \delta 7.93(\mathrm{q}, J=12.4 \mathrm{~Hz}, 2 \mathrm{H}), 7.71(\mathrm{dd}, J$ $=16.3,8.1 \mathrm{~Hz}, 4 \mathrm{H}), 7.21(\mathrm{dd}, J=11.5,8.4 \mathrm{~Hz}, 2 \mathrm{H}), 6.45(\mathrm{t}, J=12.4 \mathrm{~Hz}, 1 \mathrm{H}), 6.16(\mathrm{dd}, J=29.1,13.6$ $\mathrm{Hz}, 2 \mathrm{H}), 5.29$ (d, $J=2.8 \mathrm{~Hz}, 1 \mathrm{H}), 5.05(\mathrm{~d}, J=2.8 \mathrm{~Hz}, 1 \mathrm{H}), 4.03(\mathrm{~s}, 2 \mathrm{H}), 4.00-3.93(\mathrm{~m}, 4 \mathrm{H}), 2.77(\mathrm{~s}$, 6H), 2.39 (t, $J=7.0 \mathrm{~Hz}, 2 \mathrm{H}), 1.71(\mathrm{~s}, 2 \mathrm{H}), 1.55(\mathrm{~d}, J=3.5 \mathrm{~Hz}, 12 \mathrm{H}), 1.31-1.20(\mathrm{~m}, 7 \mathrm{H}) . \mathrm{HRMS} \mathrm{m} / \mathrm{z}$ (ESI-TOF): $[\mathrm{M}+\mathrm{H}]^{2+}$ calcd for $\mathrm{C}_{38} \mathrm{H}_{50} \mathrm{~N}_{2} \mathrm{O}_{8} \mathrm{~S}_{3} 379.1359$, found 379.1359 .

\subsection{General procedure $\mathrm{F}$ for the synthesis of control probes (NHS esters)}

The preparation of thioacids were followed the similar procedure of the reported literatures. ${ }^{7}$ Take the preparation of $\mathbf{P 8}$ as one example. 4-Dimethylaminopyridine (DMAP, $12 \mathrm{mg}, 0.1 \mathrm{mmol}, 5 \% \mathrm{~mol}$ ) was added to biotin $\left(0.49 \mathrm{~g}, 2 \mathrm{mmol}, 1\right.$ equiv.) in $\mathrm{CH}_{2} \mathrm{Cl}_{2}$ solvent $30 \mathrm{~mL}$, followed by 1-(3Dimethylaminopropyl)-3-ethylcarbodiimide hydrochloride (EDC, $0.76 \mathrm{~g}, 4 \mathrm{mmol}, 2$ equiv.). After stirring for $10 \mathrm{~min}$, N-hydroxysuccinimide (NHS, $0.23 \mathrm{~g}, 2 \mathrm{mmol}, 1$ equiv.) was added and stirred at $\mathrm{rt}$ under nitrogen atmosphere. The reaction completion was monitored by TLC. The solution was washed successively with brine $(3 \times 30 \mathrm{~mL})$, then dried over $\mathrm{Na}_{2} \mathrm{SO}_{4}$. The solvent was then removed in vacuum to afford the crude product, which was purified by flash column chromatography on silica gel using $\mathrm{CH}_{2} \mathrm{Cl}_{2} / \mathrm{MeOH}(50: 1)$.<smiles>O=C1NC2CSC(CCCCC(=O)ON3C(=O)CCC3=O)C2N1</smiles>

P8, white solid, $0.62 \mathrm{~g}, 91 \%$, purified by flash column chromatography on silica gel using $\mathrm{CH}_{2} \mathrm{Cl}_{2} / \mathrm{MeOH}(50: 1) .{ }^{1} \mathrm{H}$ NMR (300 MHz, DMSO- $\left.d_{6}\right) \delta 6.42(\mathrm{~s}, 1 \mathrm{H}), 6.36(\mathrm{~s}, 1 \mathrm{H})$, $4.34-4.24(\mathrm{~m}, 1 \mathrm{H}), 4.19-4.07(\mathrm{~m}, 1 \mathrm{H}), 3.13-3.05(\mathrm{~m}, 1 \mathrm{H}), 2.89-2.80(\mathrm{~m}, 1 \mathrm{H}), 2.79(\mathrm{~s}, 4 \mathrm{H}), 2.70(\mathrm{~d}$, $J=3.1 \mathrm{~Hz}, 1 \mathrm{H}), 2.65(\mathrm{t}, J=7.4 \mathrm{~Hz}, 2 \mathrm{H}), 1.73-1.44(\mathrm{~m}, 4 \mathrm{H}), 1.44-1.30(\mathrm{~m}, 2 \mathrm{H}) .{ }^{13} \mathrm{C}$ NMR $(75 \mathrm{MHz}$, DMSO- $\left.d_{6}\right) \delta 170.7,169.4,163.2,61.4,59.6,55.7,30.4,28.3,28.0,25.9,25.7,24.7$. The NMR spectra are consistant with the reported literature. ${ }^{7}$

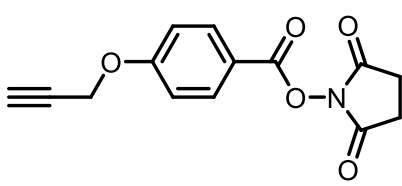

P9, white powder, $0.48 \mathrm{~g}, 88 \%$, purified by flash column chromatography on silica gel using hexane/EA (6:1). ${ }^{1} \mathrm{H}$ NMR $\left(500 \mathrm{MHz}, \mathrm{CDCl}_{3}\right) \delta 8.13-8.07(\mathrm{~m}, 2 \mathrm{H}), 7.08-7.02(\mathrm{~m}$, 2H), $4.77(\mathrm{~d}, J=2.4 \mathrm{~Hz}, 2 \mathrm{H}), 2.89(\mathrm{~s}, 4 \mathrm{H}), 2.56(\mathrm{t}, J=2.4 \mathrm{~Hz}, 1 \mathrm{H}) .{ }^{13} \mathrm{C} \mathrm{NMR}\left(126 \mathrm{MHz}, \mathrm{CDCl}_{3}\right) \delta 169.4$, $162.7,161.4,132.9,118.1,115.2,77.4,76.5,56.0,25.7$. The NMR spectra are consistant with the reported literature. ${ }^{8}$ 


\section{Biological experiments}

\subsection{Cell viability assay}

We used the MTT (3-(4,5-Dimethylthiazol-2-yl)-2,5-Diphenyl- tetrazolium Bromide) to measure the cell viability of different cell lines. The cell seed and cultured in a 96-well plate for 24 hours, and then treated with different drugs for 24 hours with $5 \%$ FBS (v/v) medium. MTT $(5 \mathrm{mg} / \mathrm{mL}, 20 \mathrm{~mL})$ was dissolved in phosphate buffered saline (PBS). The cells were continue incubated in the cell incubator with MTT for 4 hours. Then added DMSO (100 mL, Sigma) and shaked on a shaker for 10 minutes to dissolve the precipitate. Finally, the absorbance was measured at $490 \mathrm{~nm}$ using a microplate reader (Bio-Rad).

\subsection{Western blot to identify the covalent reaction efficiency of activated ester and protein}

After the activated ester formed by biotin and sulfonium salt is reacted with the target protein/lysate, the sample is digested in boiling water for 30 minutes after adding loading buffer, and the proteins of various molecular weights are separated by SDS-PAGE gel. The protein was then transferred to PVDF membrane pre-activated in methanol. After blocking the PVDF membrane with $3 \%$ bovine serum albumin (BSA) for one hour, the PVDF membrane was incubated with antibody of biotin (Abcam) conjugated with HRP that was 1000 times diluted in 3\% BSA. Then wash the membrane with TBST buffer (1M TBS, $0.05 \%$ Tween 20) for $10 \mathrm{~min}$, and repeat three times. The HRP chemiluminescence method is then used to develop and image, and the resulting image is retained.

\subsection{Cellular Imaging}

A549 cells were cultured in RPMI-1640 (Gibco, 1875093) using supplemented with $10 \%$ fetal bovine serum (FBS), imaging dishes at $37{ }^{\circ} \mathrm{C}$ and $5 \% \mathrm{CO}_{2}$ for one day. After dissolving $2.5 \mu \mathrm{M}$ activated ester in a medium containing $5 \%$ serum, we incubated the cells for 4 hours at $37^{\circ} \mathrm{C}$. The medium was removed, the cells were washed three times with PBS, and the cells were fixed with $4 \%$ paraformaldehyde for 25 minutes subsequently. Then washed three times with PBS. The cells were covered with $0.25 \%$ TritonX100 and placed at $4{ }^{\circ} \mathrm{C}$ for 5 minutes to make the cell membrane permeable. Subsequently, premixed 5 $\mu \mathrm{M}$ TAMRA- $\mathrm{N}_{3}, 10 \mu \mathrm{M}$ TBTA, $100 \mu \mathrm{M}$ TCEP and $100 \mu \mathrm{M} \mathrm{CuSO}_{4}$ were added and reacted for $2 \mathrm{~h}$, washed with PBST for ten minutes, repeated three times. Finally, the cells stained with 4', 6-diamidino2-phenylindole (DAPI) for image.

\subsection{Site-specific modification of proteins by MALDI}

Site-specific attachment to four model proteins was characterized using rapifleX MALDI-TOF/TOF (Bruker). A mount of $5 \mu \mathrm{g}$ proteins were treated with $0.1 \mathrm{mM}$ probes in indicated buffers and R.T. for 4 hours. Mixture was subjected to centrifuge ( $5000 \mathrm{rpm}$ ) by using ultrafiltration centrifuge tube (with $3 \mathrm{~K}$ or $10 \mathrm{~K}$ molecular weight cutoff), which was pretreated with water. The protein substrates were washed ( 3 X $200 \mu \mathrm{l}$ water) to remove the remaining probes and the mixture concentration was determined by Nanodrop for MALDI analysis $(+159.04 \mathrm{Da})$.

\subsection{Sample preparation for modification site analysis by MS/MS spectrum}


$2 \mathrm{mg} / \mathrm{ml}$ proteomes harvested was treated with $50 \mathrm{mM}$ probes in vitro for $4 \mathrm{~h}$. Subsequently, mixture were conjugated by CuAAC to PC-Biotin-azide tags $(10 \mathrm{mM}$ stock in DMSO, final concentration $=110$ $\mu \mathrm{M}$ ) using $1 \mathrm{mM}$ tris(2-carboxyethyl)phosphine hydrochloride (TCEP) (stock in water) and $100 \mu \mathrm{M}$ TBTA (stock in DMSO:t-butanol 1:4) and $1 \mathrm{mM} \mathrm{CuSO} 4$ (stock in water) for 1 hour at room temperature. Proteomes were collected by centrifugation ( $8000 \mathrm{~g}, 10 \mathrm{~min}$ ), and resuspended in 1.2\% SDS in DPBS. then added $5 \mathrm{~mL}$ DPBS, dilute to $0.2 \%$ SDS in DPBS. Samples were incubated with streptavidin-agarose beads slurry (Thermo) for 3 hours at $29{ }^{\circ} \mathrm{C}$ subsequently. After incubation, the beads were pelleted by centrifugation (1400 g, $3 \mathrm{~min}$ ) and were washed by $1 \mathrm{ml}$ cold PBS twice and cold water twice. Then, the beads were resuspended in $500 \mu 150 \mathrm{mM}$ Tris $\mathrm{pH} 8.5$ containing $6 \mathrm{M}$ urea. After that, beads was added $10 \mathrm{mM}$ dithiothreitol (DTT) and incubated at $37{ }^{\circ} \mathrm{C}$ for $30 \mathrm{~min}$ while $20 \mathrm{mM}$ IAA at $35^{\circ} \mathrm{C}$ for $30 \mathrm{~min}$ in dark. The bead mixture was diluted with $50 \mathrm{mM}$ Tris $\mathrm{pH} 8.5$ to $2 \mathrm{M}$ urea containing $2 \mu \mathrm{g}$ trypsin overnight. The beads were added $1000 \mu \mathrm{L}$ methonal-H2O $(7 / 3, \mathrm{v} / \mathrm{v})$ to collect the suspensions in thin-walled glass tubes, then irradiation with UV $365 \mathrm{~nm}(5000 \times 100 \mu \mathrm{J} / \mathrm{cm} 2)$ for 1 hour on ice to release probe-modified peptides. After spin down at 1,400 g, 3 min, the resulting probe-modified peptides were collected in liquid phase. The beads were washed with 2 X $500 \mu \mathrm{l}$ methonal- $\mathrm{H}_{2} \mathrm{O}(7 / 3, \mathrm{v} / \mathrm{v})$, solution combined and dry for LC-MS/MS analysis.

\subsection{LC-MS/MS Analysis}

After dry in the speed VAC, obtained samples were loaded onto a Thermo analytical column ( $75 \mu \mathrm{m}$ i.d. $\times 250 \mathrm{~mm}$ ) C18 column with an Easy-nLC 1200 chromatography pump. For each analysis, we reconstituted peptides in $10 \mu \mathrm{l} 0.1 \% \mathrm{FA}$ and loaded $8 \mu \mathrm{l}$ onto the column for running. Peptides in each running were separated on a $105 \mathrm{~min}(5-40 \% \mathrm{ACN})$ gradient. Parameters are as follows in Full MS/ data dependent -MS2 TopN mode: mass analyzer over $\mathrm{m} / \mathrm{z}$ range of $350-1500$ with a mass resolution of 60000 (at $\mathrm{m} / \mathrm{z}=200$ ) in a data-dependent mode, $1.6 \mathrm{~m} / \mathrm{z}$ isolation window. 20 most intense ions are selected for MS/MS analysis at a resolution of 15000 using collision mode of HCD. Peptides labeled in vitro were analyzed by Orbitrap Exploris 480, under the same setting parameters.

\subsection{Peptide and protein identification}

Spectral data was searched against the Uniprot/Swiss-prot protein database using PD 2.4 and filtered to $1 \%$ FDR (false discovery rate) at the protein level. Default parameters used following exceptions: a minimum of 1 unique peptide was required for quantitation; peptide matching between runs was included and peptides containing oxidation $(\mathrm{O}), \mathrm{N}$-terminal acetylation (protein $\mathrm{N}$-term), and carbamidomethyl (C) as variable modifications. For reactivity profiling experiments, lysine residues were searched with up to the modification for usp7-4 modification (+80.026 Da), P4 amidation tag (+258.112 Da). Only tryptic peptides with two missed cleavage sites were allowed; fragment mass tolerance was set to 0.02 Da for MS/MS fragment ions; mini and max peptide lengths were 6 and 144. For analysis of the residues labeled by probe, peptide and protein identification was conducted as detailed above with P4 modification $(+258.112 \mathrm{Da})$ allowed on lysine, cysteine, arginine, histidine, serine, threonine and tyrosine.

\subsection{Sequence motifs}

For all lysine identified in the proteome profiling experiments, the flanking sequence ( \pm 7 amino acids) was determined with an R package (ggseqlogo ${ }^{9}$ ), parsing the UniProtKB entries for all proteins identified. 


\section{Reference}

1.Hu, P.; Ben-David, Y.; Milstein, D., General Synthesis of Amino Acid Salts from Amino Alcohols and Basic Water Liberating H2. J. Am. Chem. Soc. 2016, 138, 6143-6146.

2.Liu, H.; Zhao, L.; Yuan, Y.; Xu, Z.; Chen, K.; Qiu, S.; Tan, H., Potassium Thioacids Mediated Selective Amide and Peptide Constructions Enabled by Visible Light Photoredox Catalysis. ACS Catal. 2016, 6 , 1732-1736.

3.Ghosh, S.; Purkait, A.; Jana, C. K., Environmentally benign decarboxylative N-, O-, and S-acetylations and acylations. Green Chem. 2020, 22, 8721-8727.

4.Mandai, H.; Hongo, K.; Fujiwara, T.; Fujii, K.; Mitsudo, K.; Suga, S., Dynamic Kinetic Resolution of Azlactones by a Chiral N,N-Dimethyl-4-aminopyridine Derivative Containing a 1,1'-Binaphthyl Unit: Importance of Amide Groups. Org. Lett. 2018, 20, 4811-4814.

5. (a) Yang, J.; Wang, C.; Xu, S.; Zhao, J., Ynamide-Mediated Thiopeptide Synthesis. Angew. Chem. Int. Ed. Engl. 2019, 58, 1382-1386. (b) Yao, C.; Yang, J.; Lu, X.; Zhang, S.; Zhao, J., Ynamide-Mediated Thionoester and Dithioester Syntheses. Org. Lett. 2020, 22, 6628-6631. (c) Yang, J.; Wang, C.; Yao, C.; Chen, C.; Hu, Y.; He, G.; Zhao, J., Site-Specific Incorporation of Multiple Thioamide Substitutions into a Peptide Backbone via Solid Phase Peptide Synthesis. J. Org. Chem. 2020, 85, 1484-1494.

6. (a) Shen, S. J.; Du, X. L.; Xu, X. L.; Zhao, M. G.; Liang, J. Y., Regioselective N-Addition/Substitution Reaction of alpha-Alkylidene Pyrazolinones with Propargyl Sulfonium Salts to Construct AllylthioContaining Pyrazolones. J. Org. Chem. 2019, 84, 12520-12531. (b) Lollar, C. T.; Krenek, K. M.; Bruemmer, K. J.; Lippert, A. R., Ylide mediated carbonyl homologations for the preparation of isatin derivatives. Org. Biomol. Chem. 2014, 12, 406-409.

7.Sandfort, F.; Knecht, T.; Pinkert, T.; Daniliuc, C. G.; Glorius, F., Site-Selective Thiolation of (Multi)halogenated Heteroarenes. J. Am. Chem. Soc. 2020, 142, 6913-6919.

8.Gavrilyuk, J. I.; Wuellner, U.; Salahuddin, S.; Goswami, R. K.; Sinha, S. C.; Barbas, C. F., An efficient chemical approach to bispecific antibodies and antibodies of high valency. Bioorg. Med. Chem. Lett. 2009, 19, 3716-3720.

9.Wagih, O., ggseqlogo: a versatile R package for drawing sequence logos. Bioinformatics 2017, 33, 3645-3647. 
6. NMR spectra and ESI-MS analysis of peptides

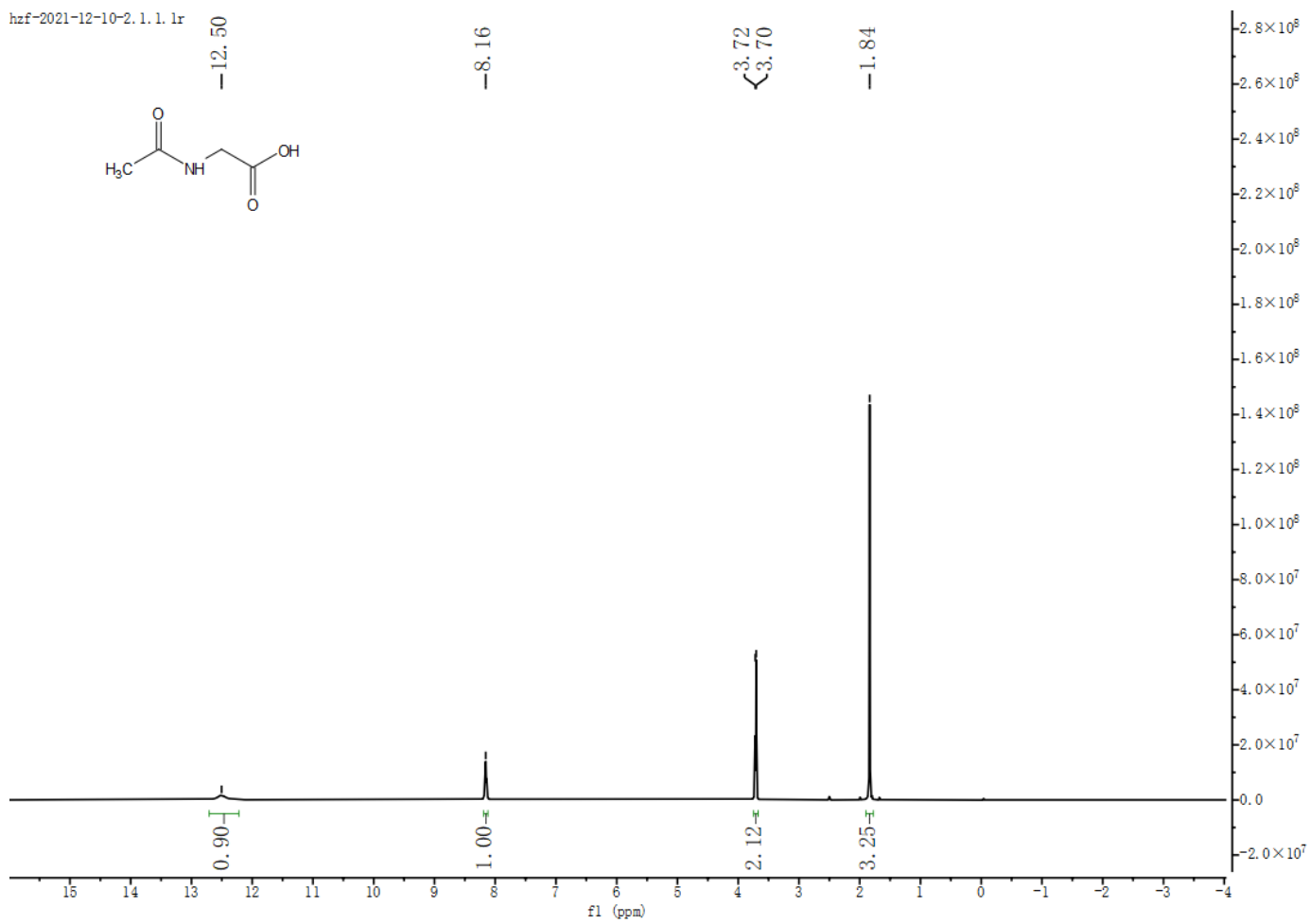

${ }^{1} \mathrm{H}$ NMR (400 MHz, DMSO- $d_{6}$ ) spectrum of $\mathbf{4 a}$

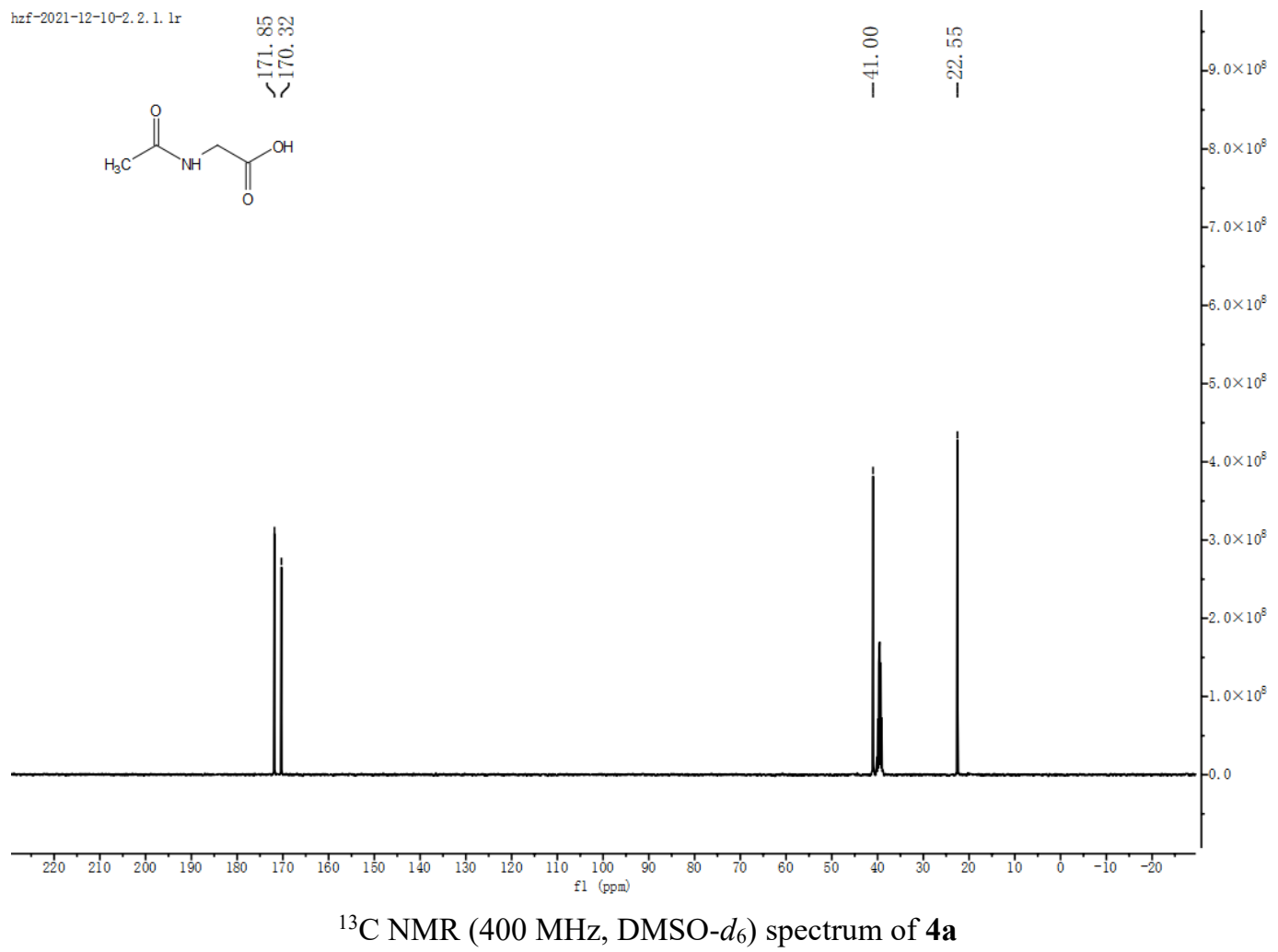




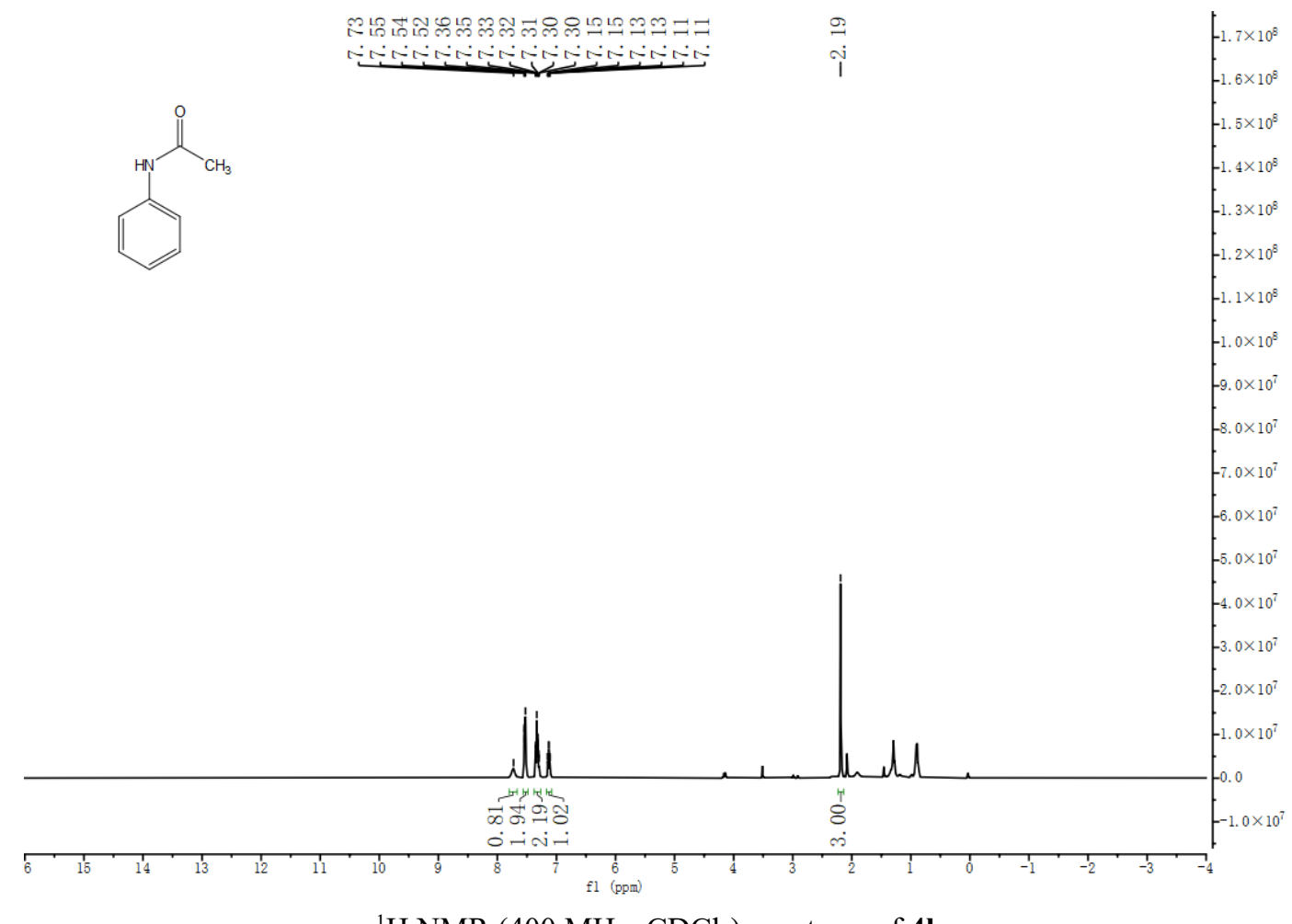

${ }^{1} \mathrm{H}$ NMR $\left(400 \mathrm{MHz}, \mathrm{CDCl}_{3}\right)$ spectrum of $\mathbf{4 b}$

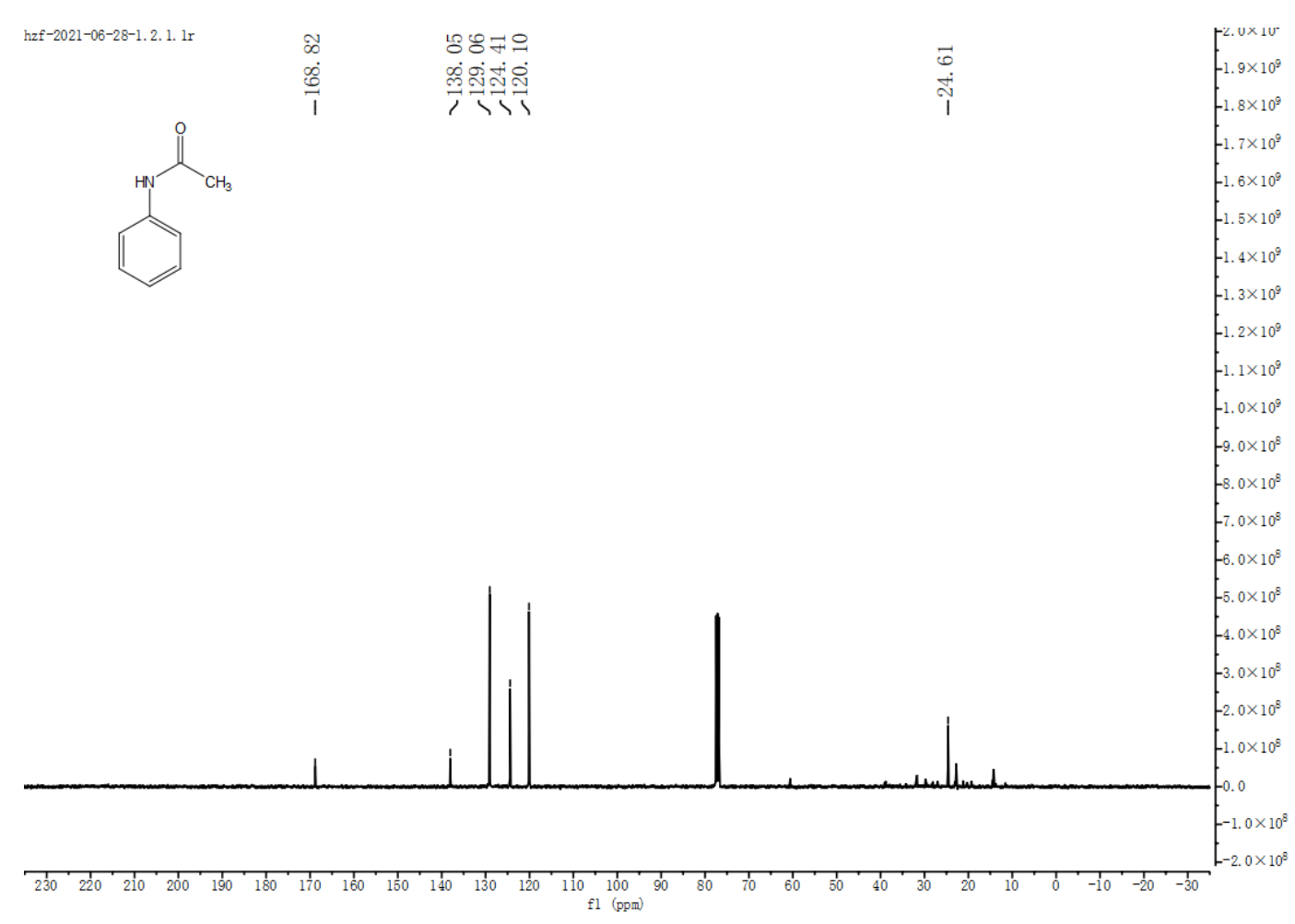

${ }^{13} \mathrm{C}$ NMR (101 MHz, $\mathrm{CDCl}_{3}$ ) spectrum of $\mathbf{4 b}$ 


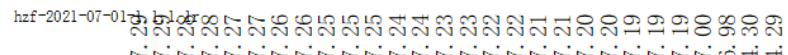

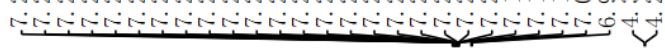

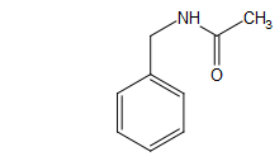

\&
$-2.6 \times 10^{8}$
$-2.4 \times 10^{8}$
$-2.2 \times 10^{8}$
$-2.0 \times 10^{8}$
$-1.8 \times 10^{8}$
$-1.6 \times 10^{8}$
$-1.4 \times 10^{8}$
$-1.0 \times 10^{8}$
$-8.0 \times 10^{8}$
$-6.0 \times 10^{7}$
$-4.0 \times 10^{7}$
$-2.0 \times 10^{7}$
-0.0
$-2.0 \times 10^{7}$

${ }^{1} \mathrm{H}$ NMR $\left(400 \mathrm{MHz}, \mathrm{CDCl}_{3}\right)$ spectrum of $\mathbf{4 c}$

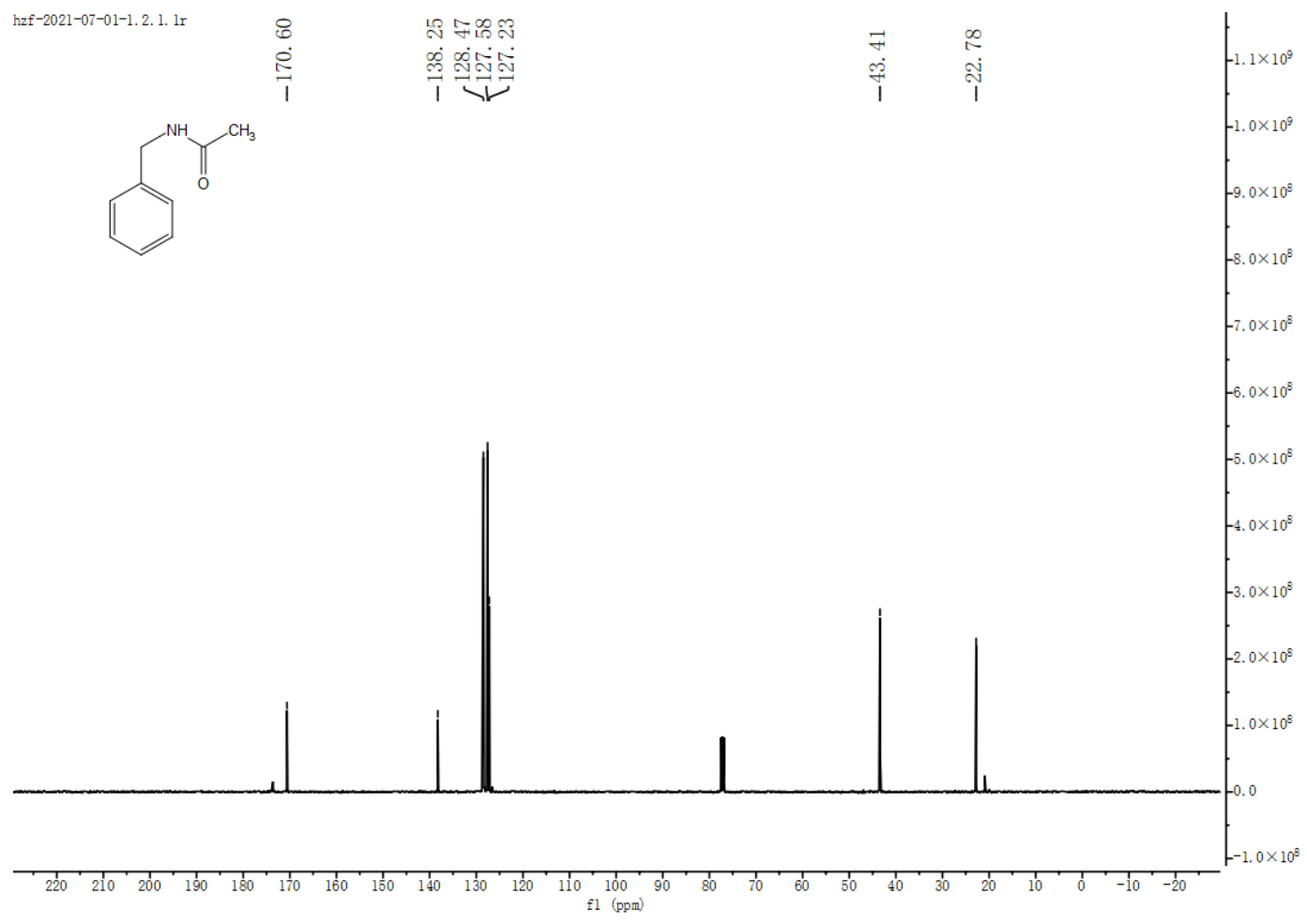

${ }^{13} \mathrm{C} \mathrm{NMR}\left(101 \mathrm{MHz}, \mathrm{CDCl}_{3}\right)$ spectrum of $\mathbf{4 c}$

S23 


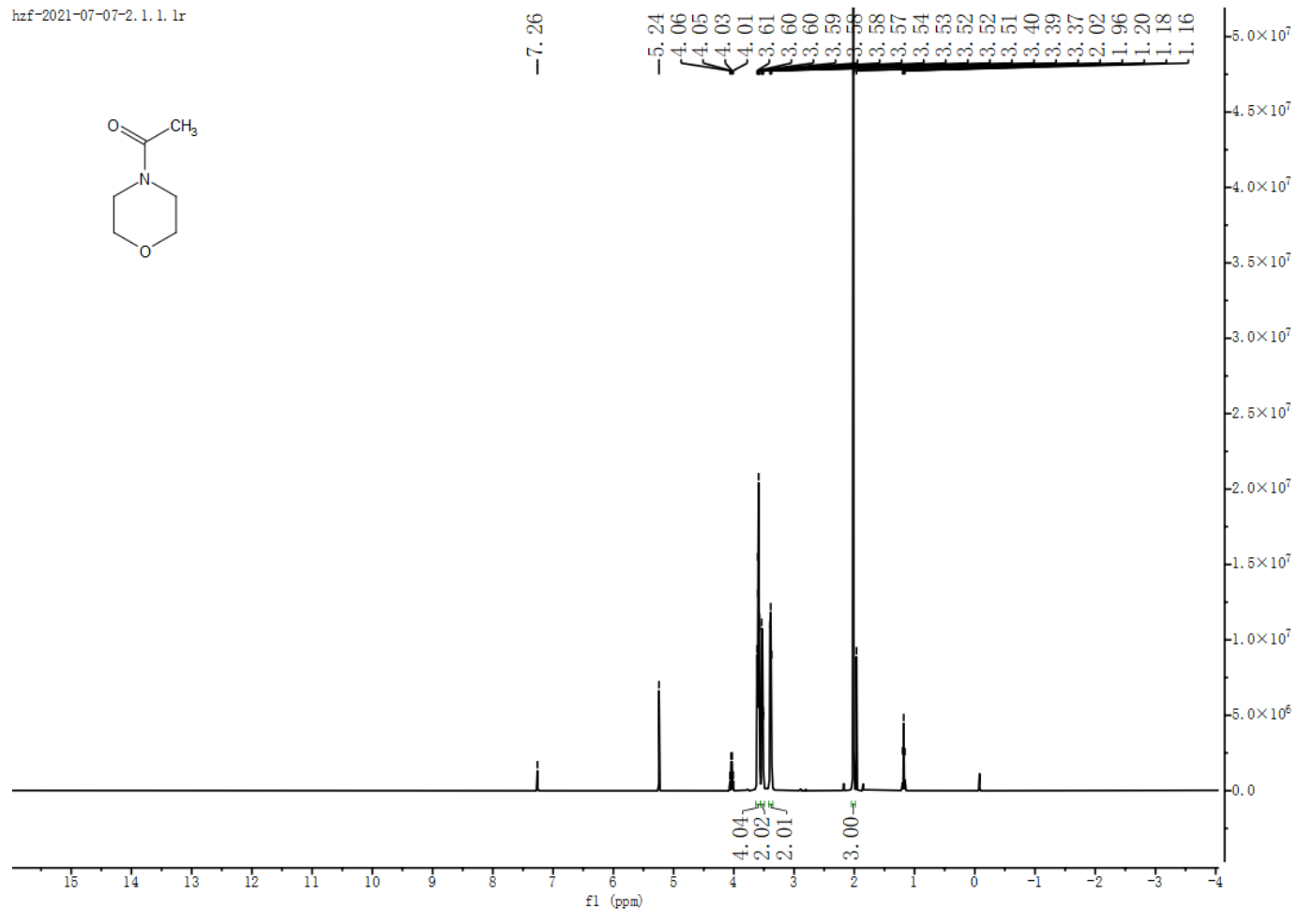

${ }^{1} \mathrm{H}$ NMR (400 MHz, $\mathrm{CDCl}_{3}$ ) spectrum of $\mathbf{4 d}$

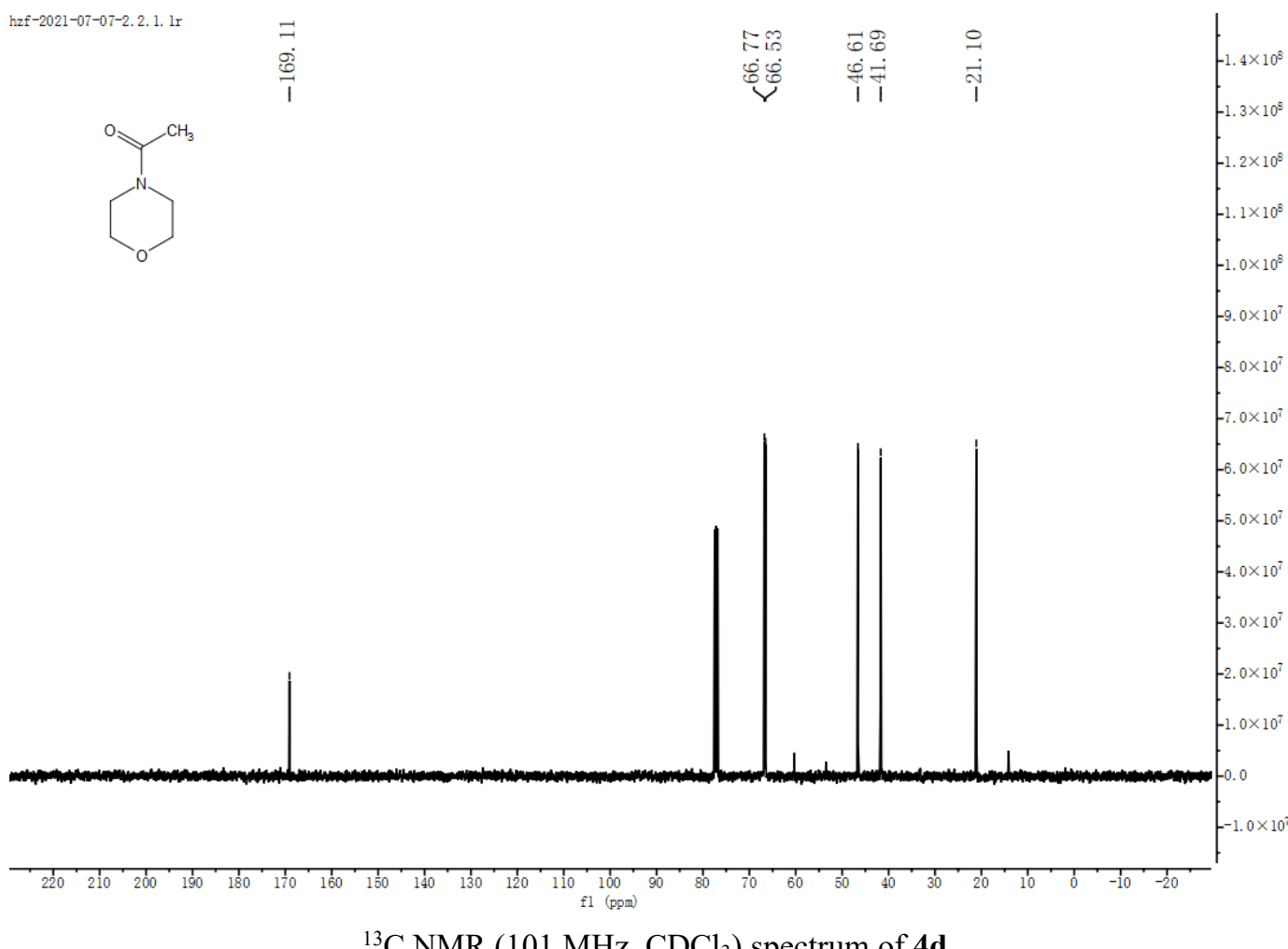

${ }^{13} \mathrm{C}$ NMR $\left(101 \mathrm{MHz}, \mathrm{CDCl}_{3}\right)$ spectrum of $\mathbf{4 d}$ 


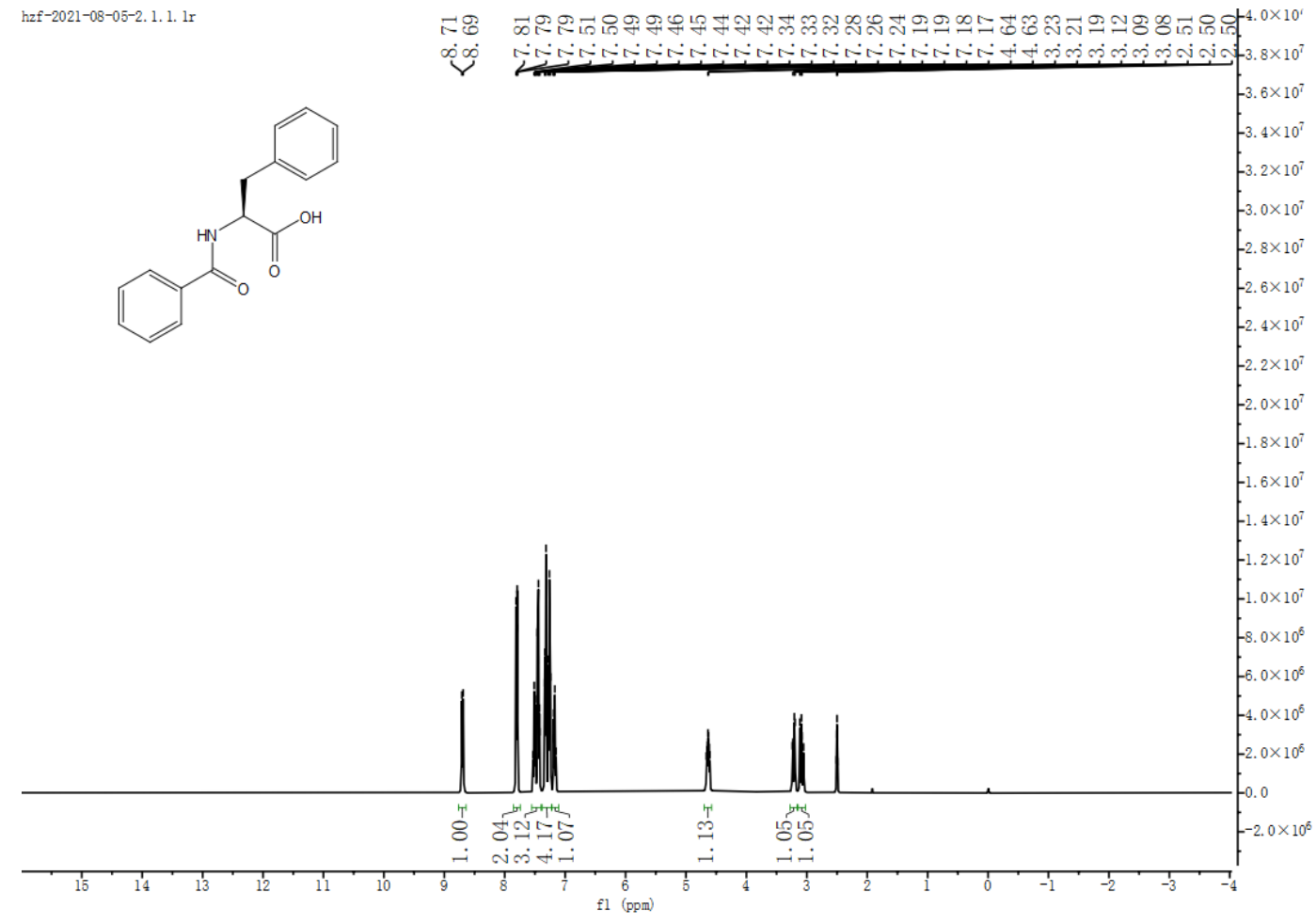

${ }^{1} \mathrm{H}$ NMR (400 MHz, DMSO- $d_{6}$ ) spectrum of $4 \mathbf{e}$

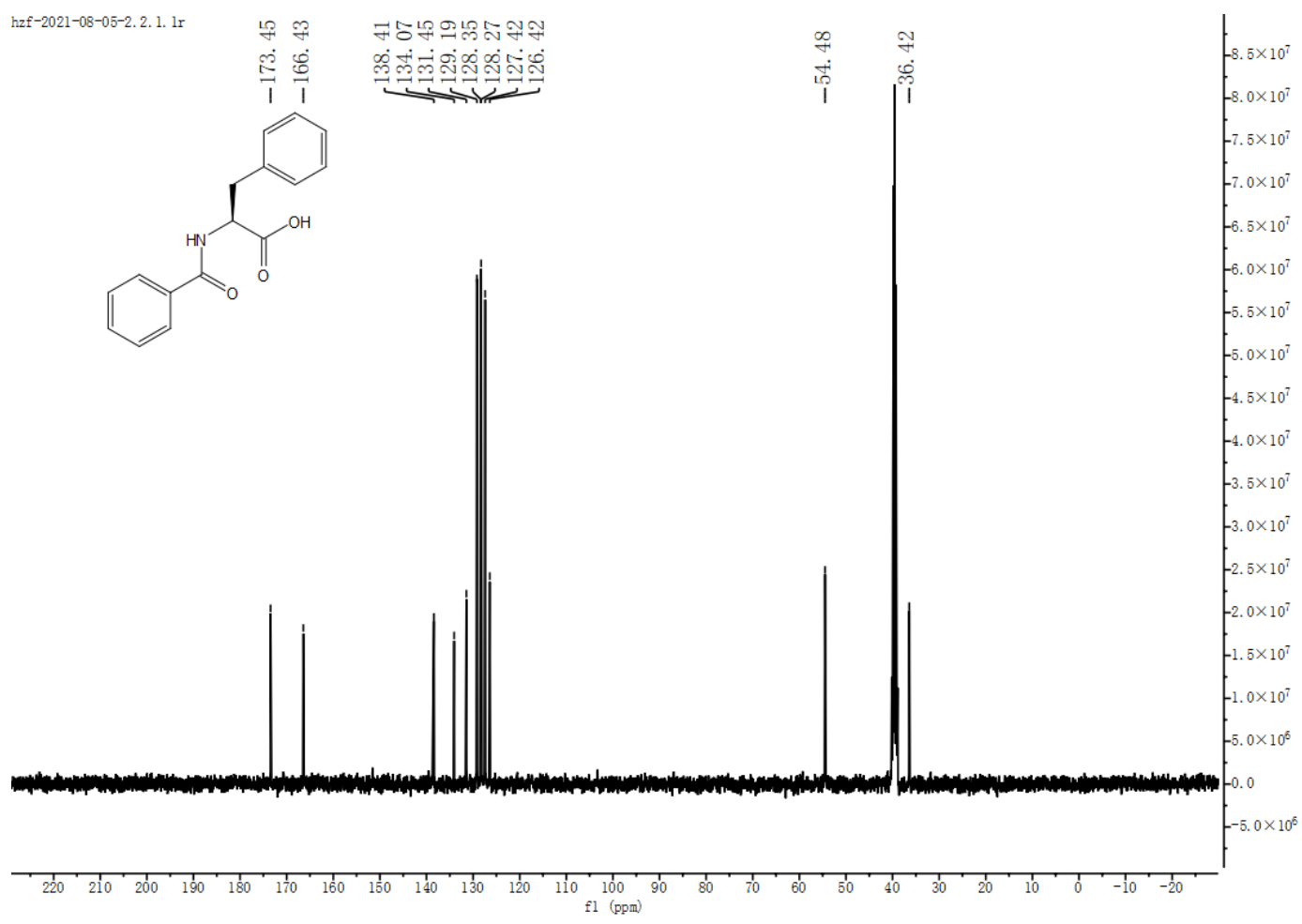

${ }^{13} \mathrm{C}$ NMR (101 MHz, DMSO- $d_{6}$ ) spectrum of $\mathbf{4 e}$ 


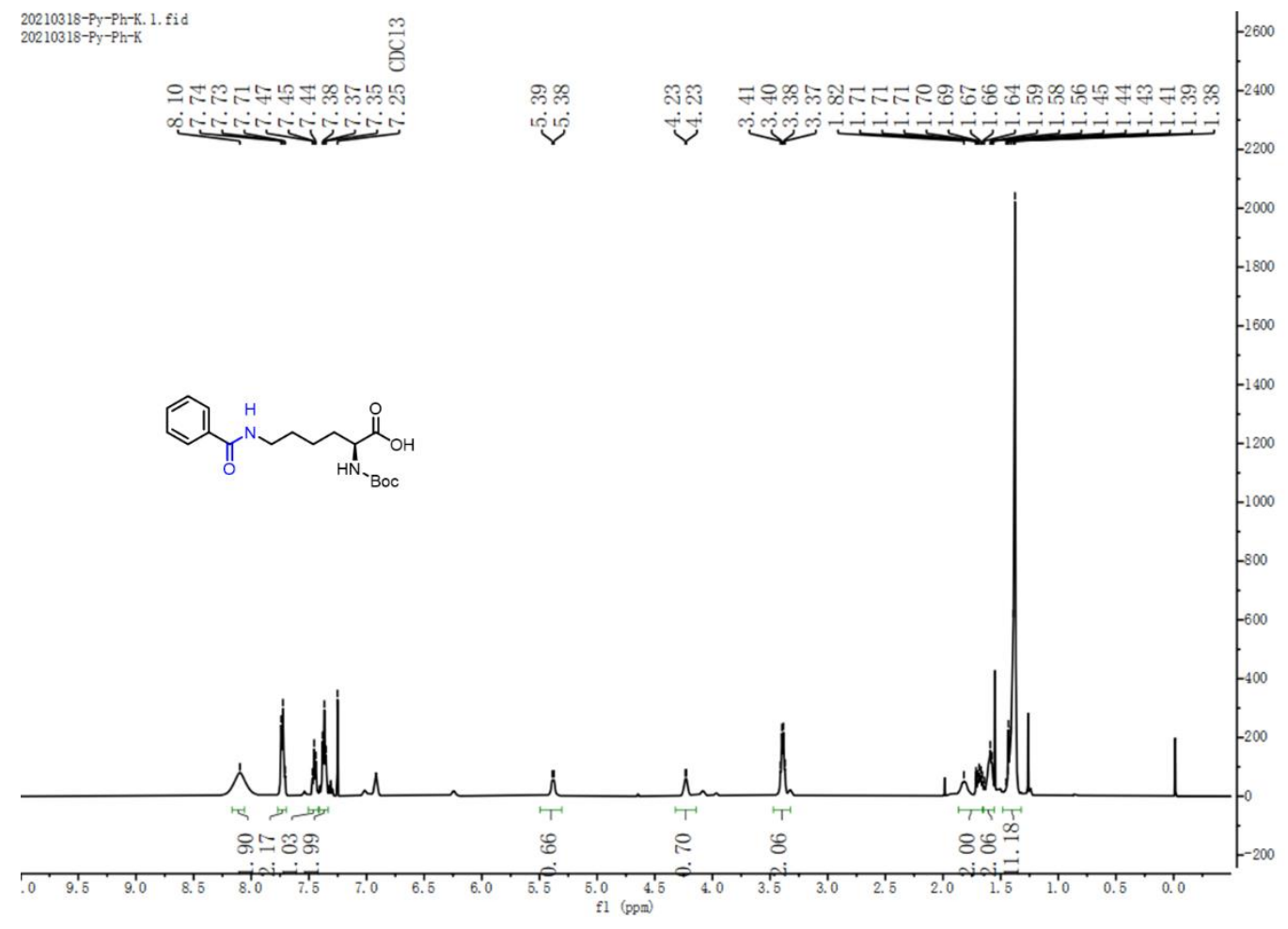

${ }^{1} \mathrm{H}$ NMR (500 MHz, $\mathrm{CDCl}_{3}$ ) spectrum of $\mathbf{4 f}$

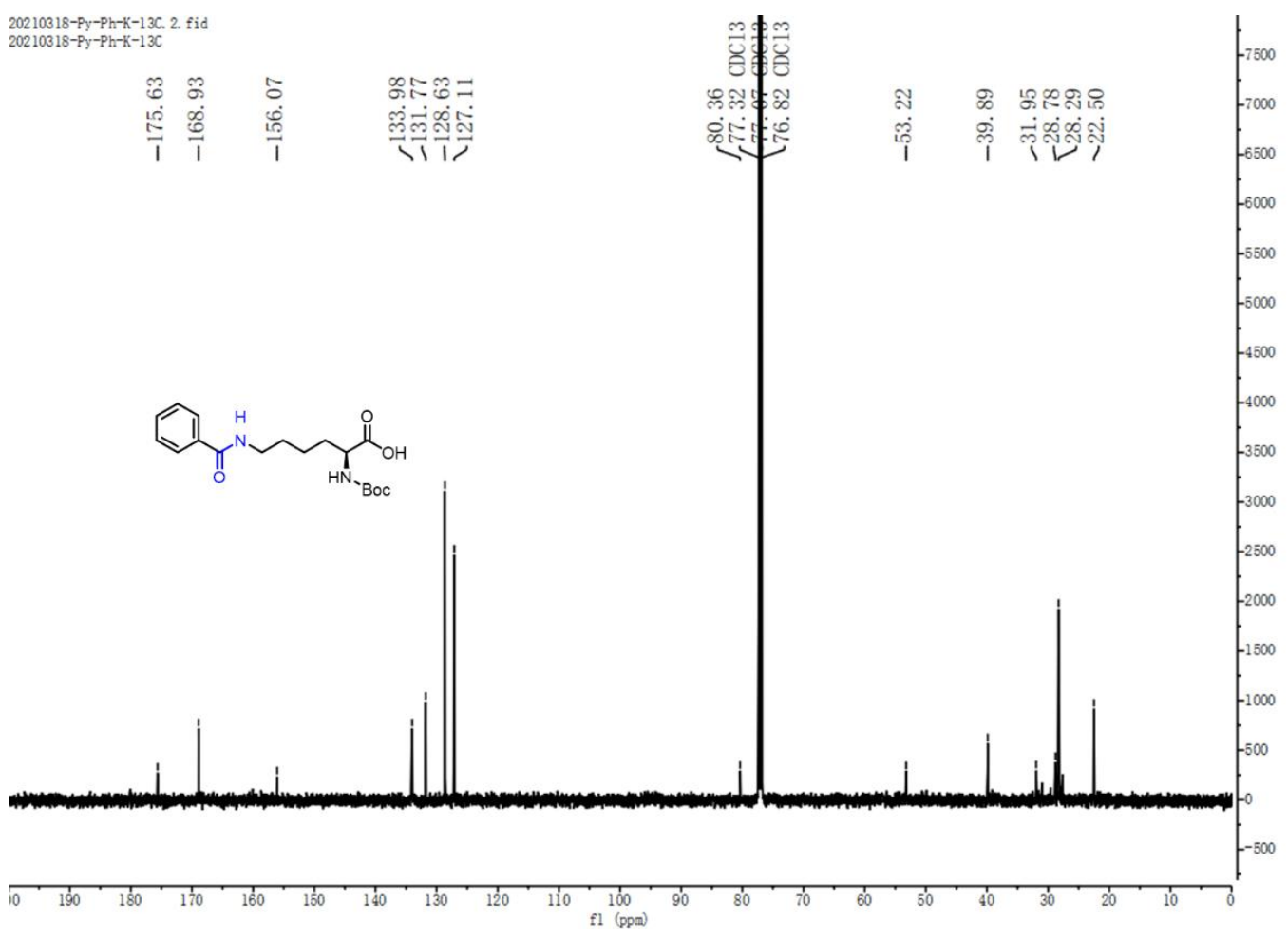

${ }^{13} \mathrm{C}$ NMR $\left(126 \mathrm{MHz}, \mathrm{CDCl}_{3}\right)$ spectrum of $\mathbf{4 f}$ 


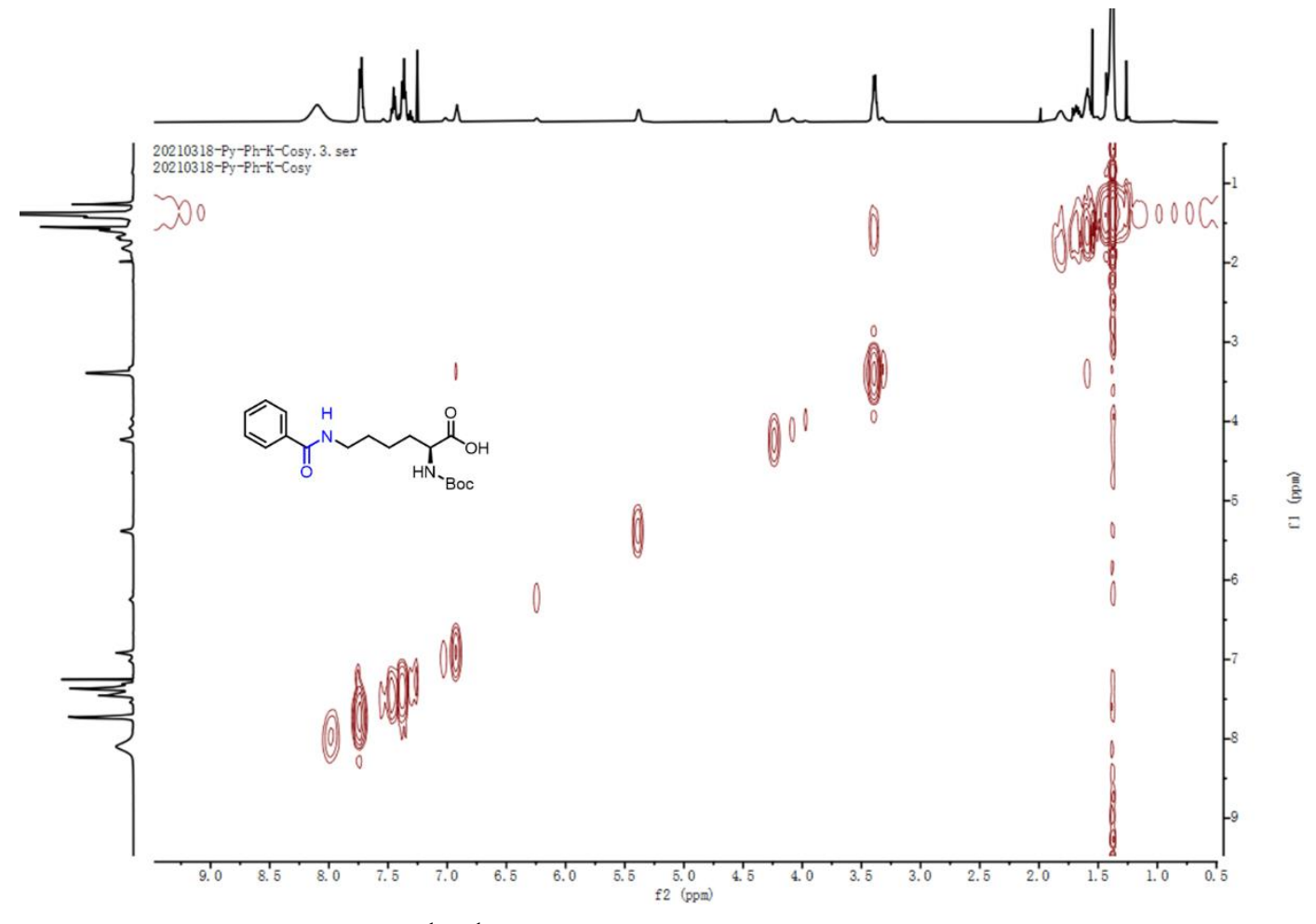

${ }^{1} \mathrm{H}-{ }^{1} \mathrm{H}$ COSY NMR spectrum of $\mathbf{4} \mathbf{f}$

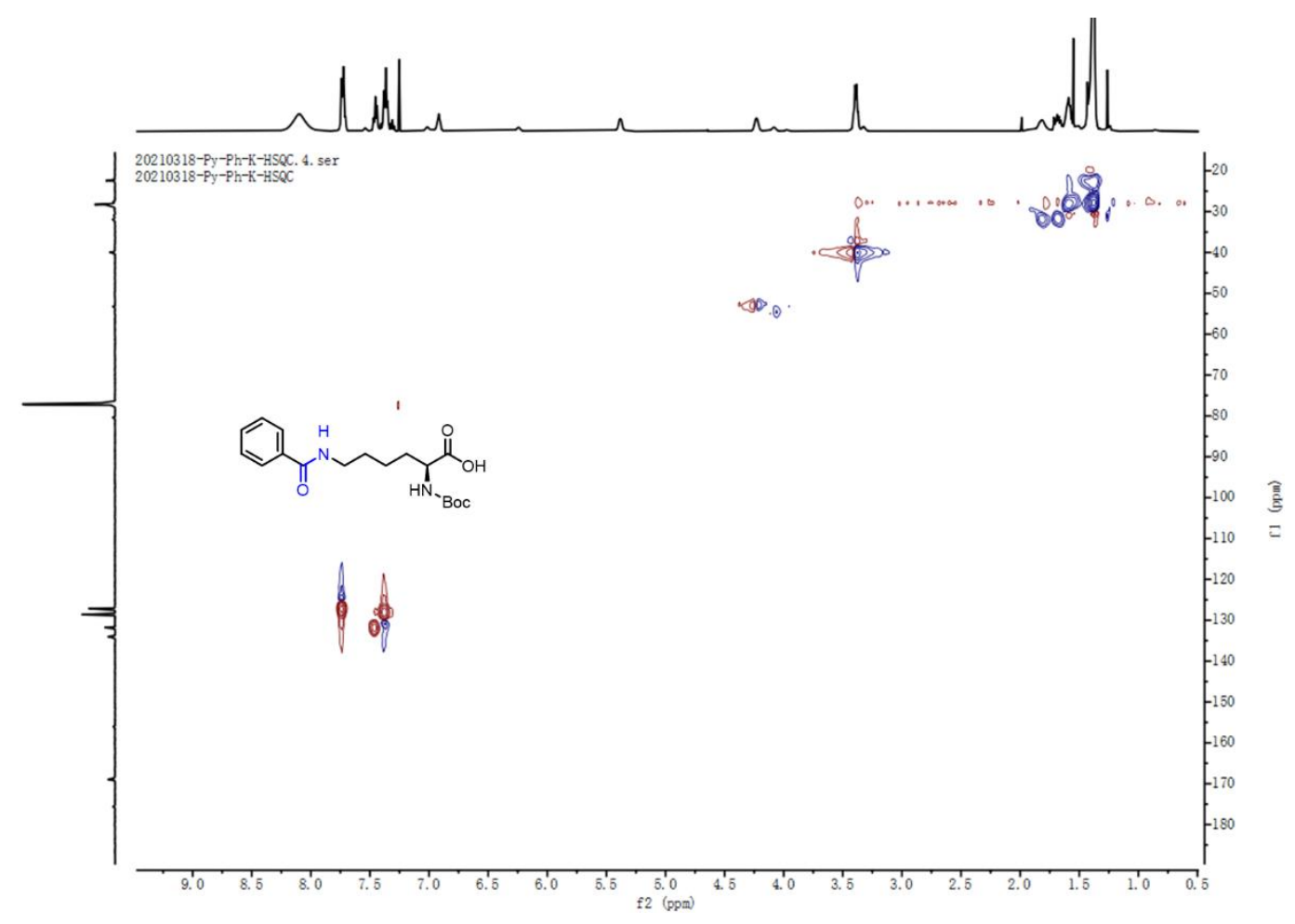

${ }^{1} \mathrm{H}-{ }^{13} \mathrm{C}$ HSQC NMR spectrum of $\mathbf{4} \mathbf{f}$ 


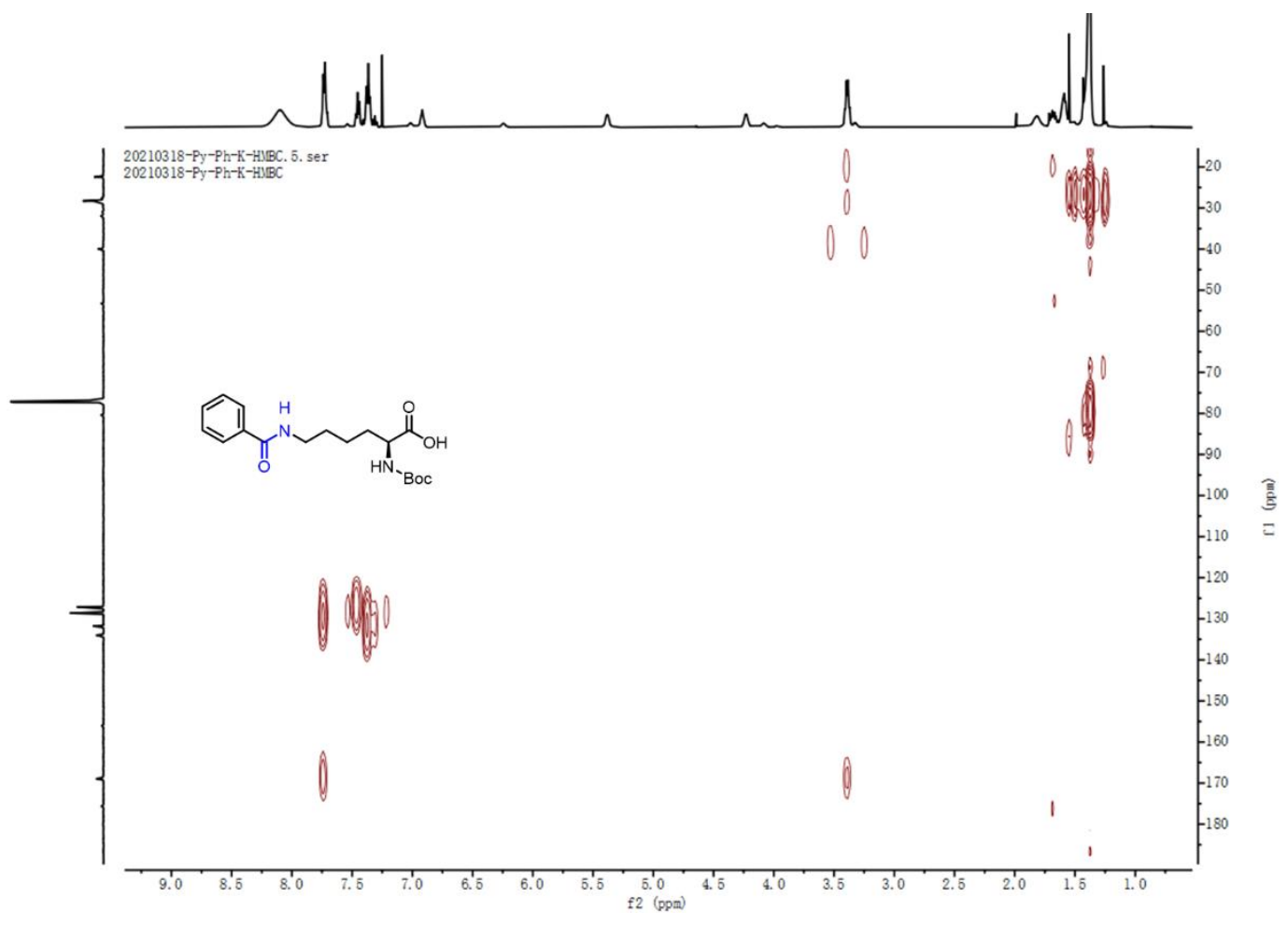

${ }^{1} \mathrm{H}-{ }^{13} \mathrm{C}$ HMBC NMR spectrum of $\mathbf{4} \mathbf{f}$

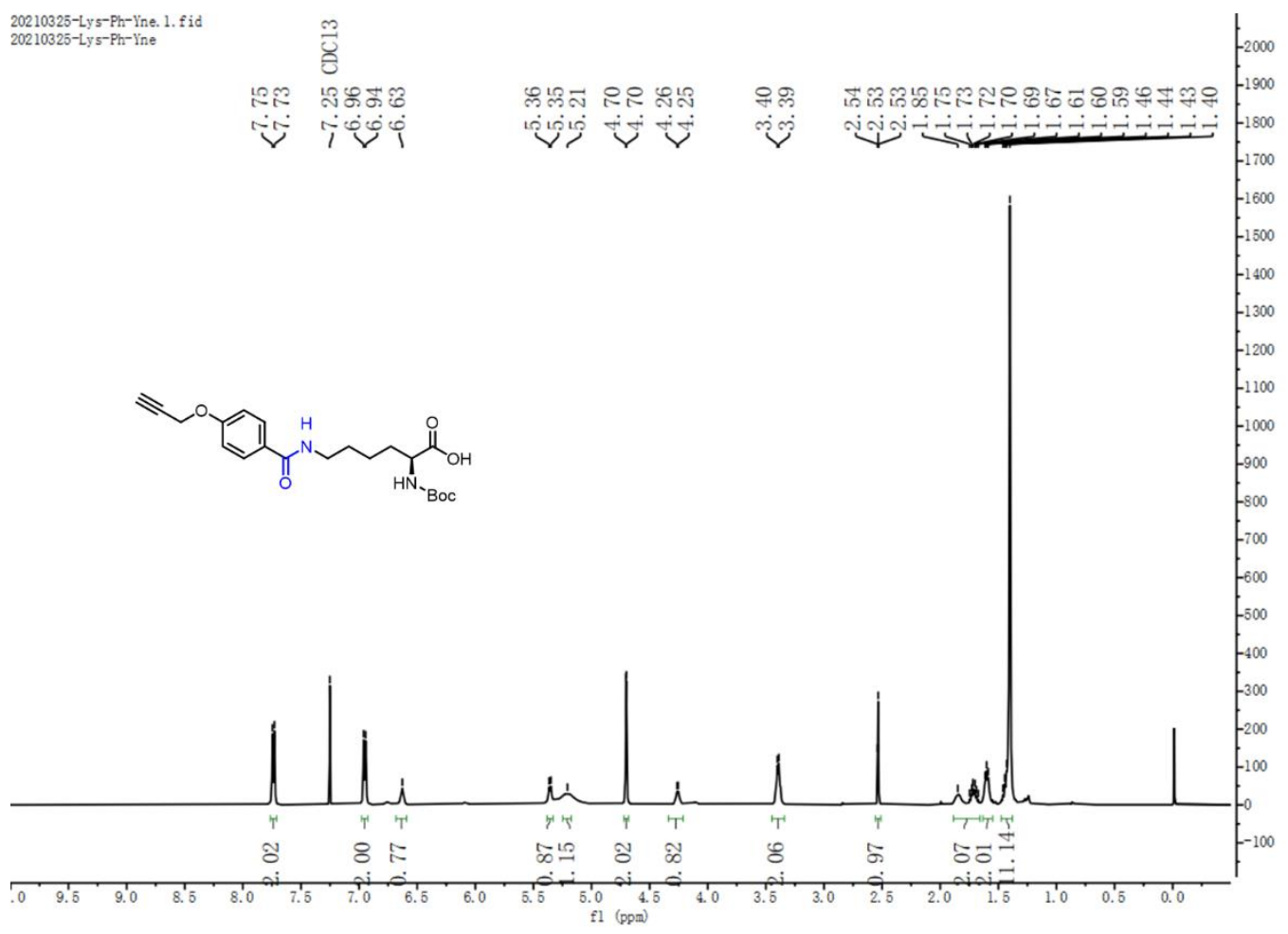

${ }^{1} \mathrm{H}$ NMR (500 MHz, $\mathrm{CDCl}_{3}$ ) spectrum of $\mathbf{4 g}$ 


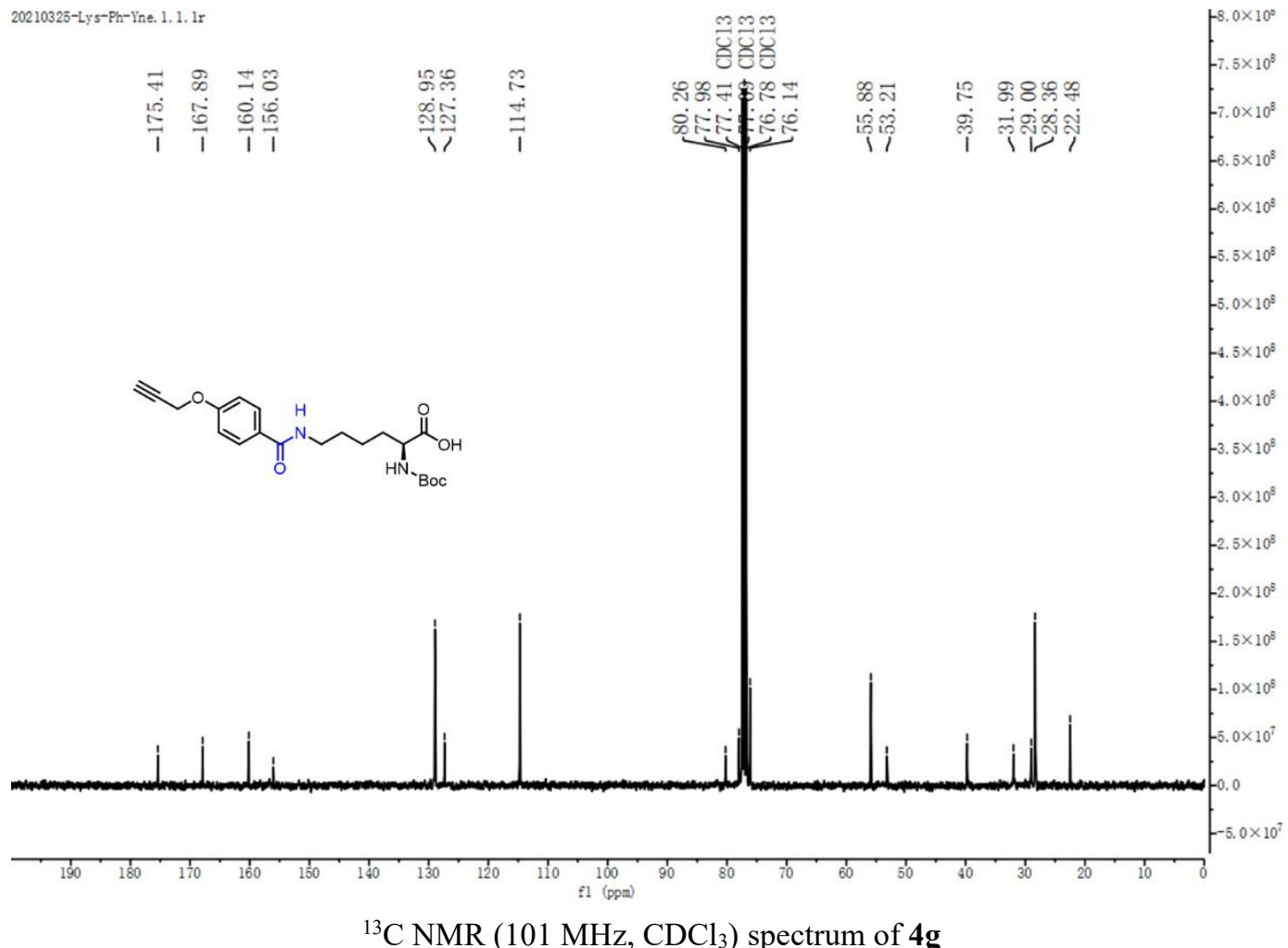

${ }^{13} \mathrm{C}$ NMR (101 MHz, $\mathrm{CDCl}_{3}$ ) spectrum of $\mathbf{4 g}$

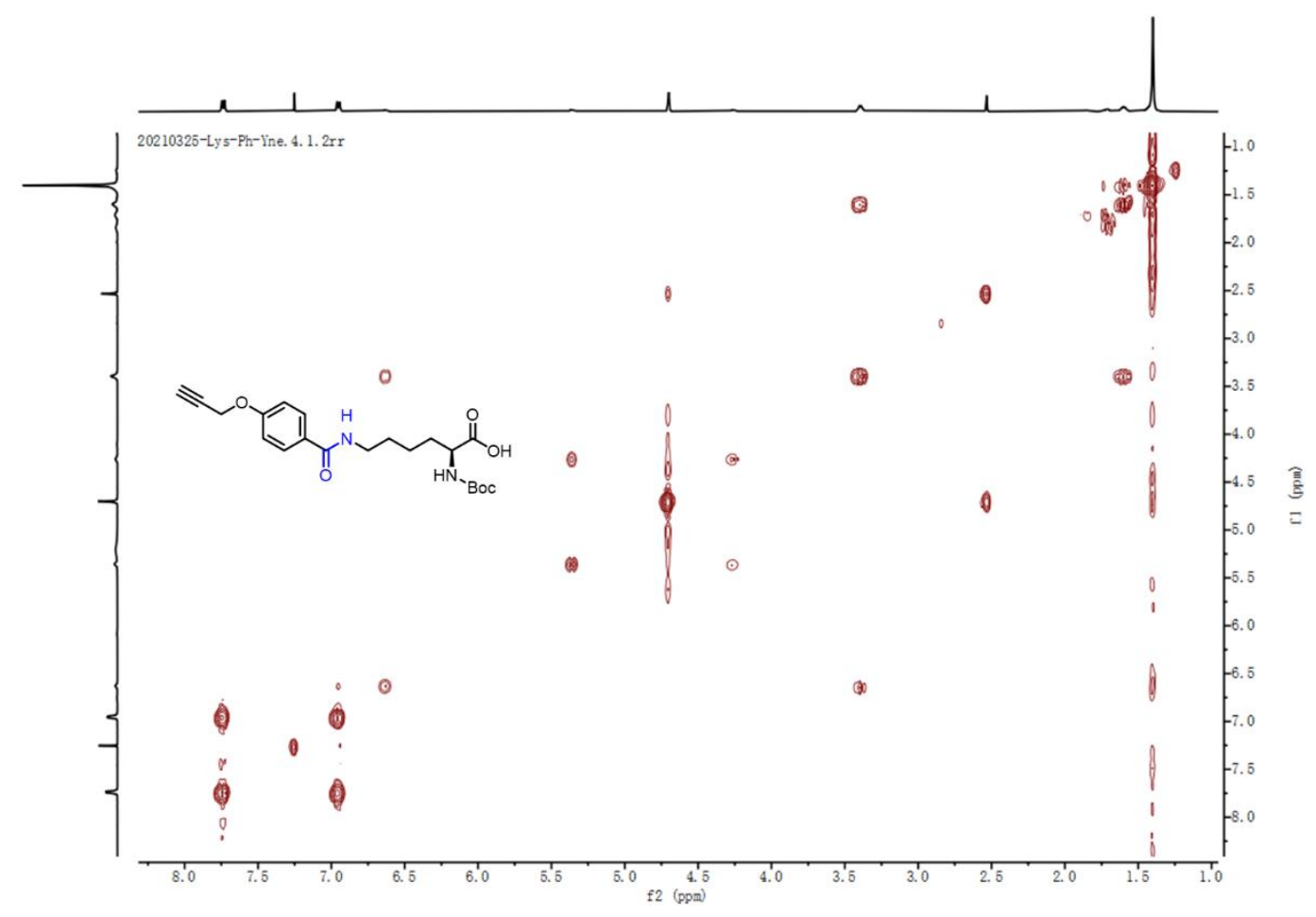

${ }^{1} \mathrm{H}-{ }^{-1} \mathrm{H}$ COSY NMR spectrum of $\mathbf{4 g}$ 


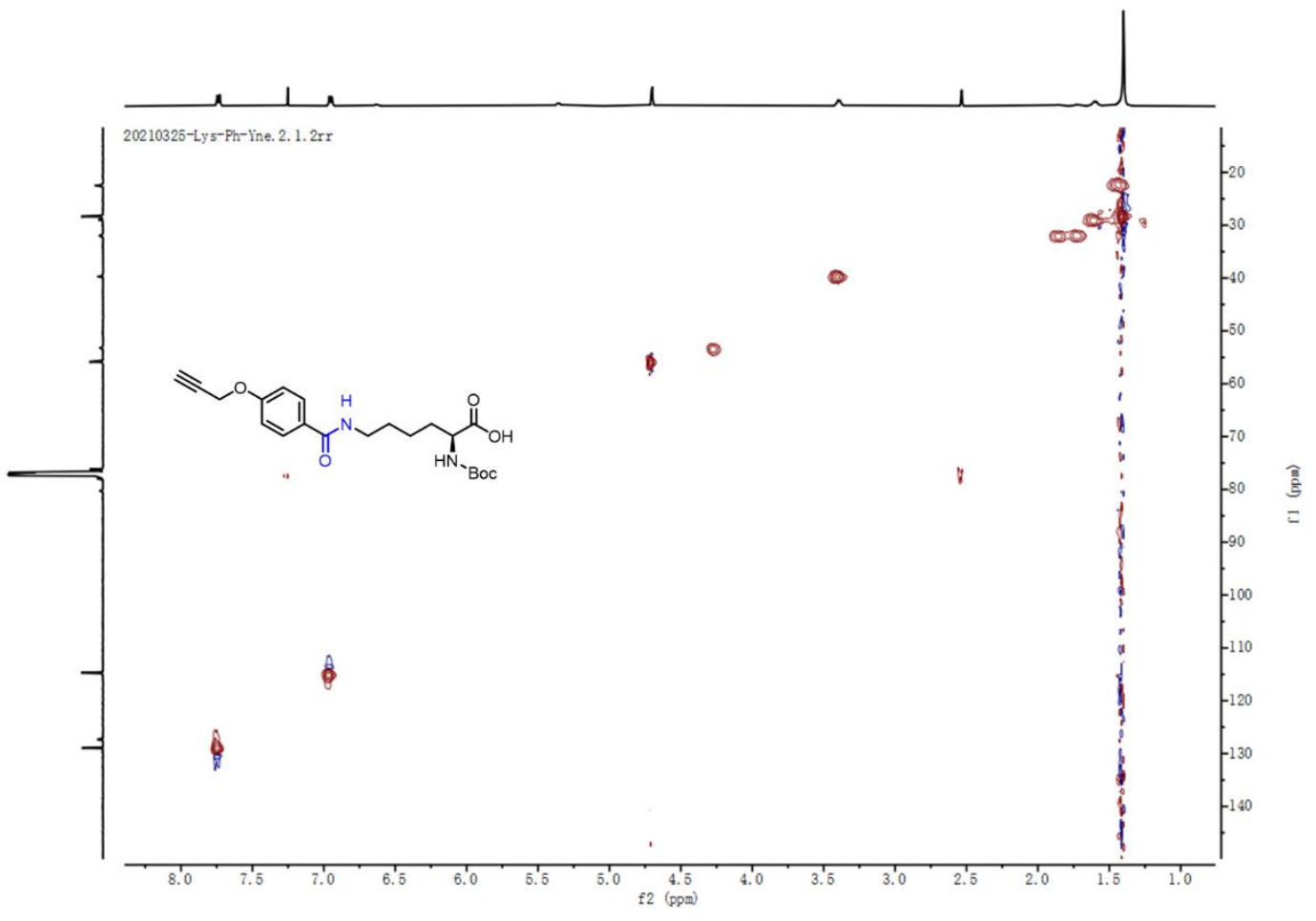

${ }^{1} \mathrm{H}-{ }^{13} \mathrm{C}$ HSQC NMR spectrum of $\mathbf{4 g}$

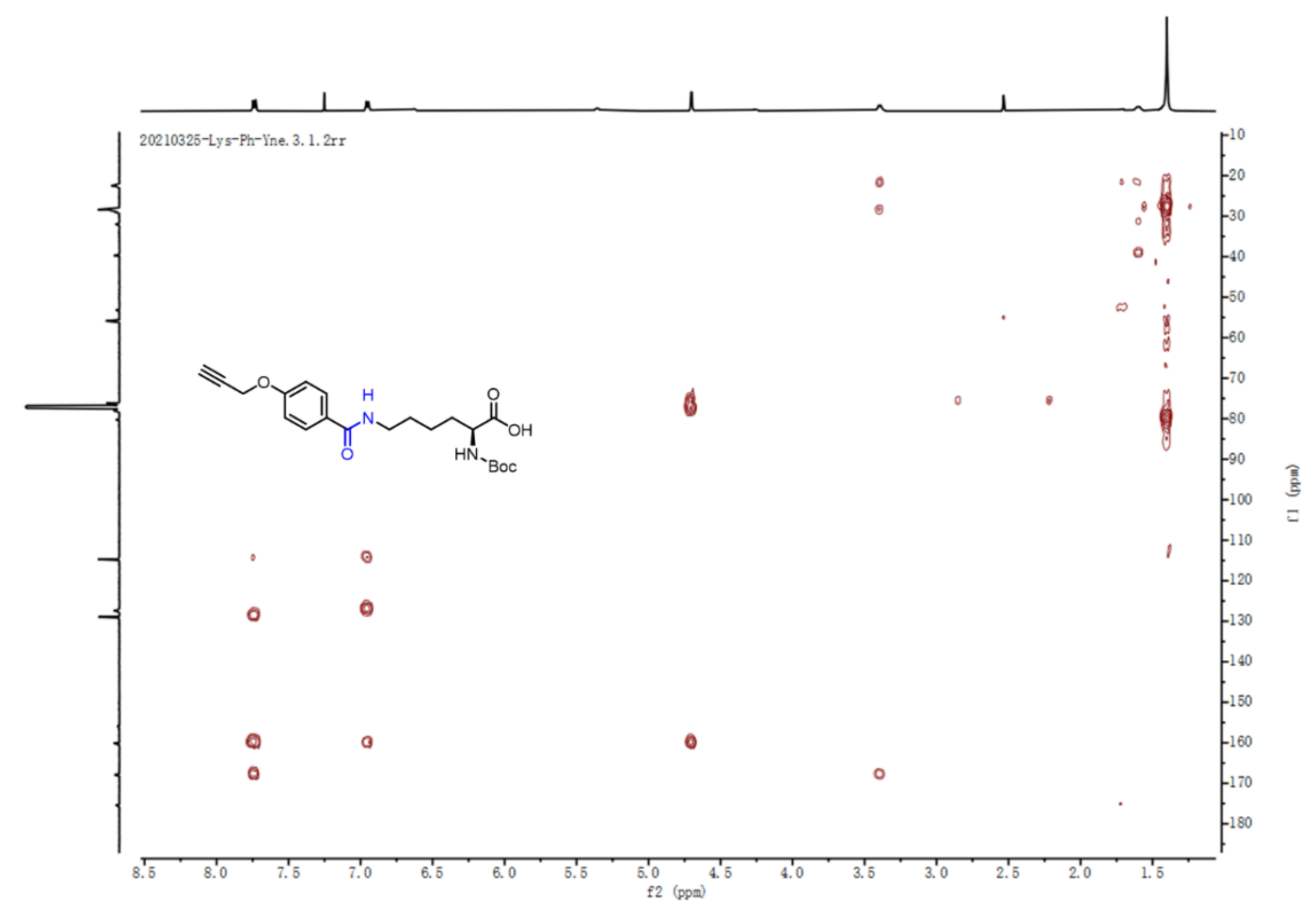

${ }^{1} \mathrm{H}-{ }^{13} \mathrm{C}$ HMBC NMR spectrum of $\mathbf{4 g}$ 


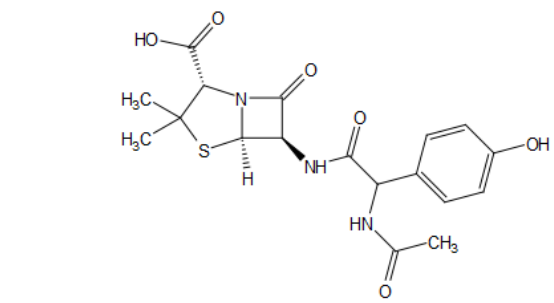

${ }^{1} \mathrm{H}$ NMR (400 MHz, Methanol- $d_{4}$ ) spectrum of $\mathbf{4 h}$

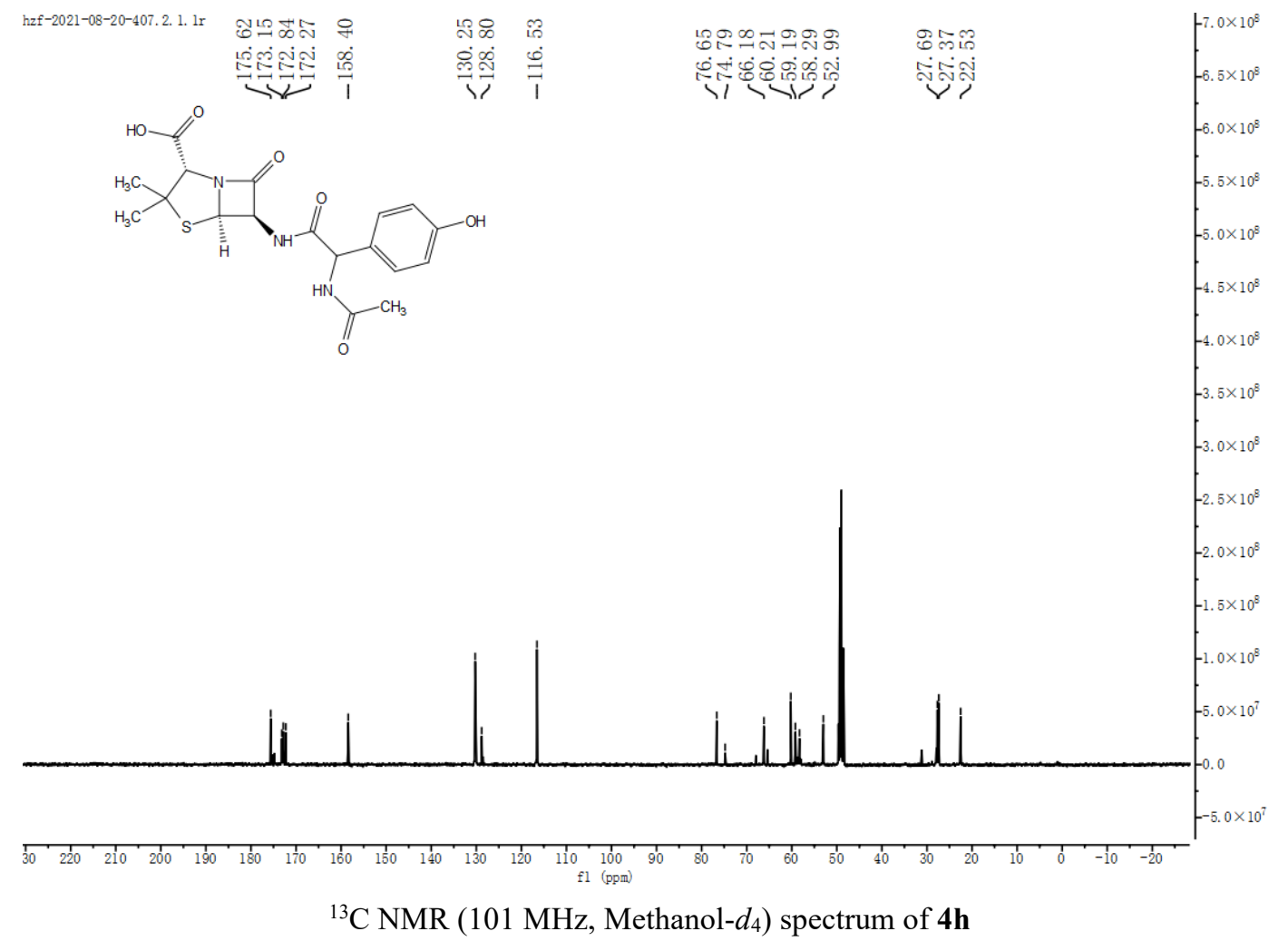




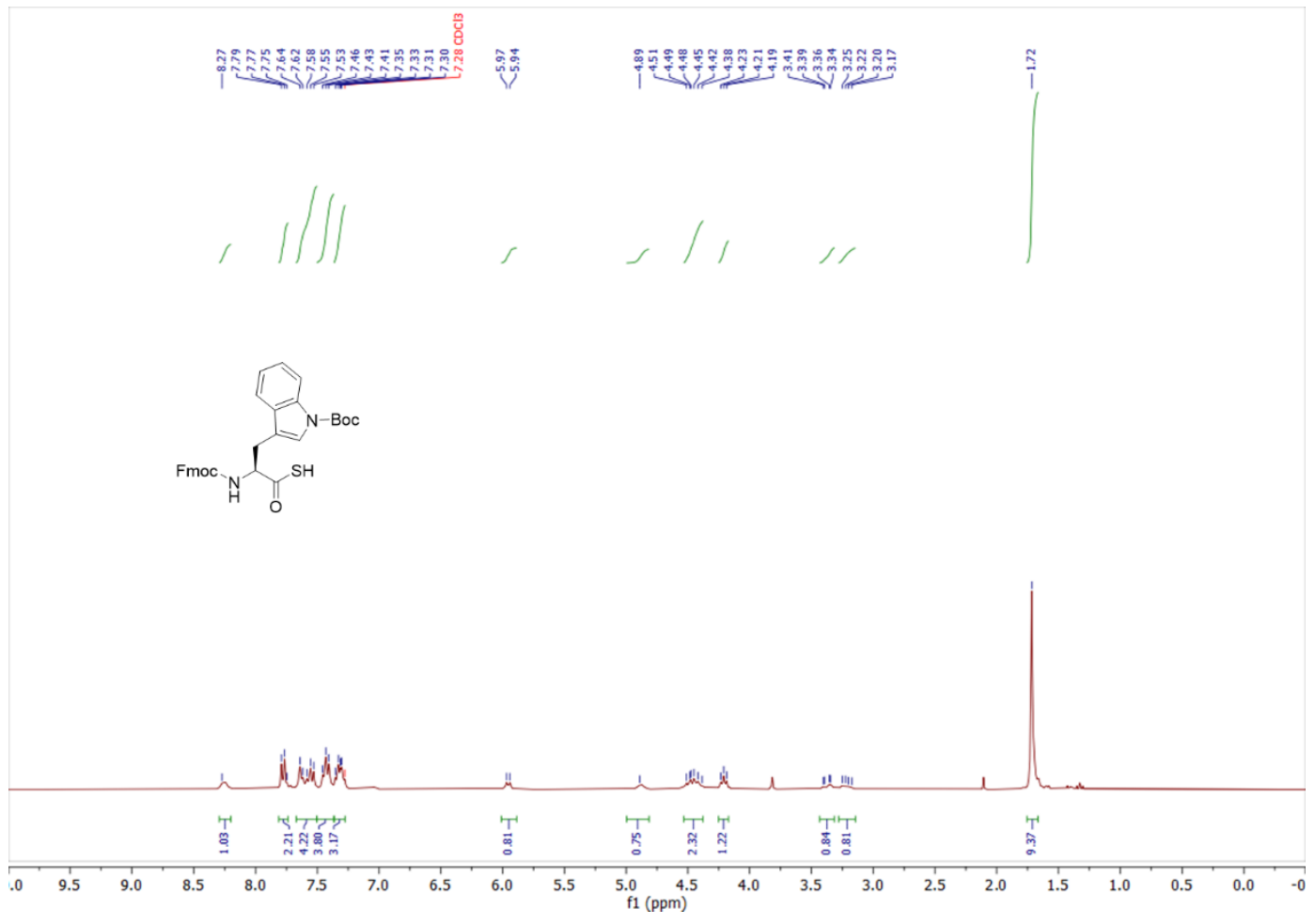

${ }^{1} \mathrm{H}$ NMR (300 MHz, $\mathrm{CDCl}_{3}$ ) spectrum of TA1

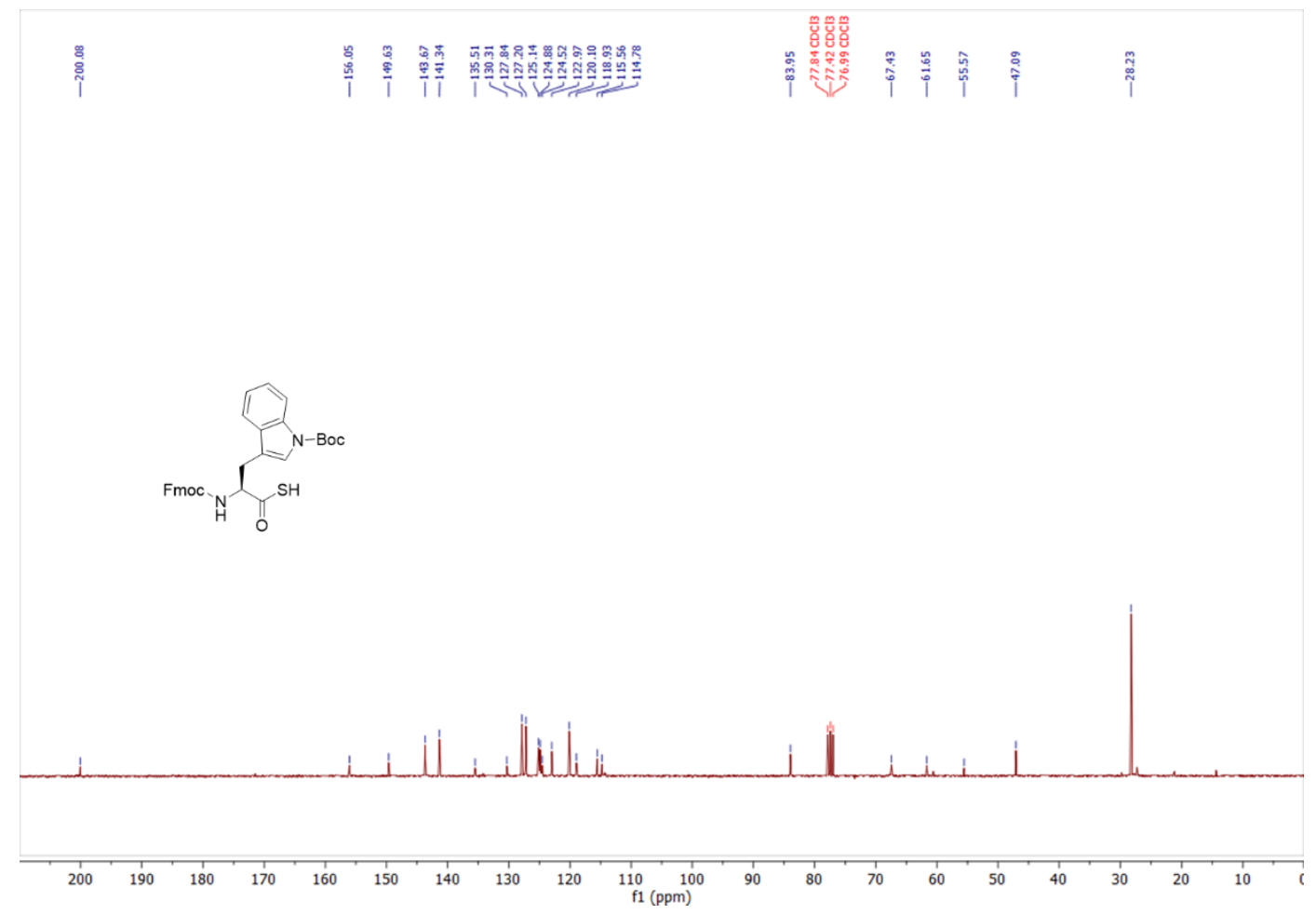

${ }^{13} \mathrm{C}$ NMR (75 MHz, $\mathrm{CDCl}_{3}$ ) spectrum of TA1 


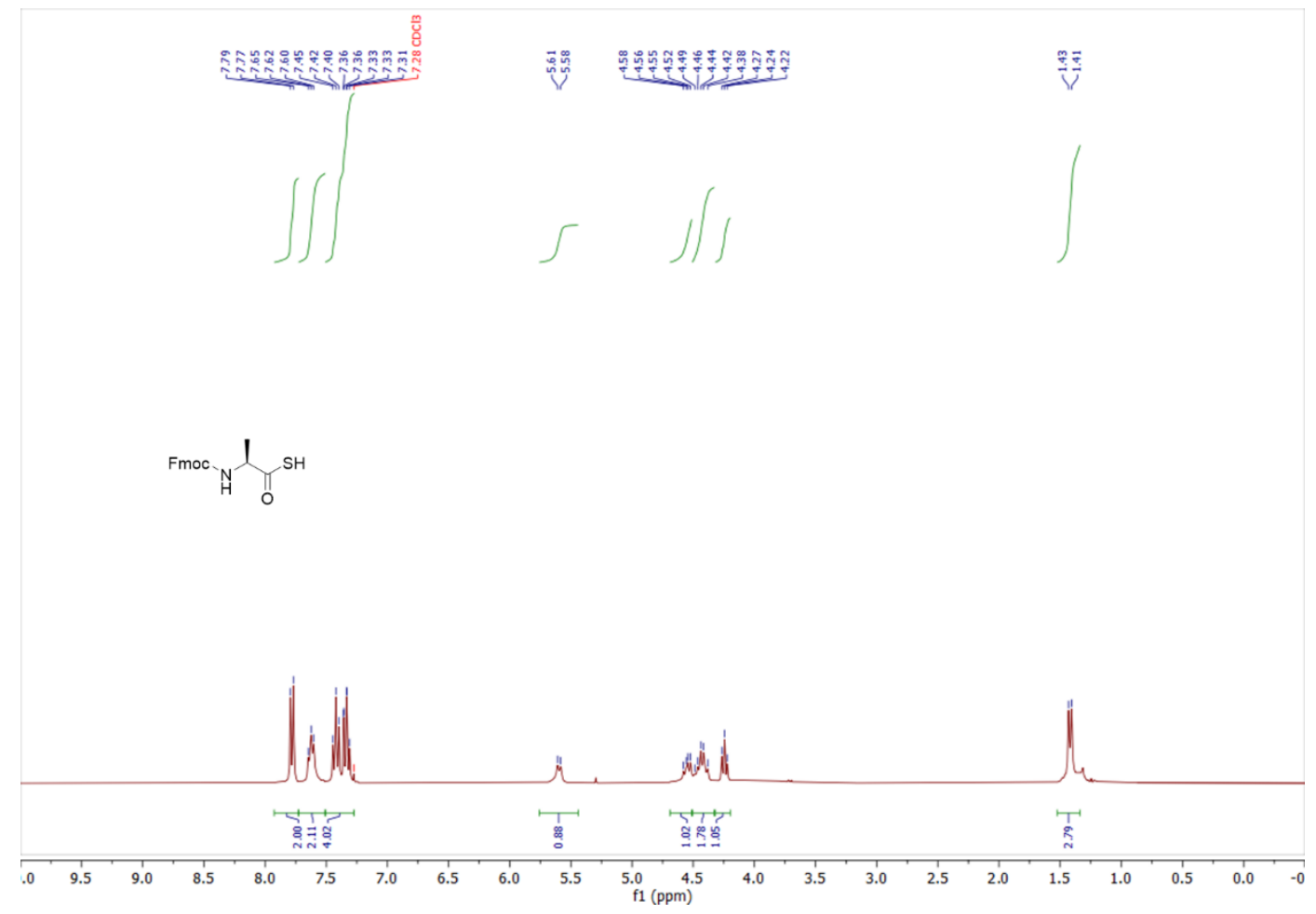

${ }^{1} \mathrm{H}$ NMR (300 MHz, $\left.\mathrm{CDCl}_{3}\right)$ spectrum of TA2

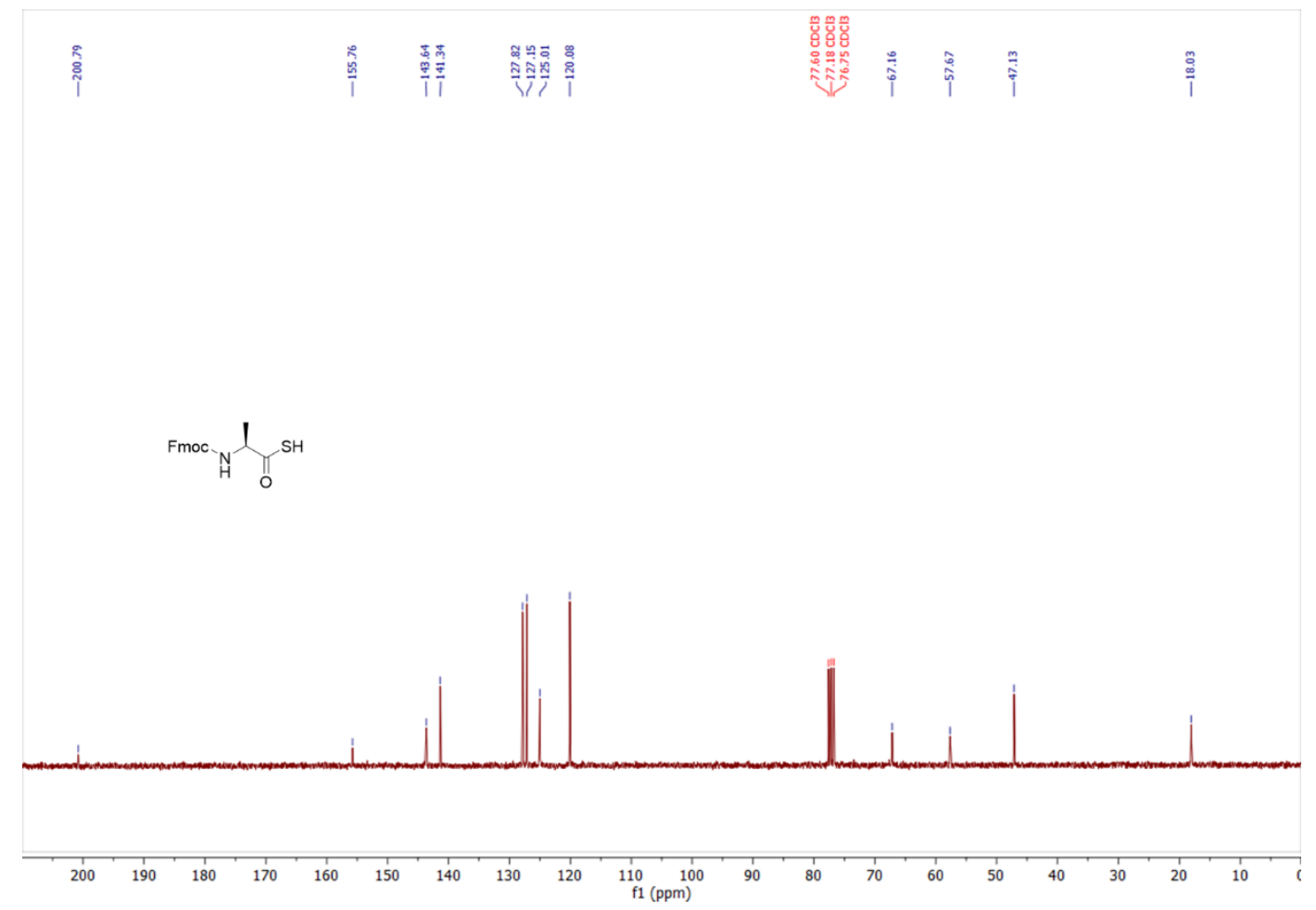

${ }^{13} \mathrm{C}$ NMR (75 MHz, $\mathrm{CDCl}_{3}$ ) spectrum of TA2 


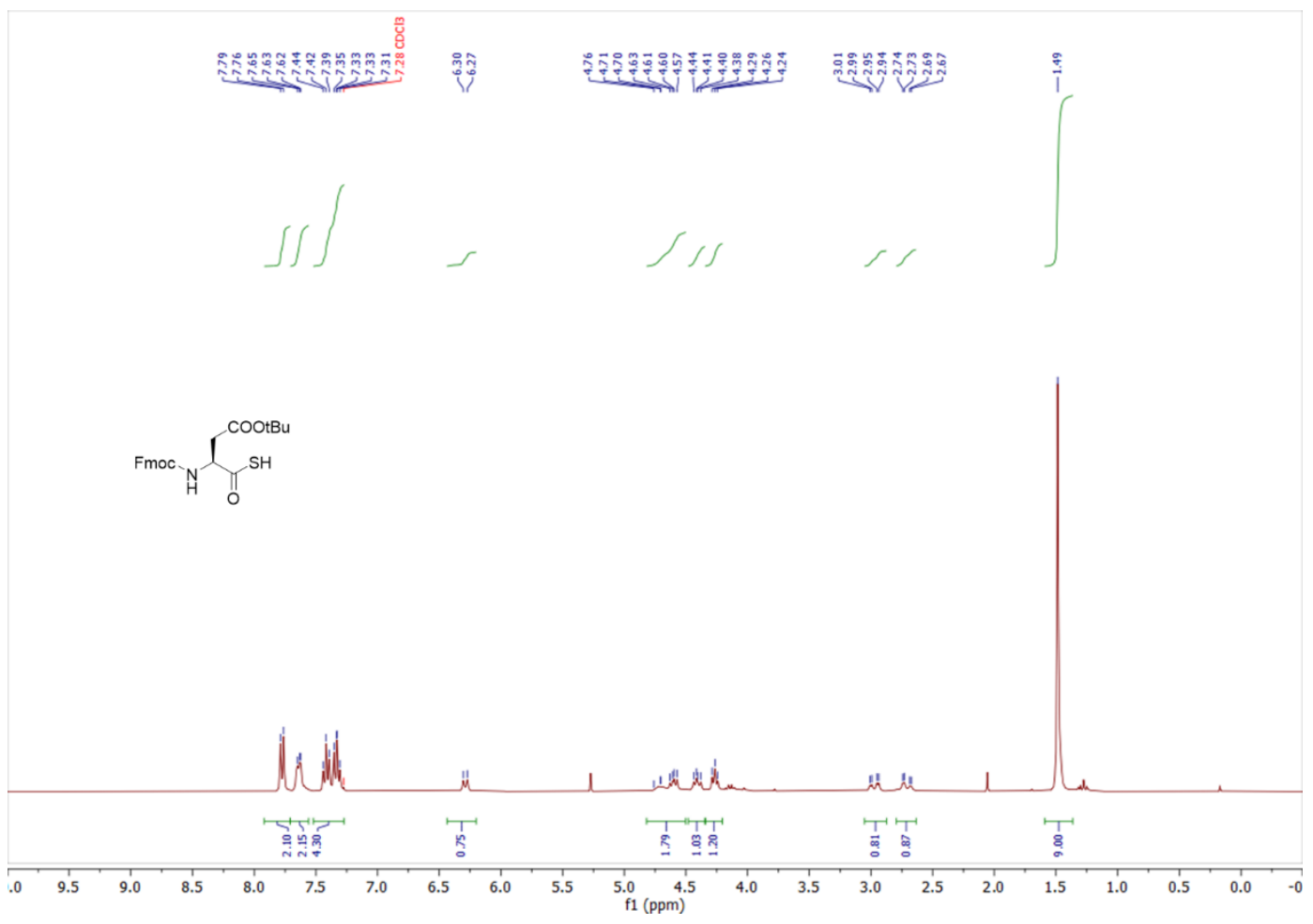

${ }^{1} \mathrm{H}$ NMR (300 MHz, $\mathrm{CDCl}_{3}$ ) spectrum of TA3

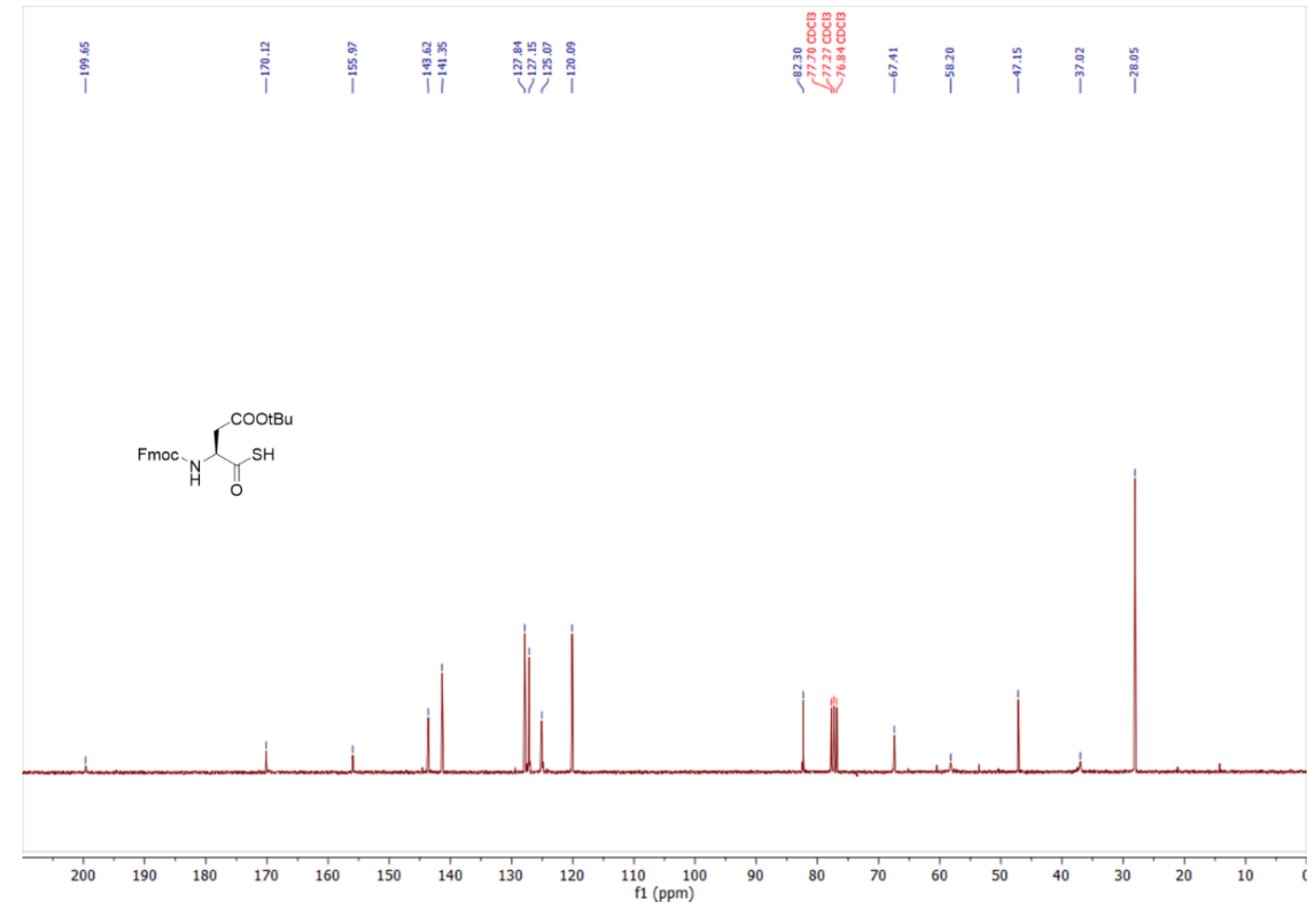

${ }^{13} \mathrm{C}$ NMR (75 MHz, $\mathrm{CDCl}_{3}$ ) spectrum of TA4 


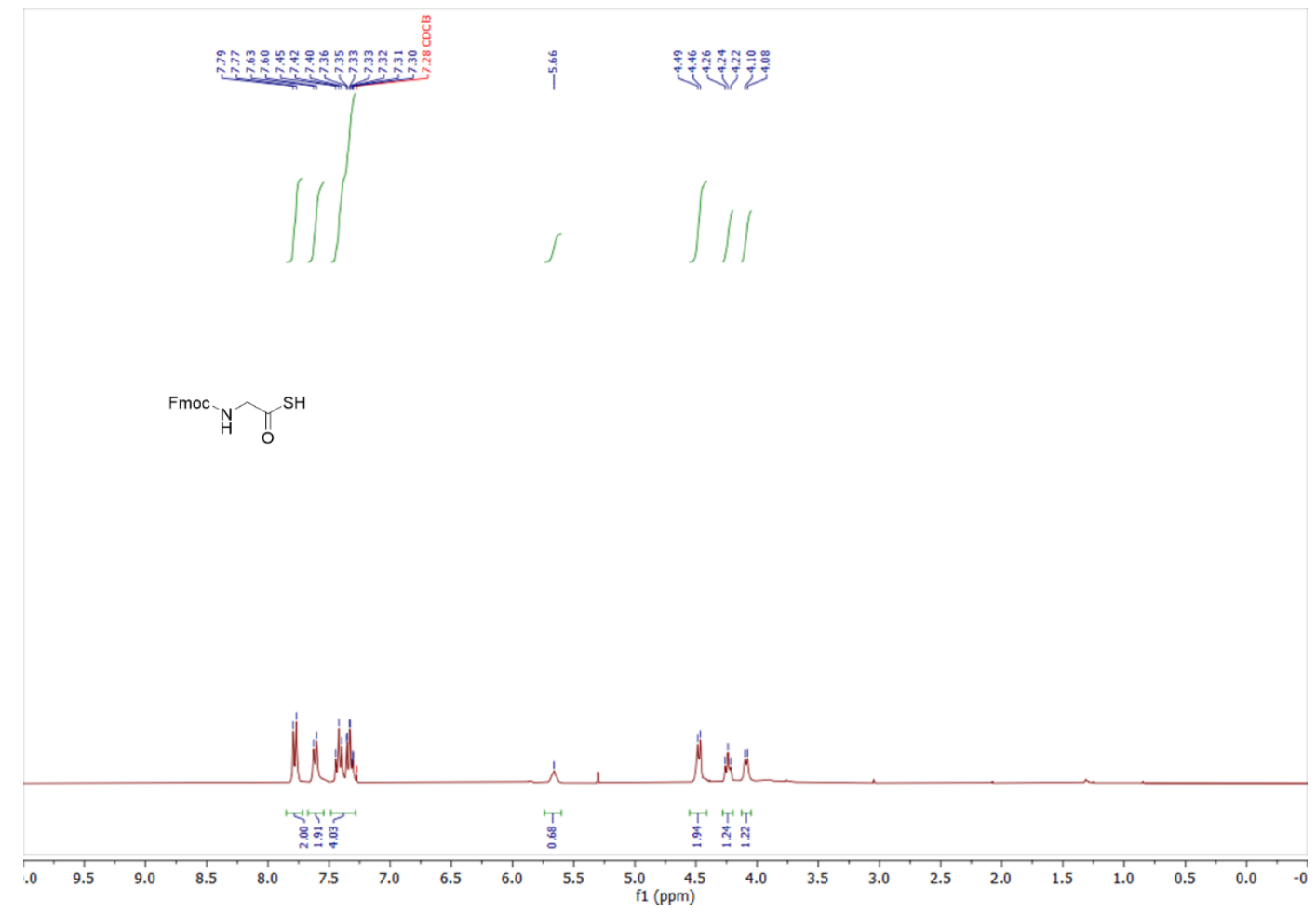

${ }^{1} \mathrm{H}$ NMR (300 MHz, $\mathrm{CDCl}_{3}$ ) spectrum of TA4

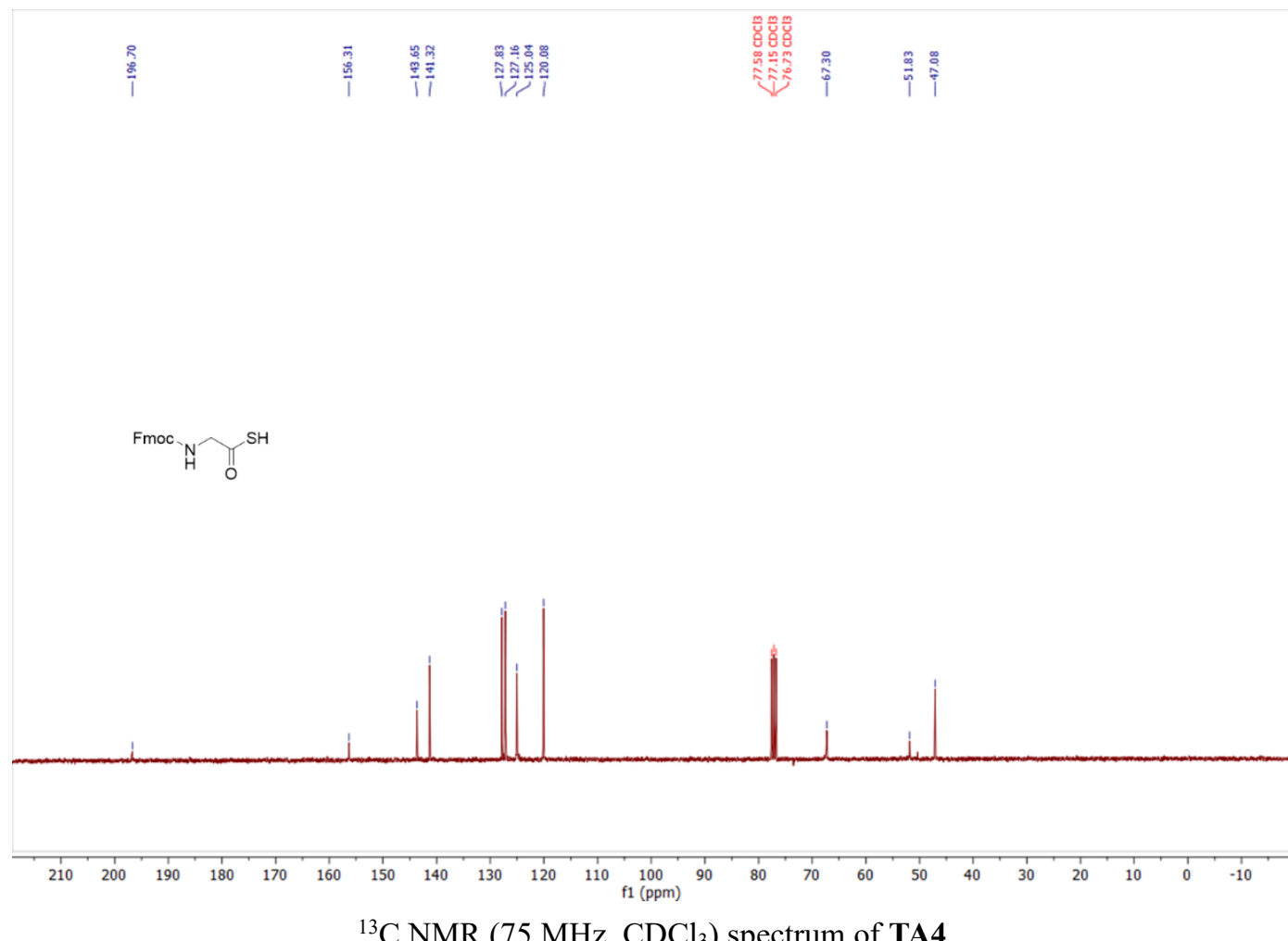

${ }^{13} \mathrm{C}$ NMR (75 MHz, $\mathrm{CDCl}_{3}$ ) spectrum of TA4 


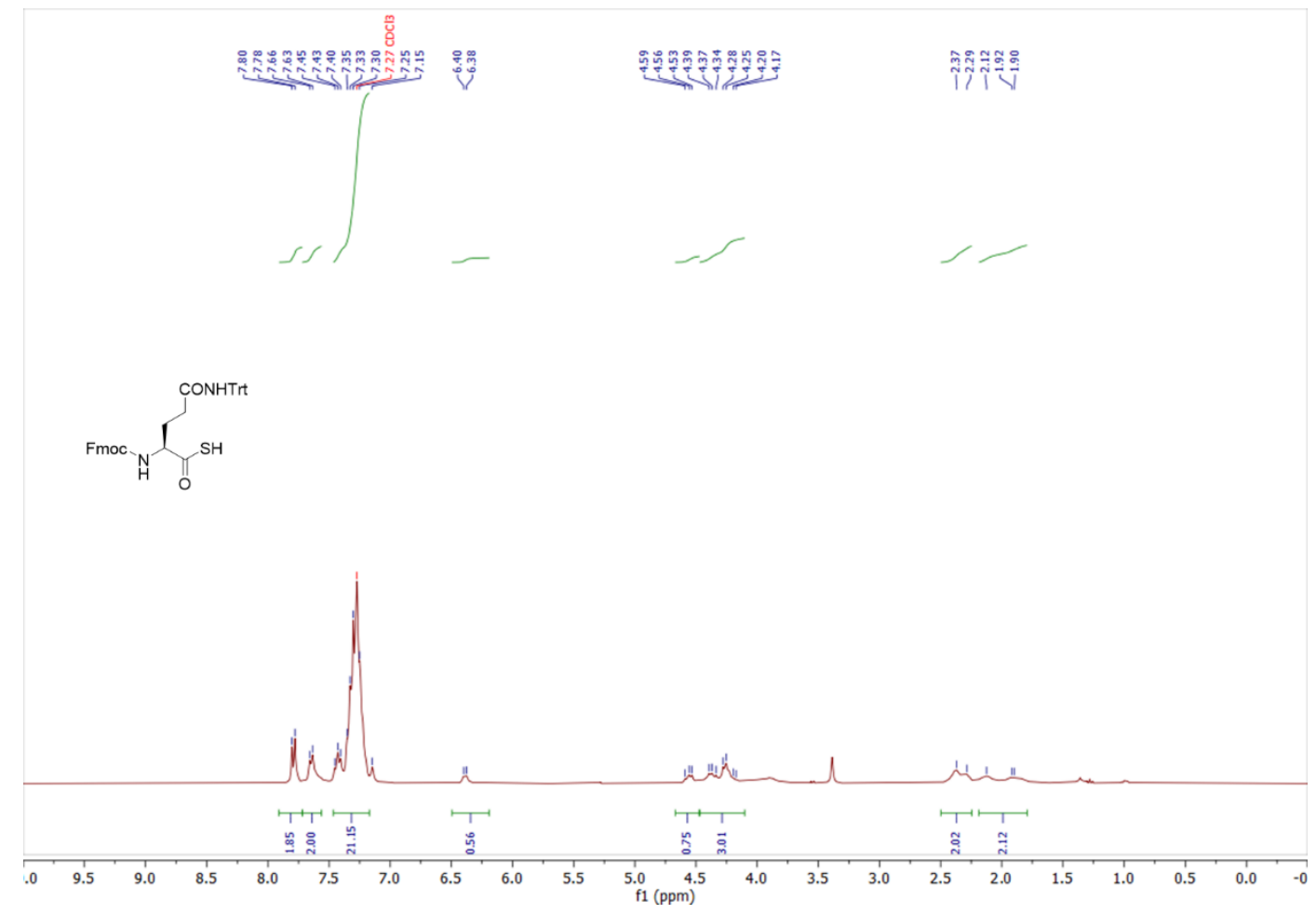

${ }^{1} \mathrm{H}$ NMR (300 MHz, $\left.\mathrm{CDCl}_{3}\right)$ spectrum of TA5

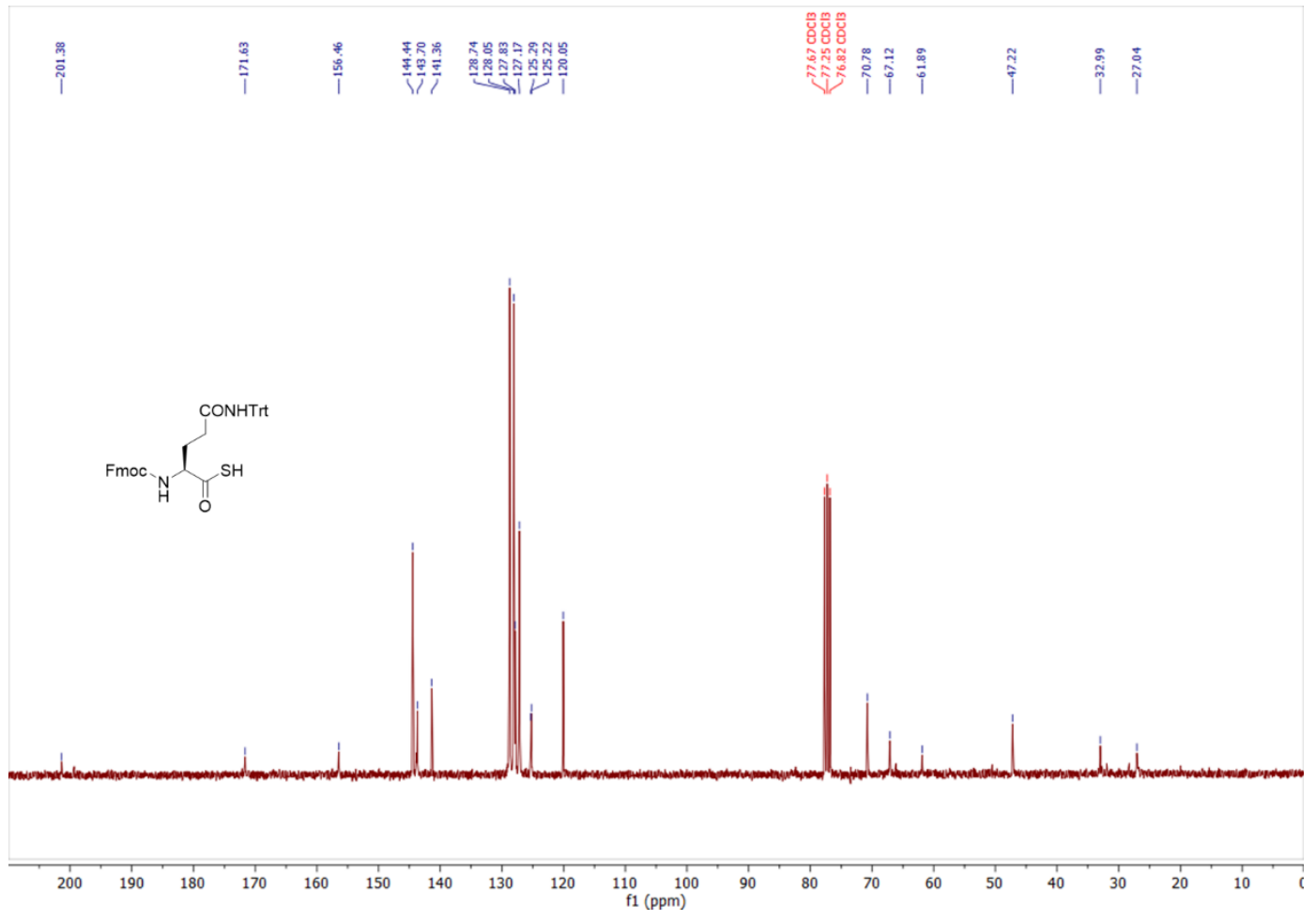

${ }^{13} \mathrm{C}$ NMR (75 MHz, $\mathrm{CDCl}_{3}$ ) spectrum of TA5 


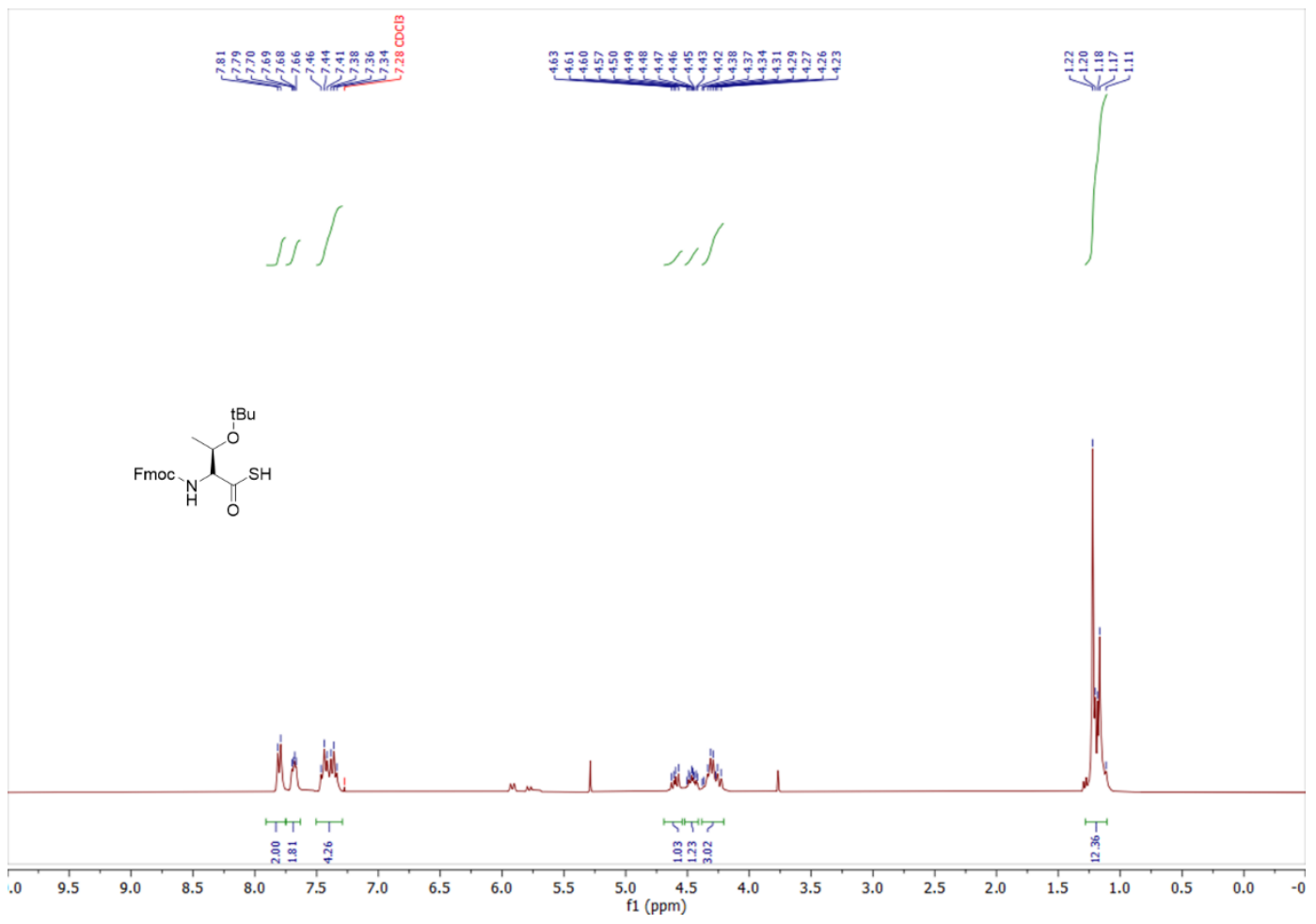

${ }^{1} \mathrm{H}$ NMR (300 MHz, $\mathrm{CDCl}_{3}$ ) spectrum of TA6

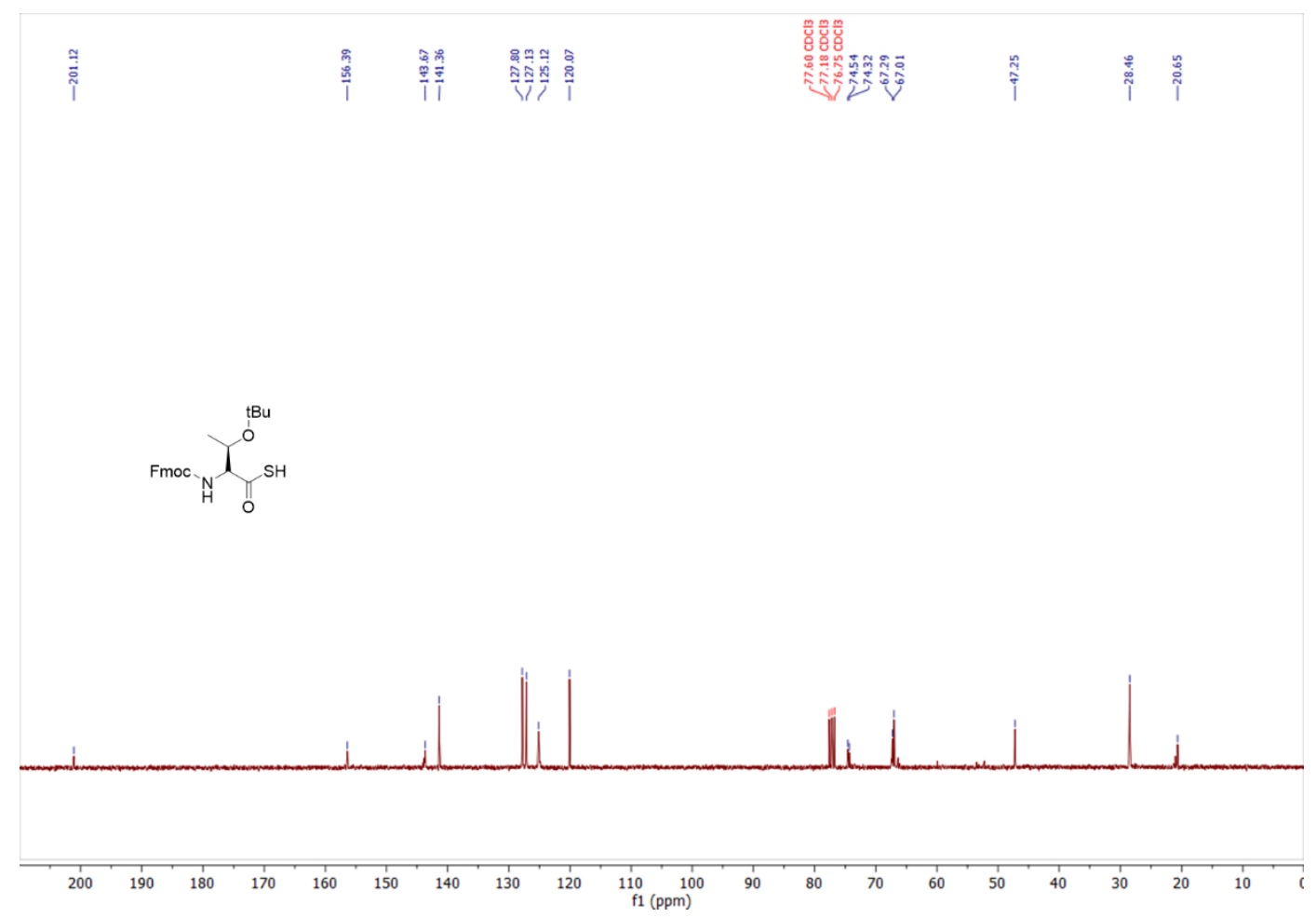

${ }^{13} \mathrm{C}$ NMR (75 MHz, $\mathrm{CDCl}_{3}$ ) spectrum of TA6 


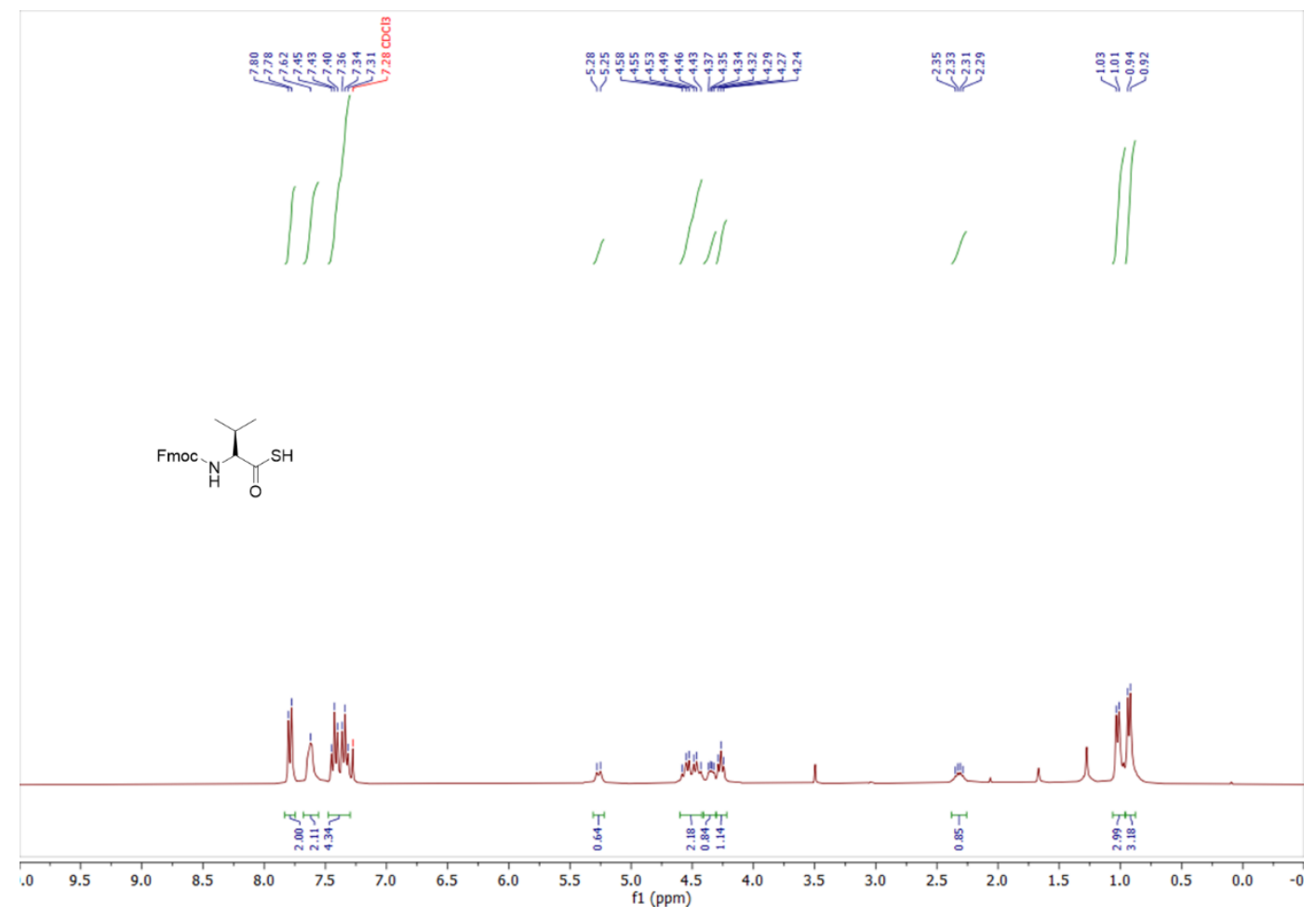

${ }^{1} \mathrm{H}$ NMR (300 MHz, $\left.\mathrm{CDCl}_{3}\right)$ spectrum of TA7

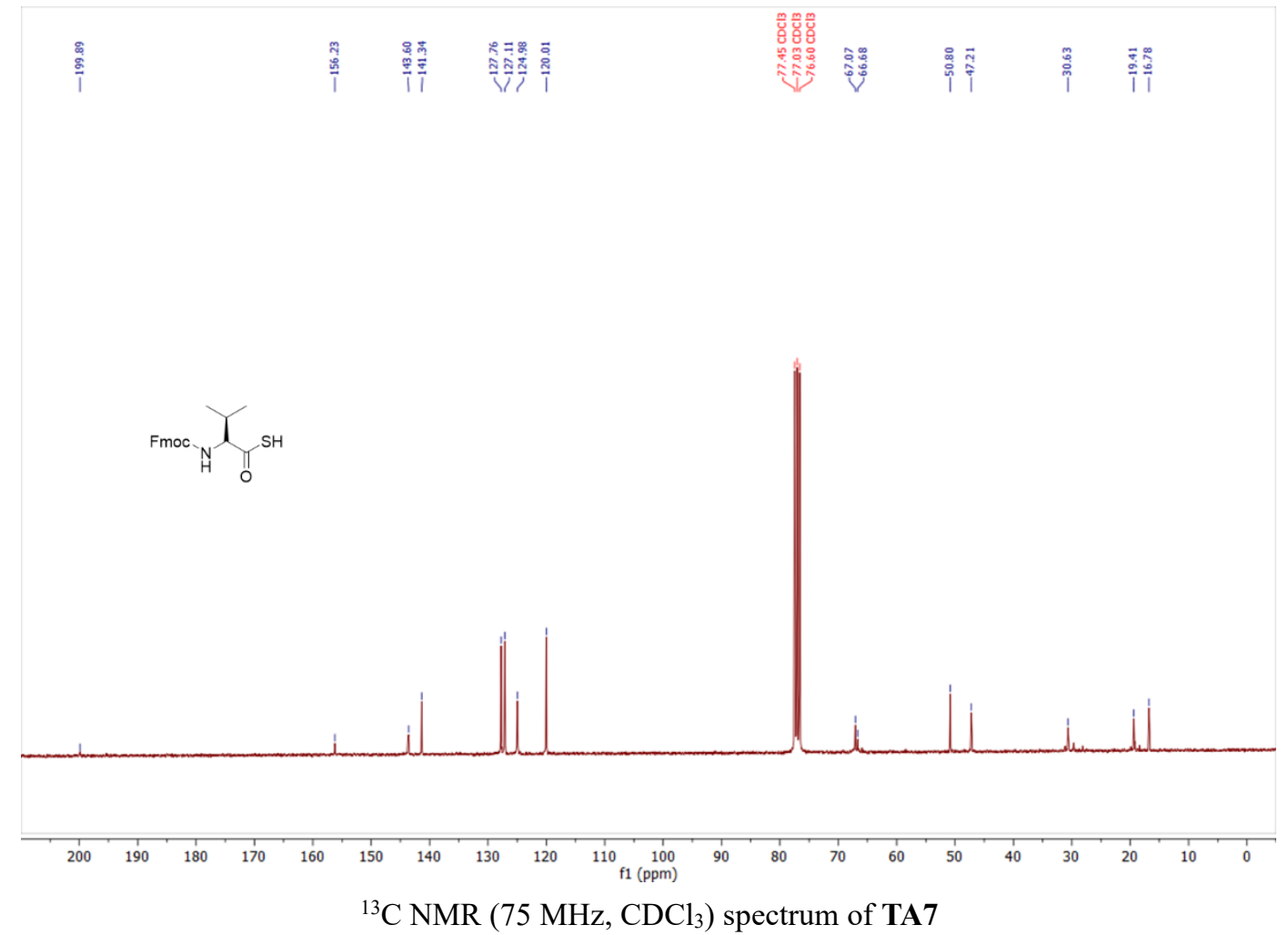




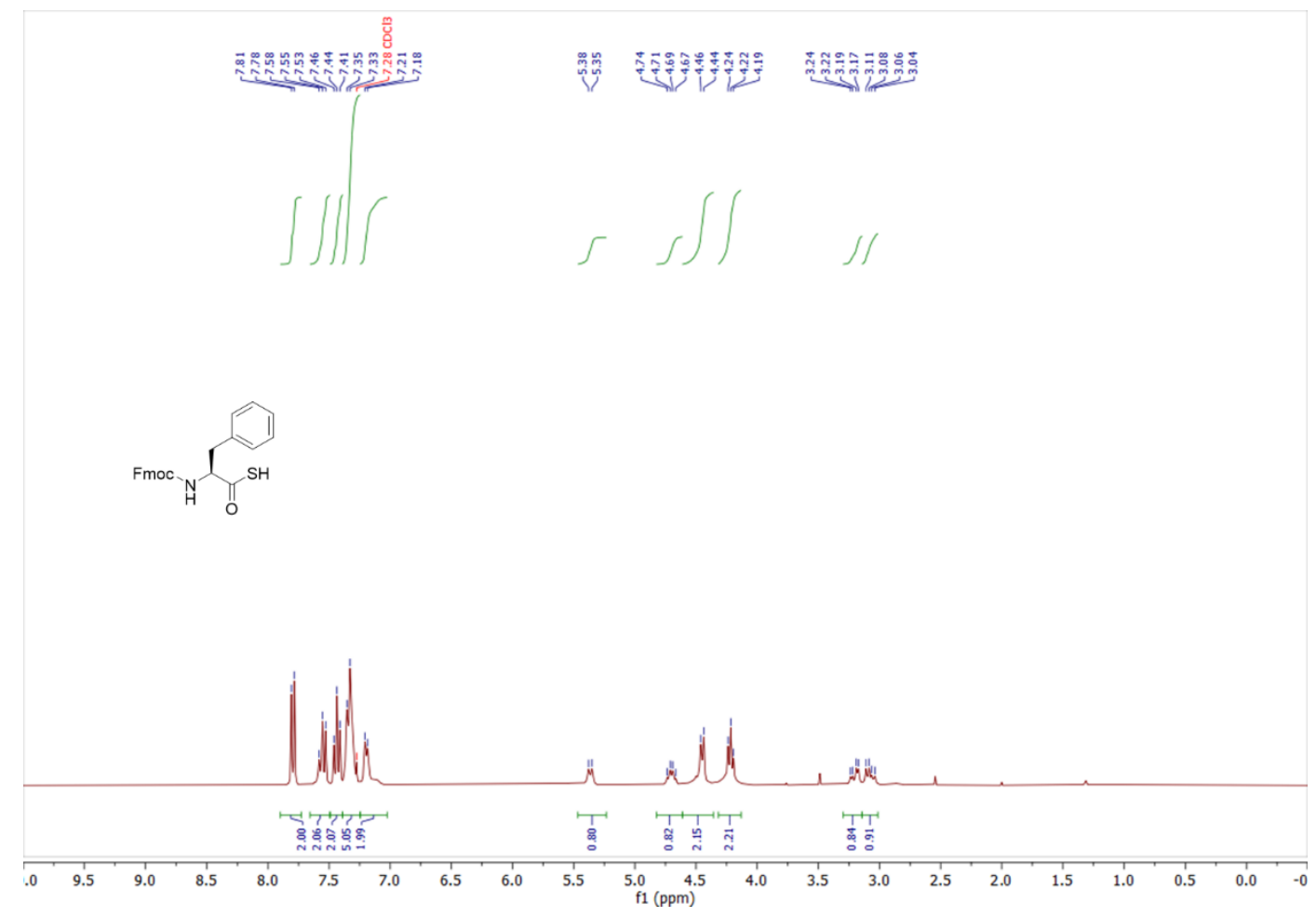

${ }^{1} \mathrm{H}$ NMR (300 MHz, $\mathrm{CDCl}_{3}$ ) spectrum of TA8

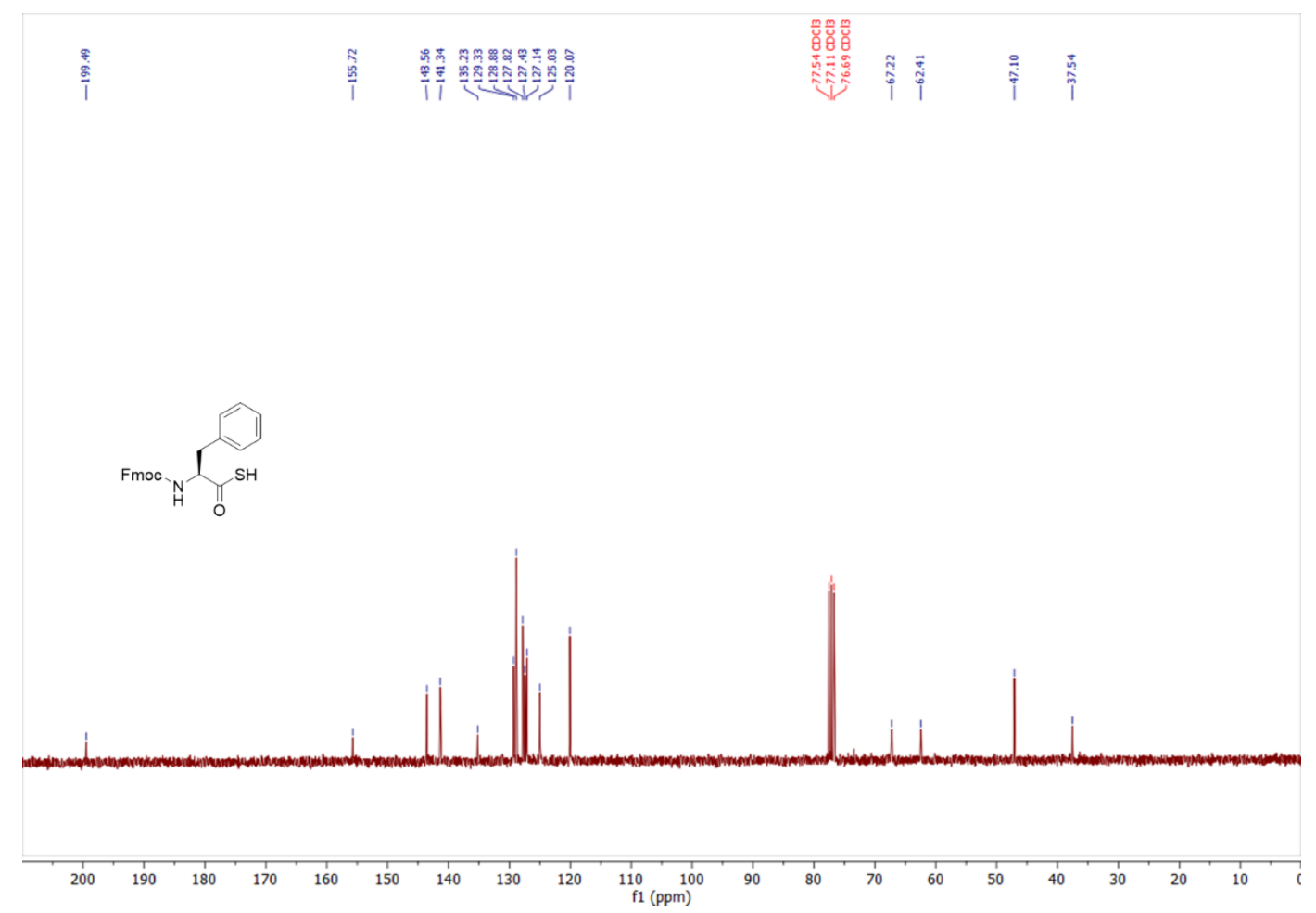

${ }^{13} \mathrm{C}$ NMR $\left(75 \mathrm{MHz}, \mathrm{CDCl}_{3}\right.$ ) spectrum of TA8 


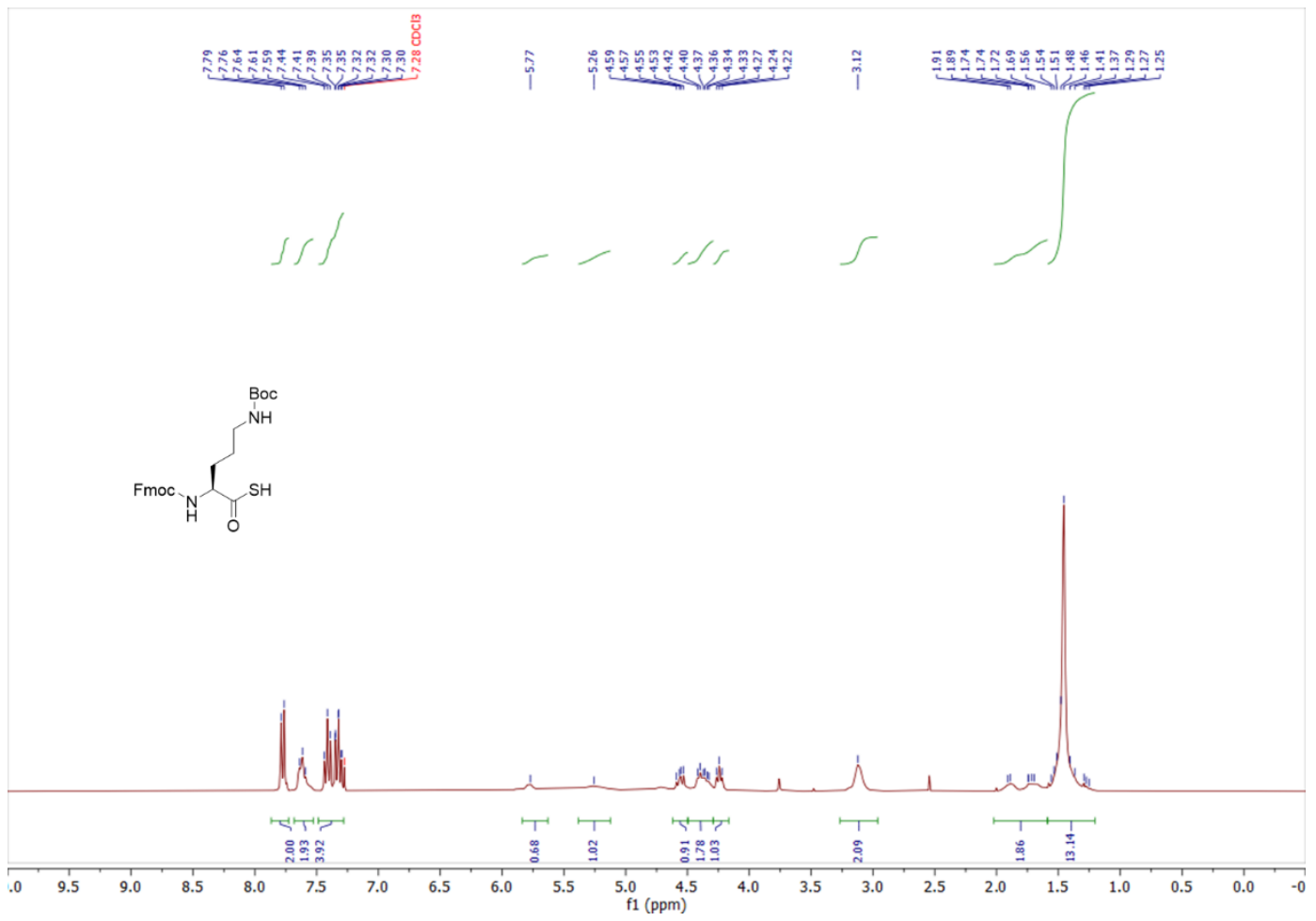

${ }^{1} \mathrm{H}$ NMR (300 MHz, $\mathrm{CDCl}_{3}$ ) spectrum of TA9
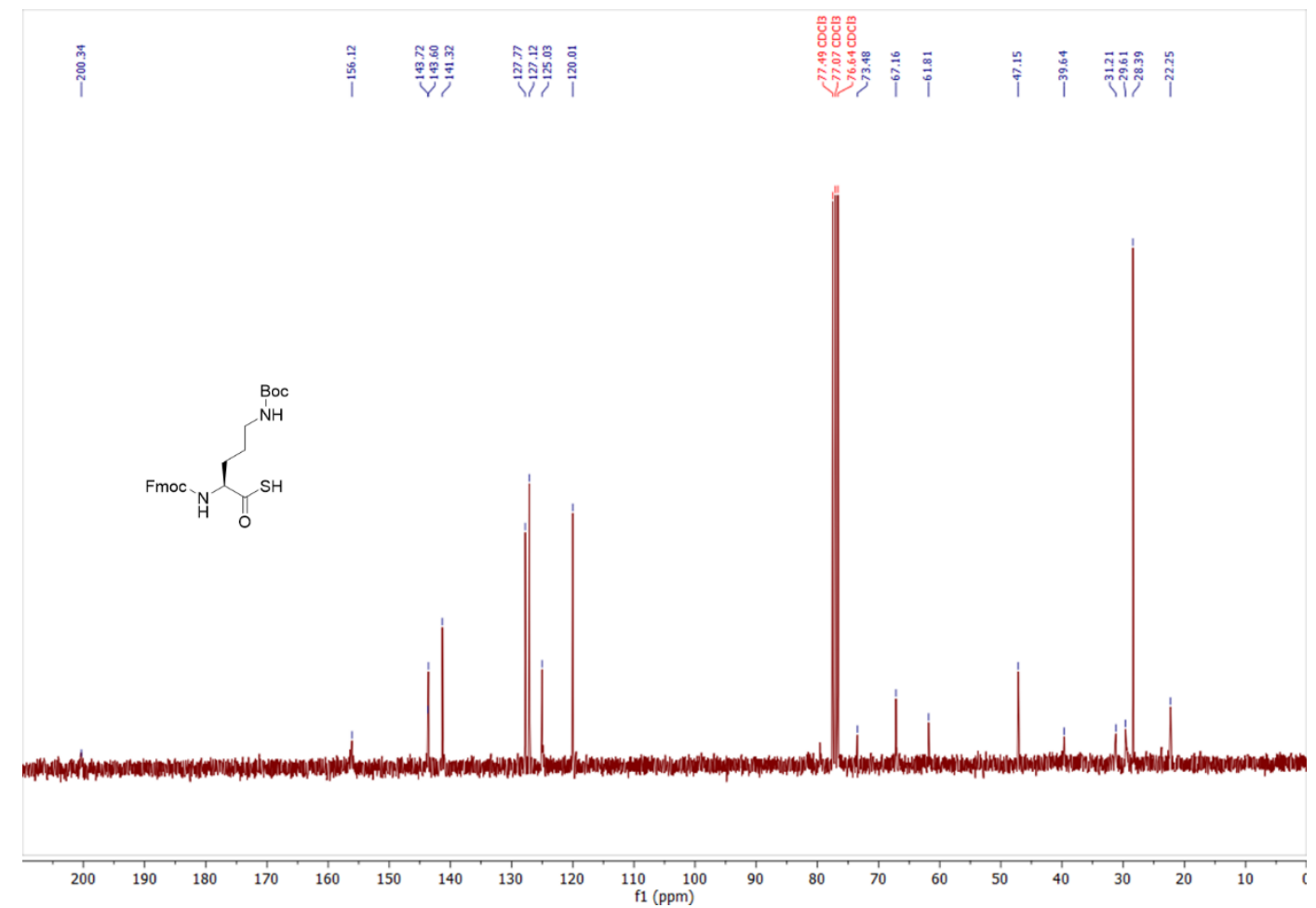

${ }^{13} \mathrm{C}$ NMR (75 MHz, $\mathrm{CDCl}_{3}$ ) spectrum of TA9 


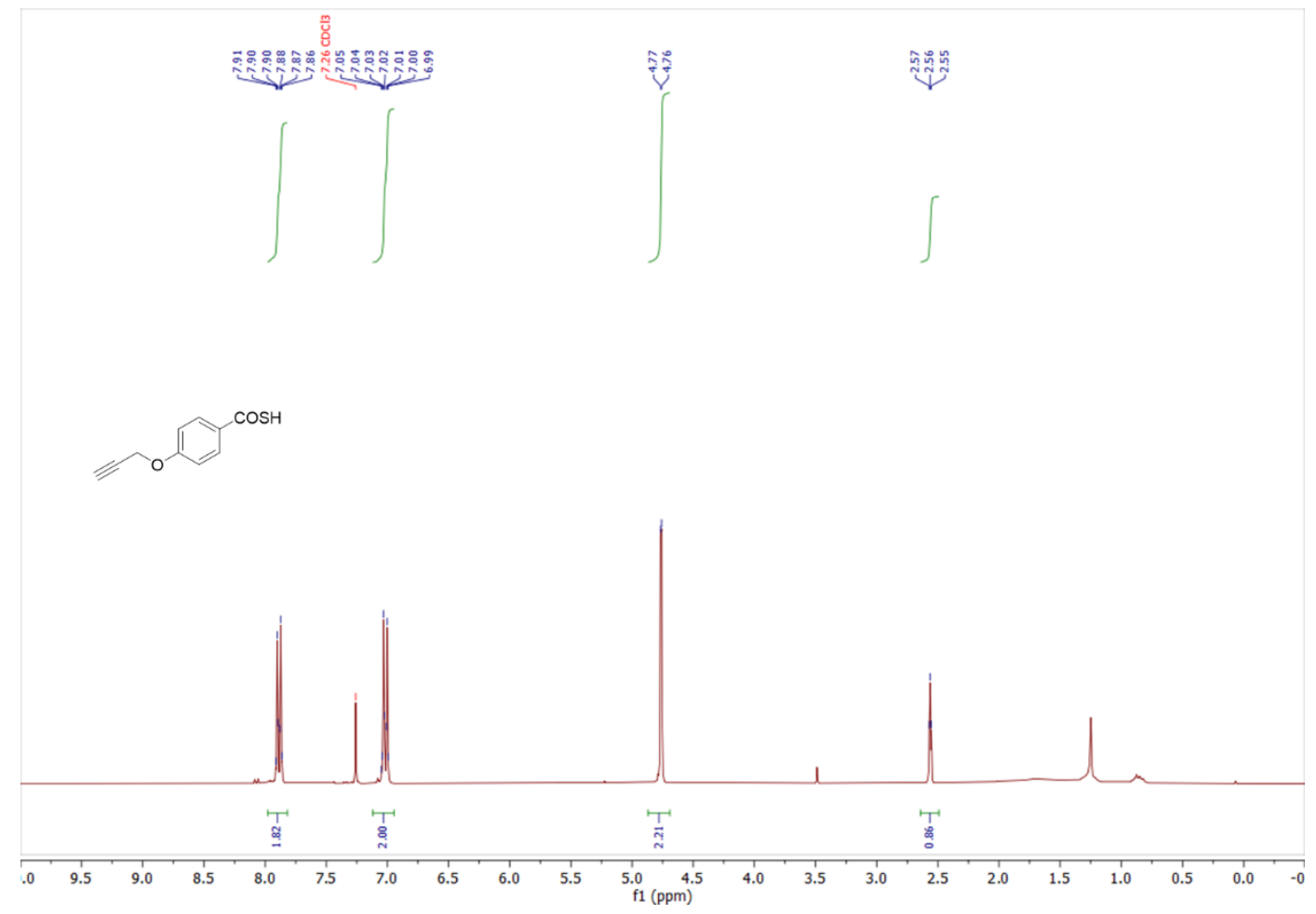

${ }^{1} \mathrm{H}$ NMR (300 MHz, $\mathrm{CDCl}_{3}$ ) spectrum of TA10

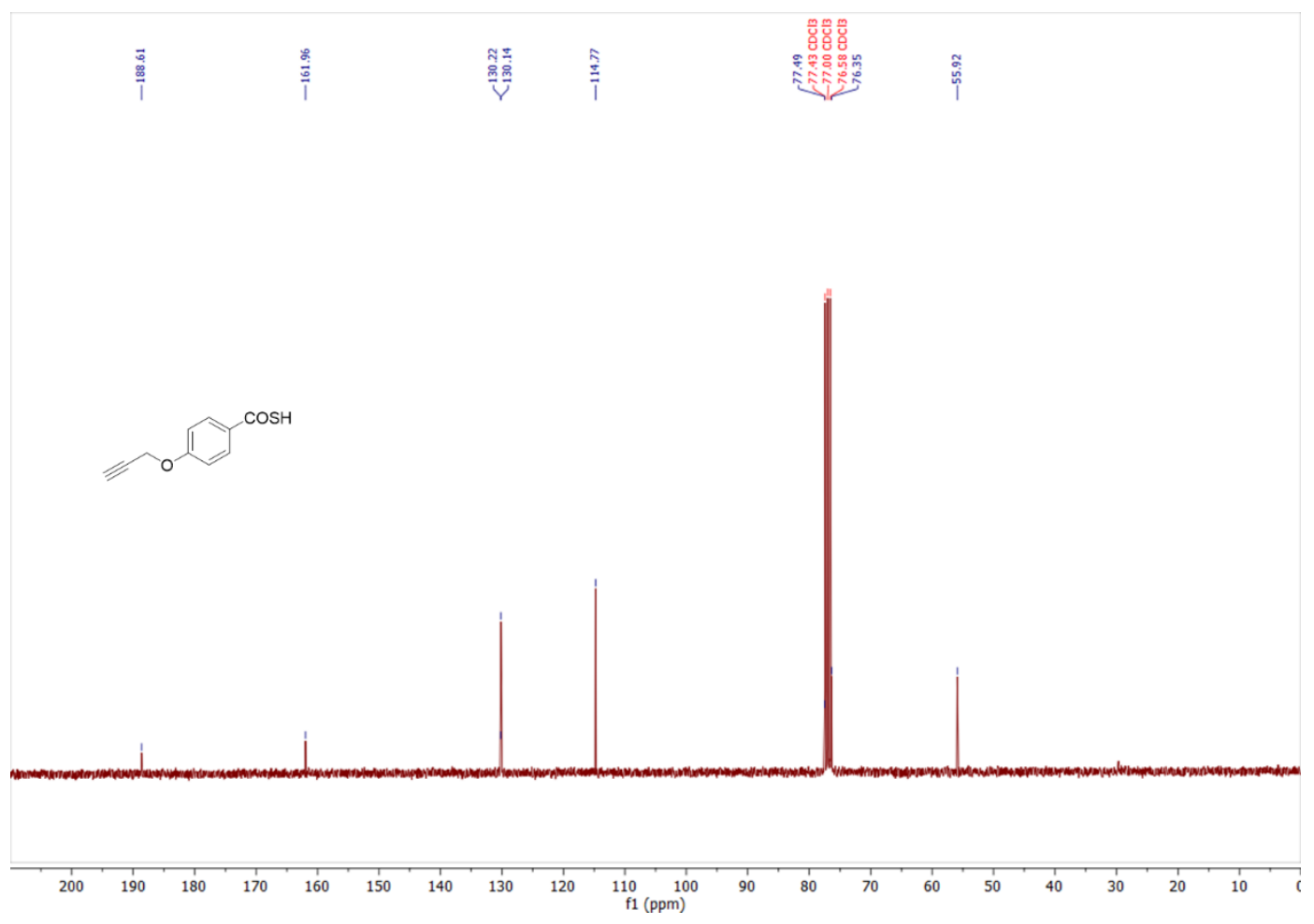

${ }^{13} \mathrm{C}$ NMR (75 MHz, $\mathrm{CDCl}_{3}$ ) spectrum of TA10 


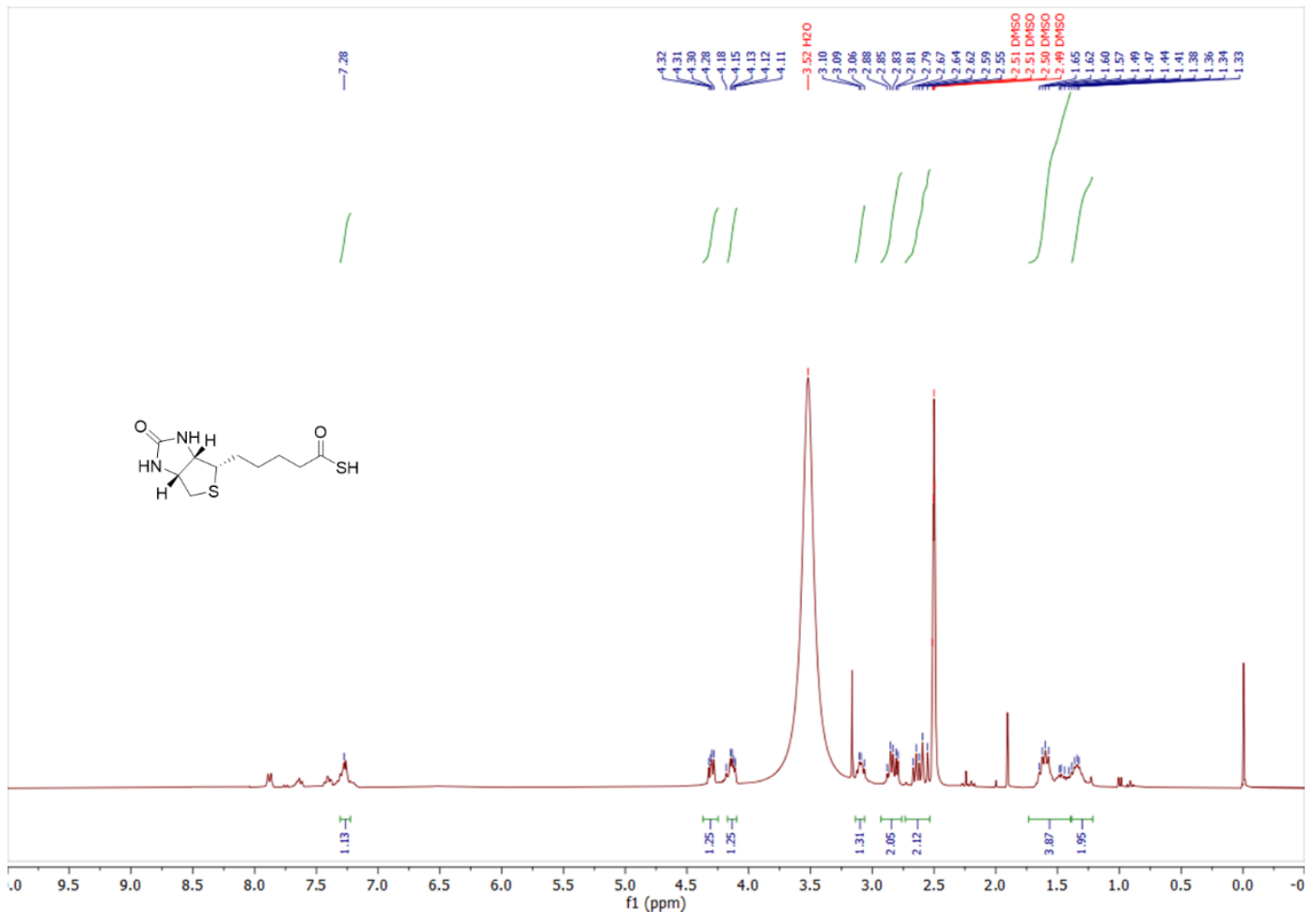

${ }^{1} \mathrm{H}$ NMR (300 MHz, DMSO- $d_{6}$ ) spectrum of P1

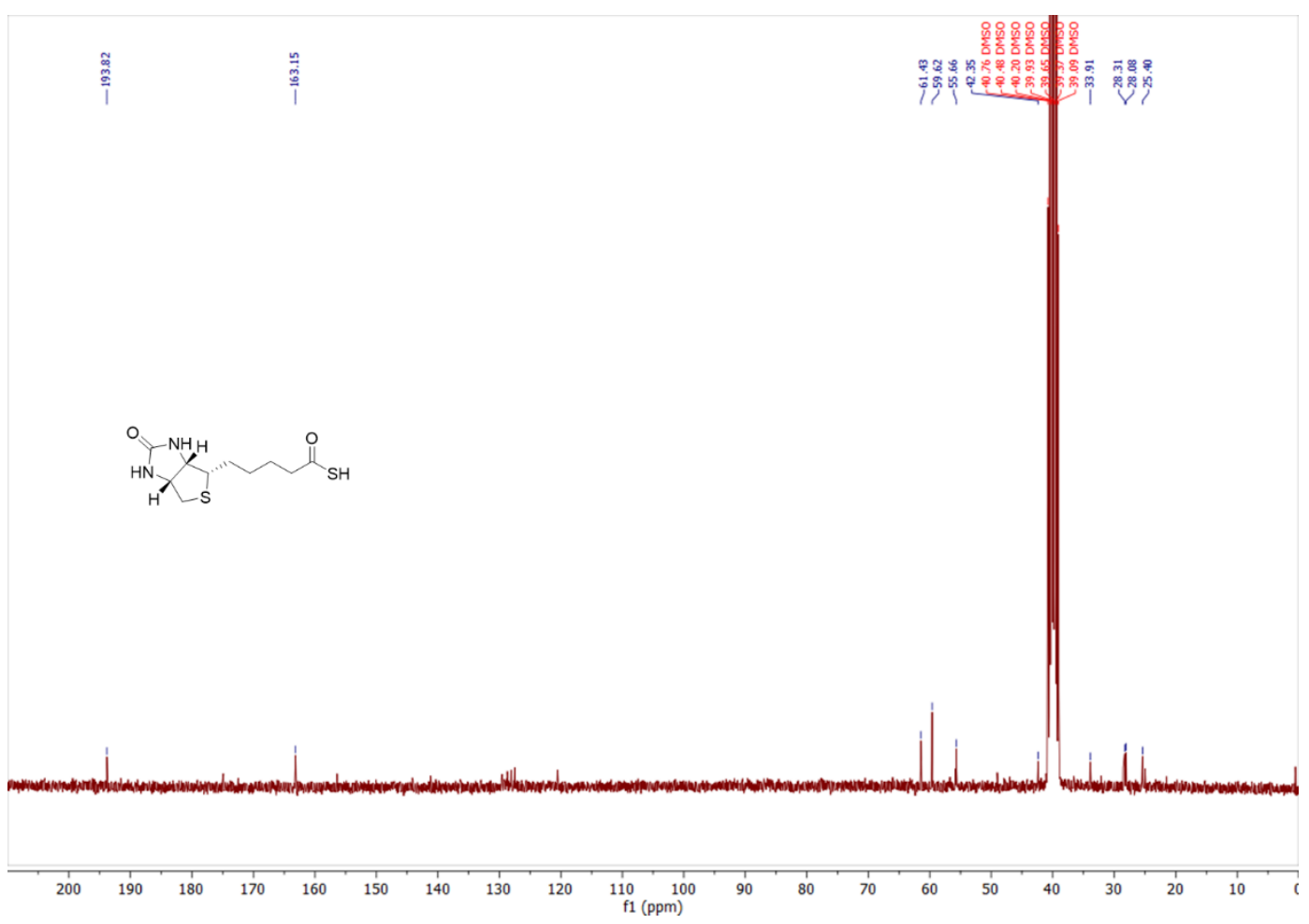

${ }^{13} \mathrm{C}$ NMR (75 MHz, DMSO- $d_{6}$ ) spectrum of $\mathbf{P 1}$ 


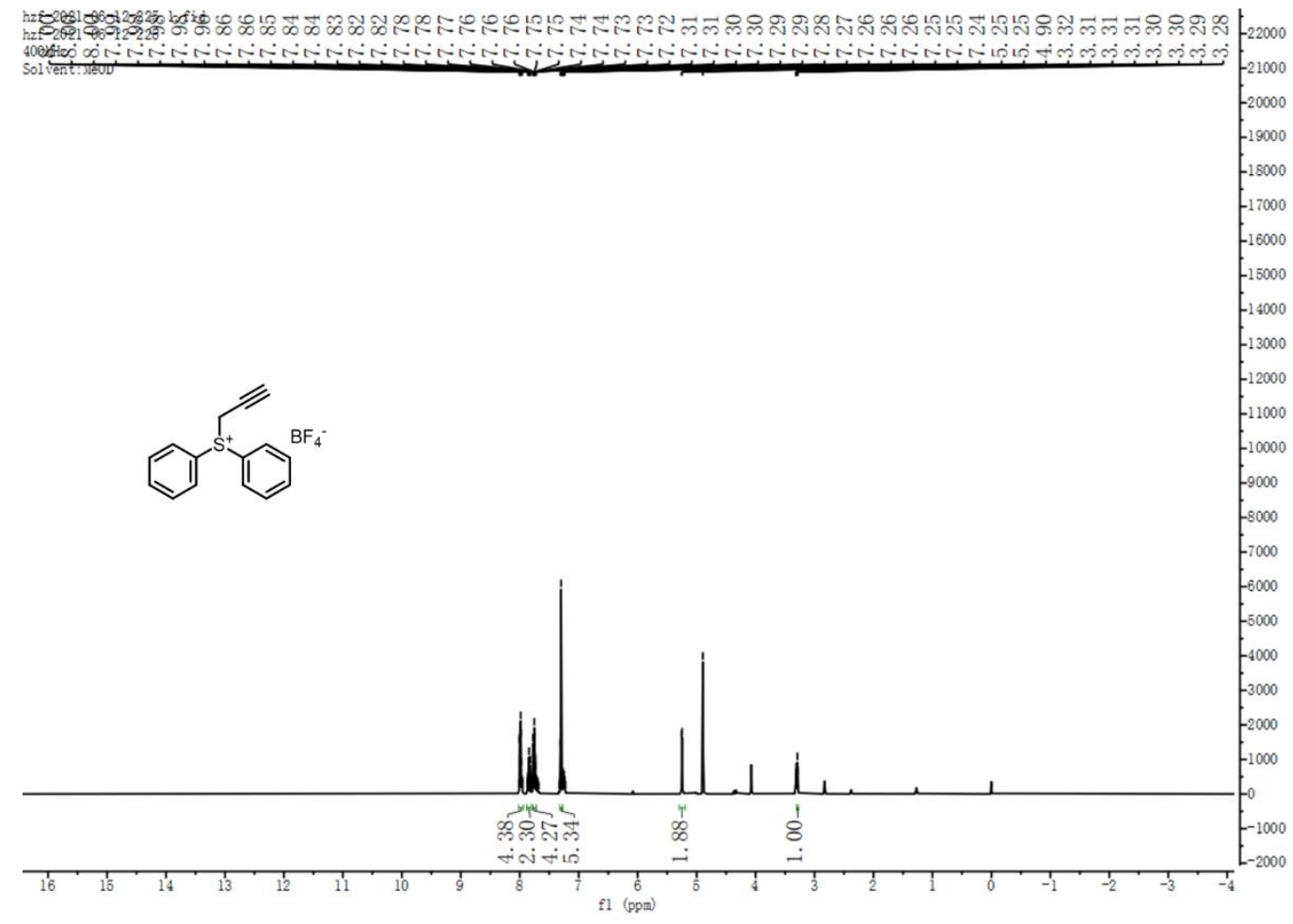

${ }^{1} \mathrm{H}$ NMR (400 MHz, Methanol- $d_{4}$ ) spectrum of 3c

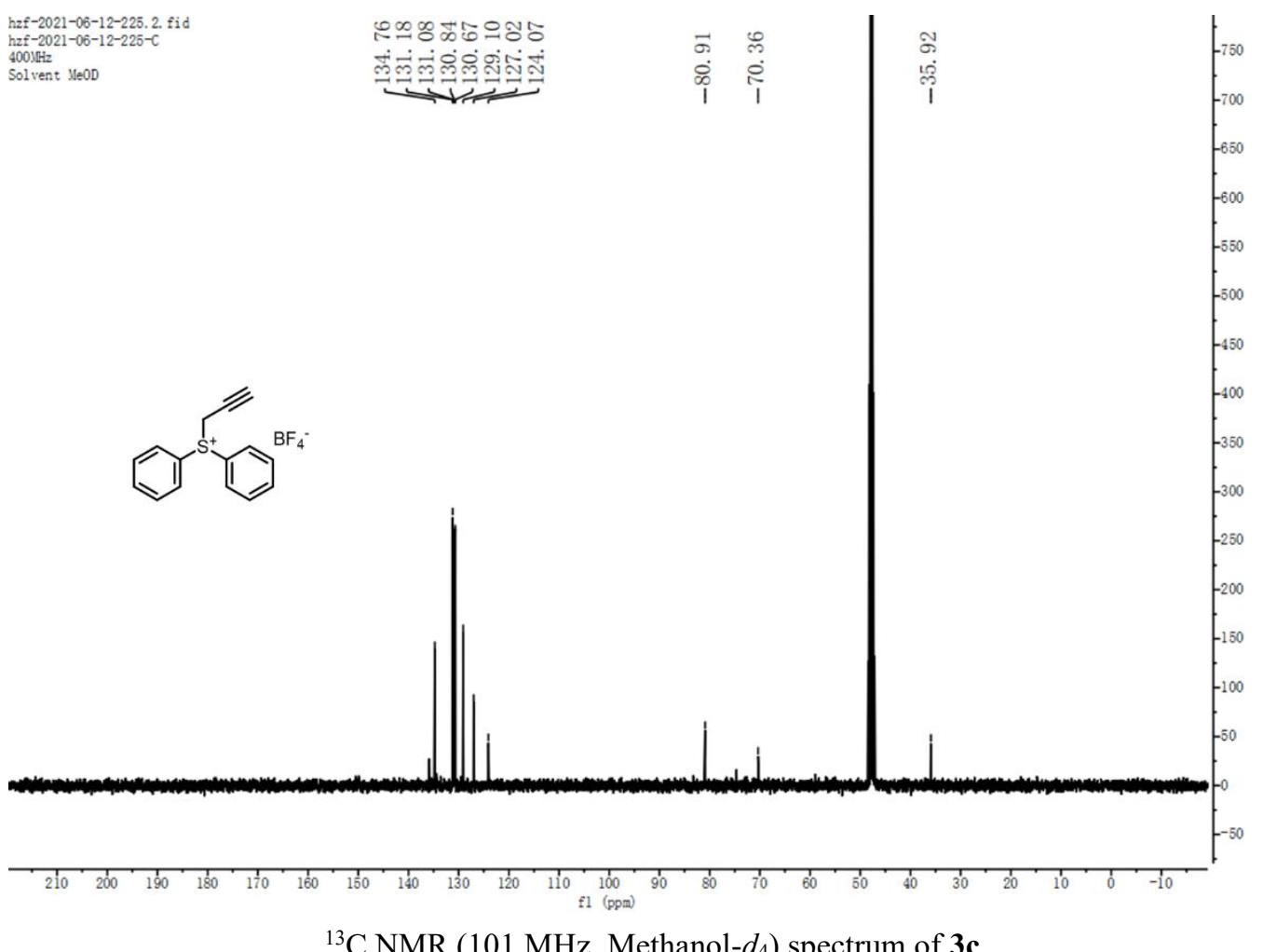

${ }^{13} \mathrm{C}$ NMR $\left(101 \mathrm{MHz}\right.$, Methanol- $\left.d_{4}\right)$ spectrum of $3 \mathbf{c}$ 


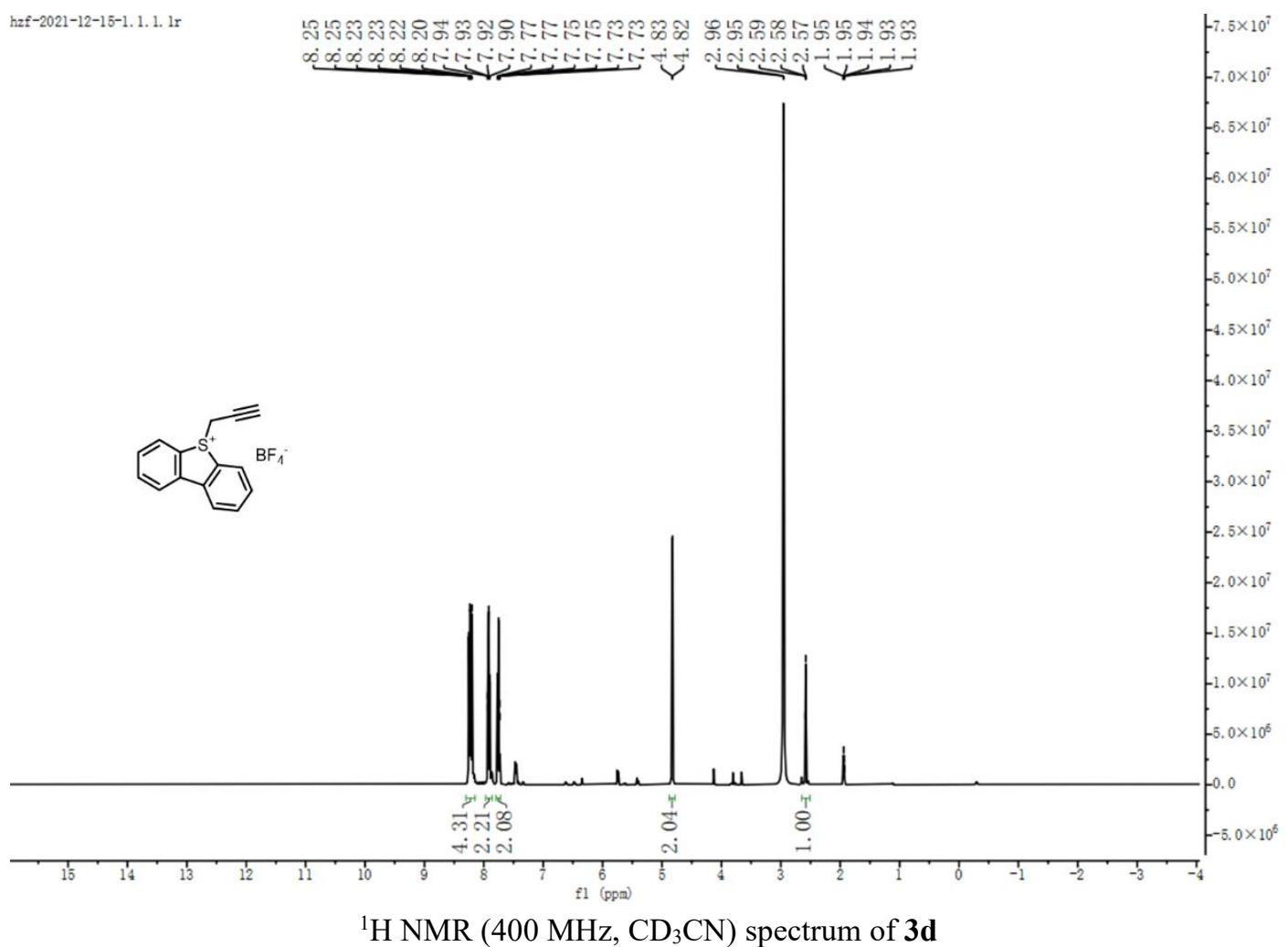

${ }^{1} \mathrm{H}$ NMR (400 MHz, $\mathrm{CD}_{3} \mathrm{CN}$ ) spectrum of $\mathbf{3 d}$

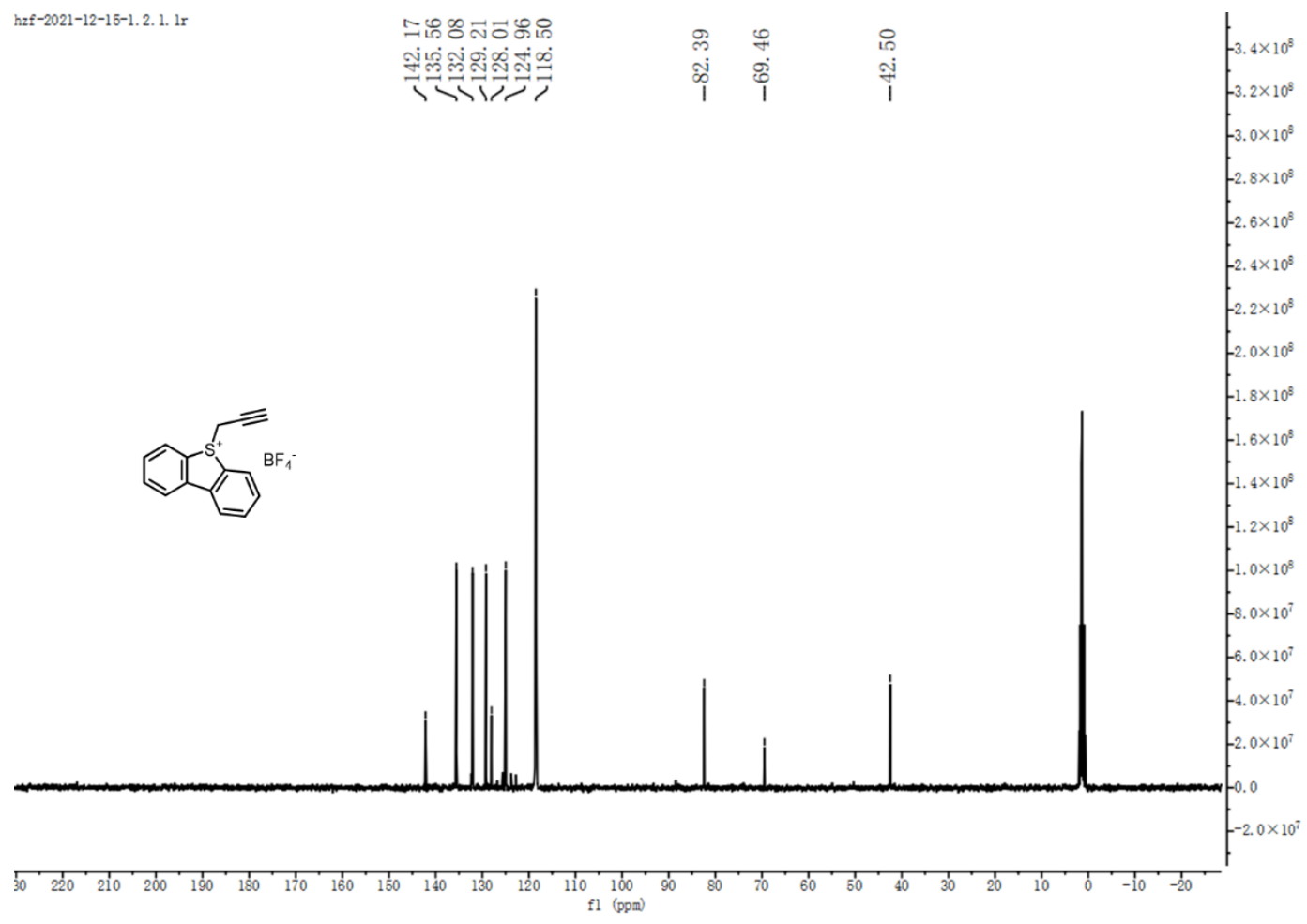

${ }^{13} \mathrm{C}$ NMR $\left(101 \mathrm{MHz}, \mathrm{CD}_{3} \mathrm{CN}\right)$ spectrum of $\mathbf{3 d}$

S44 


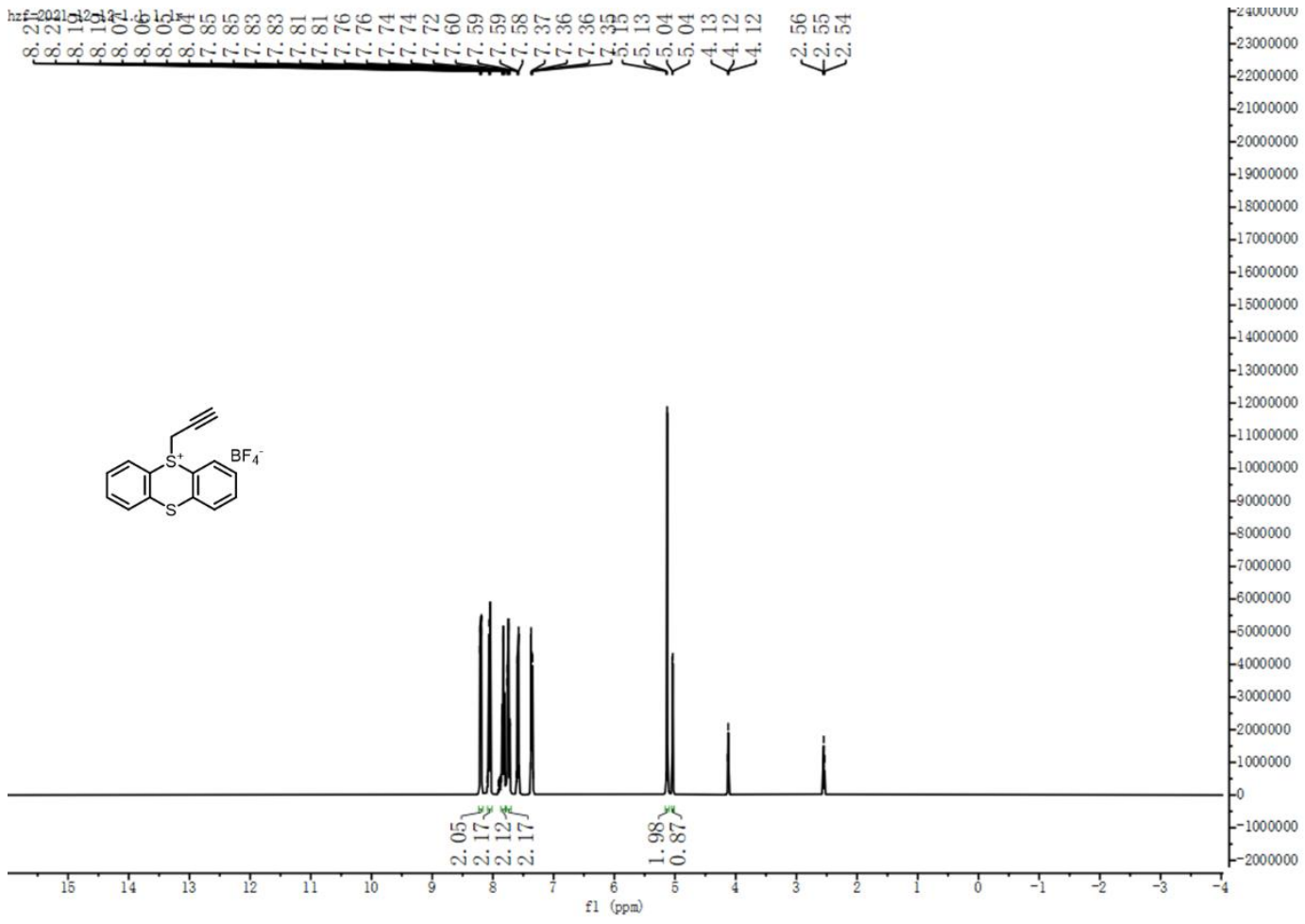

${ }^{1} \mathrm{H}$ NMR (400 MHz, DMSO- $d_{6}$ ) spectrum of $3 \mathbf{e}$

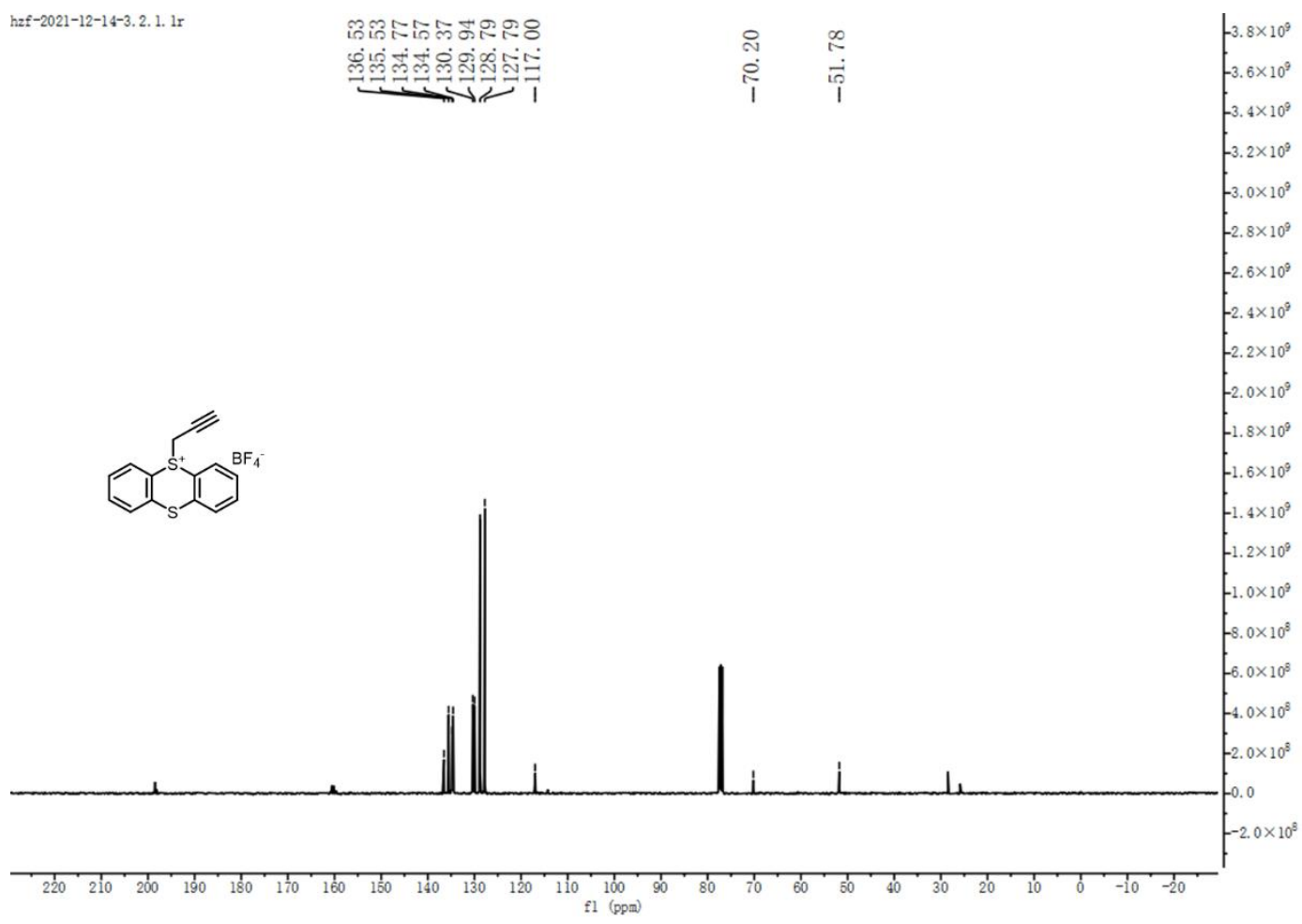

${ }^{13} \mathrm{C}$ NMR (101 MHz, DMSO- $d_{6}$ ) spectrum of $\mathbf{3 e}$ 


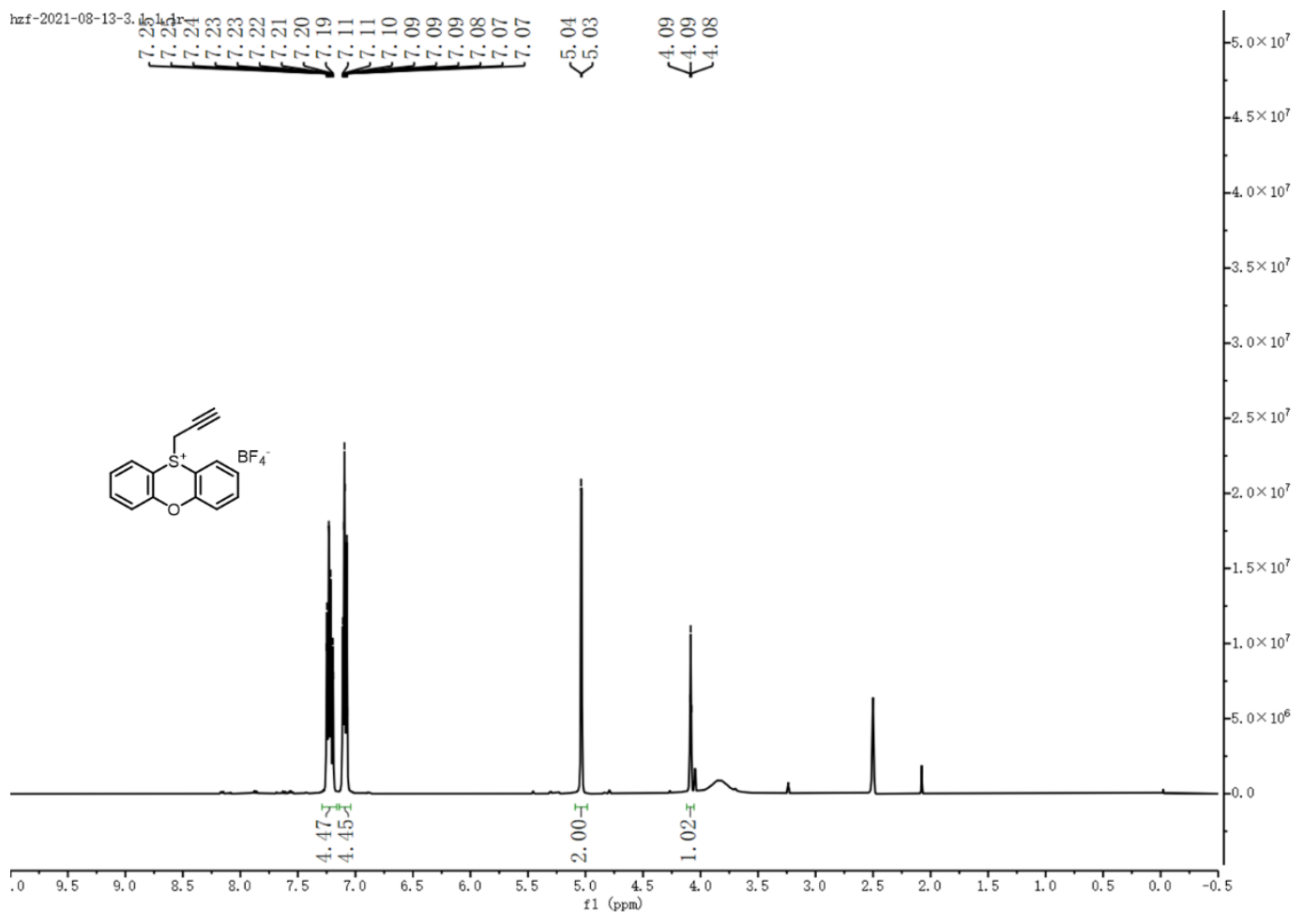

${ }^{1} \mathrm{H}$ NMR (400 MHz, DMSO- $d_{6}$ ) spectrum of $\mathbf{3 f}$

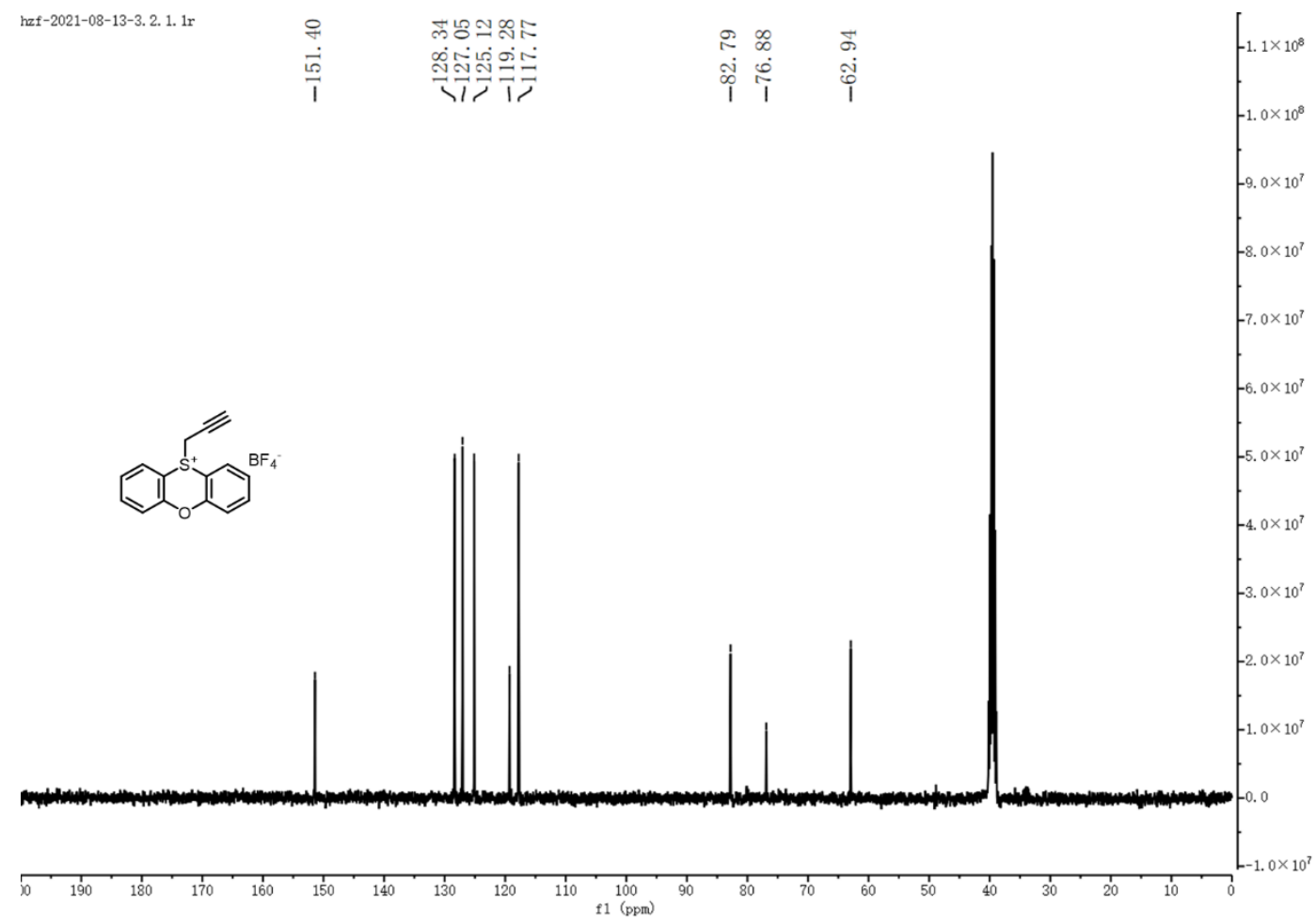

${ }^{13} \mathrm{C}$ NMR (101 MHz, DMSO- $d_{6}$ ) spectrum of $\mathbf{3 f}$ 


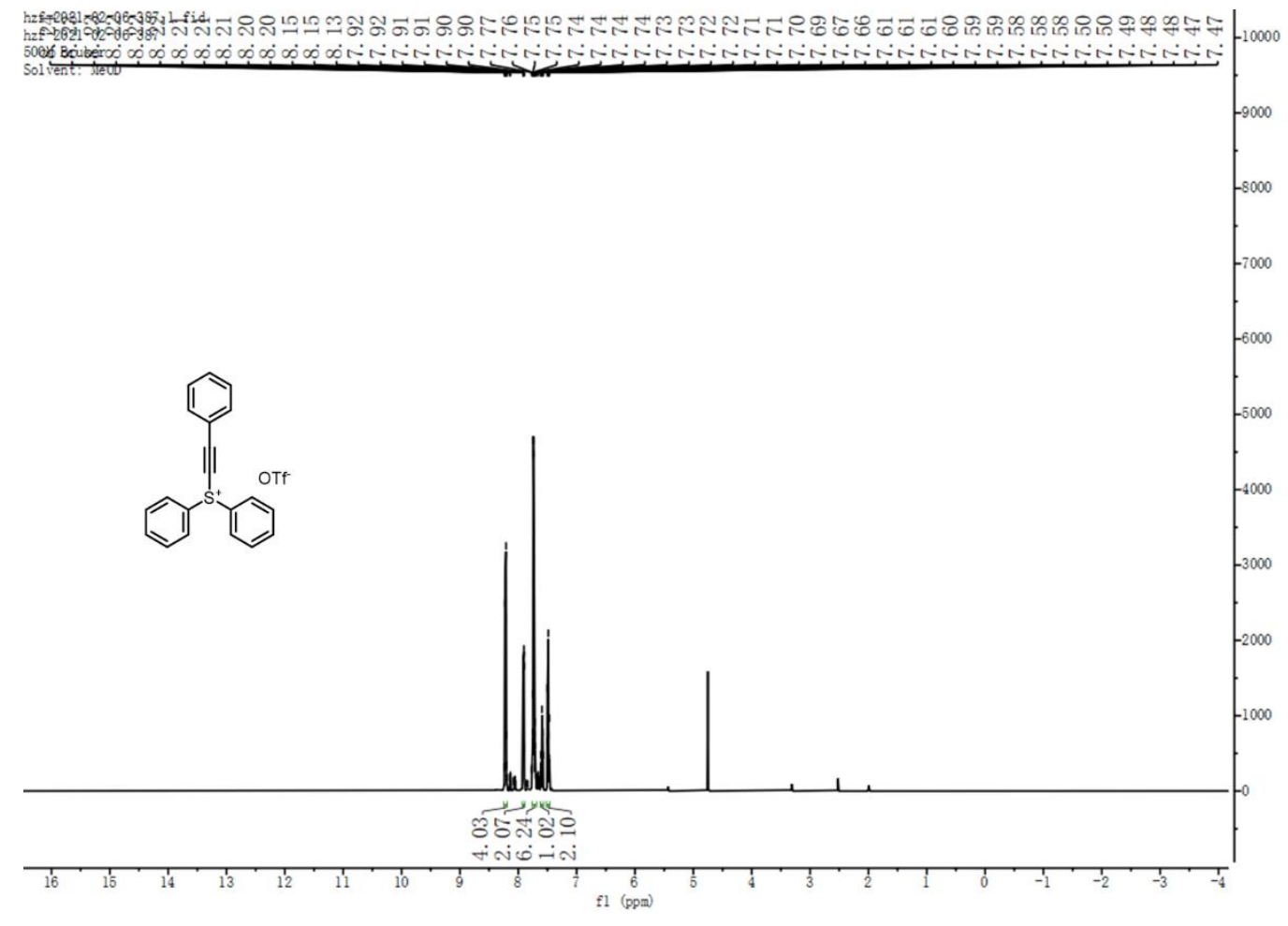

${ }^{1} \mathrm{H}$ NMR (500 MHz, Methanol- $\left.d_{4}\right)$ spectrum of $\mathbf{3 g}$

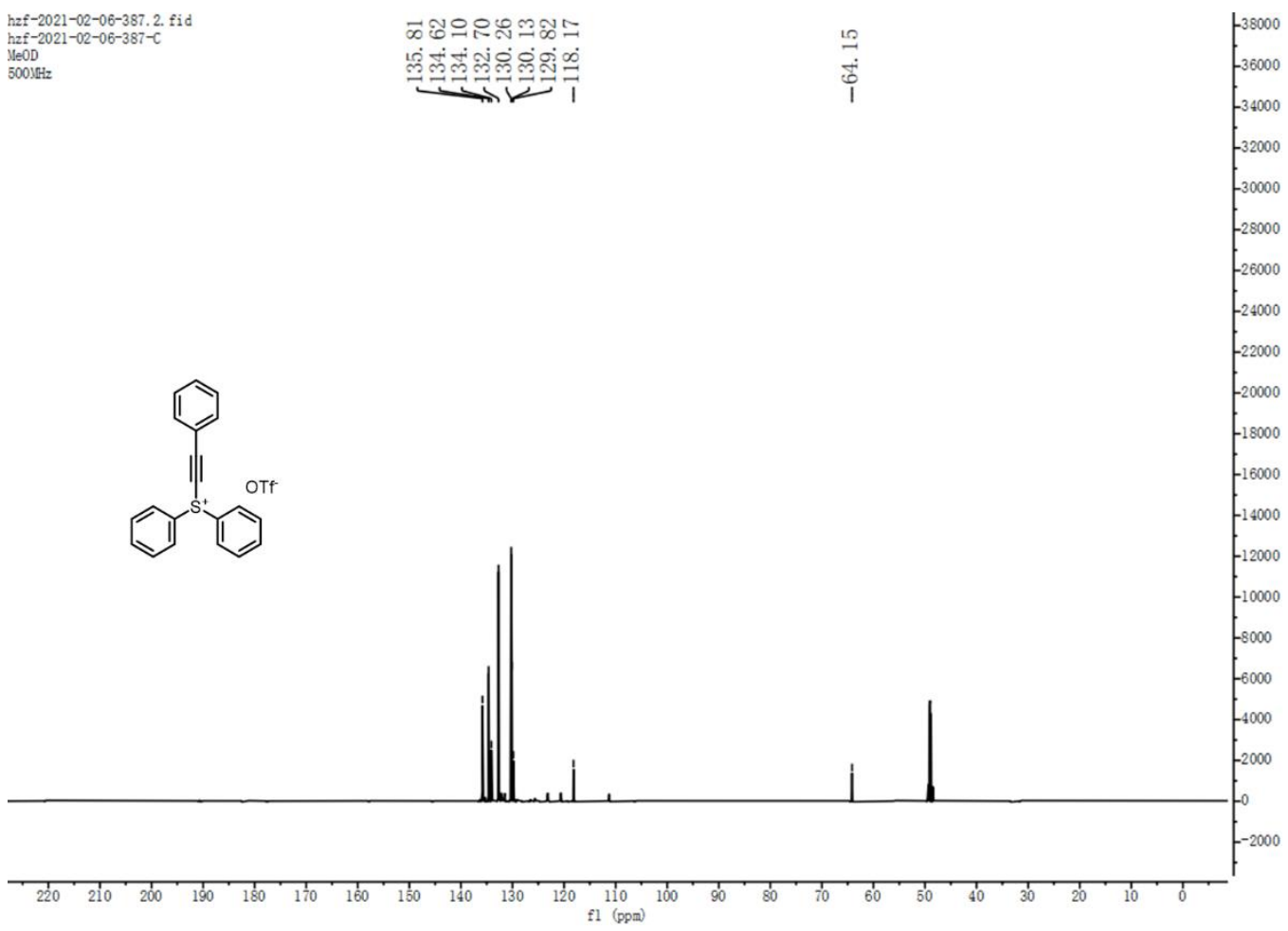

${ }^{13} \mathrm{C}$ NMR (126 MHz, Methanol- $d_{4}$ ) spectrum of $\mathbf{3 g}$ 


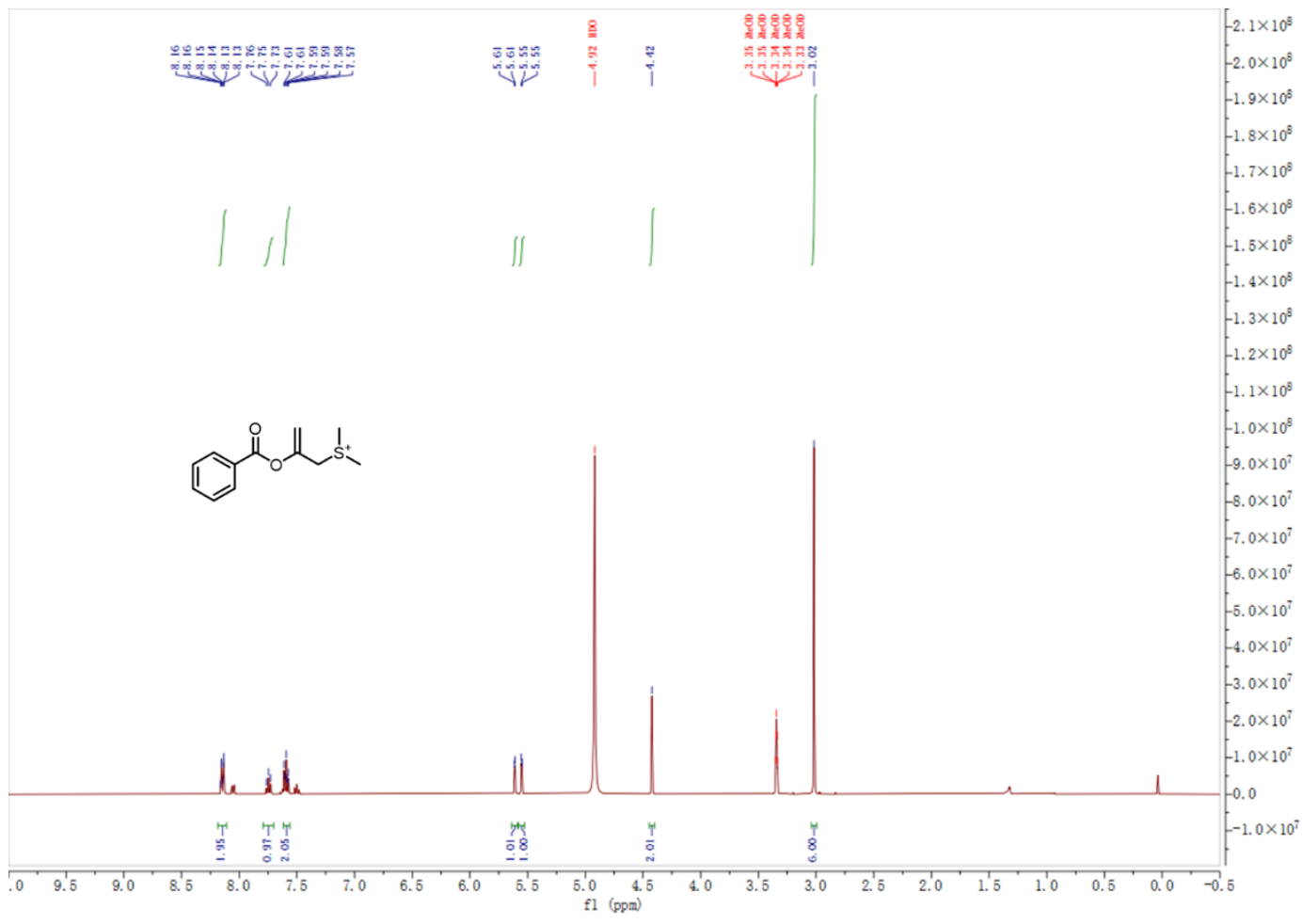

${ }^{1} \mathrm{H}$ NMR (400 MHz, Methanol- $d_{4}$ ) spectrum of $\mathbf{S 1}$

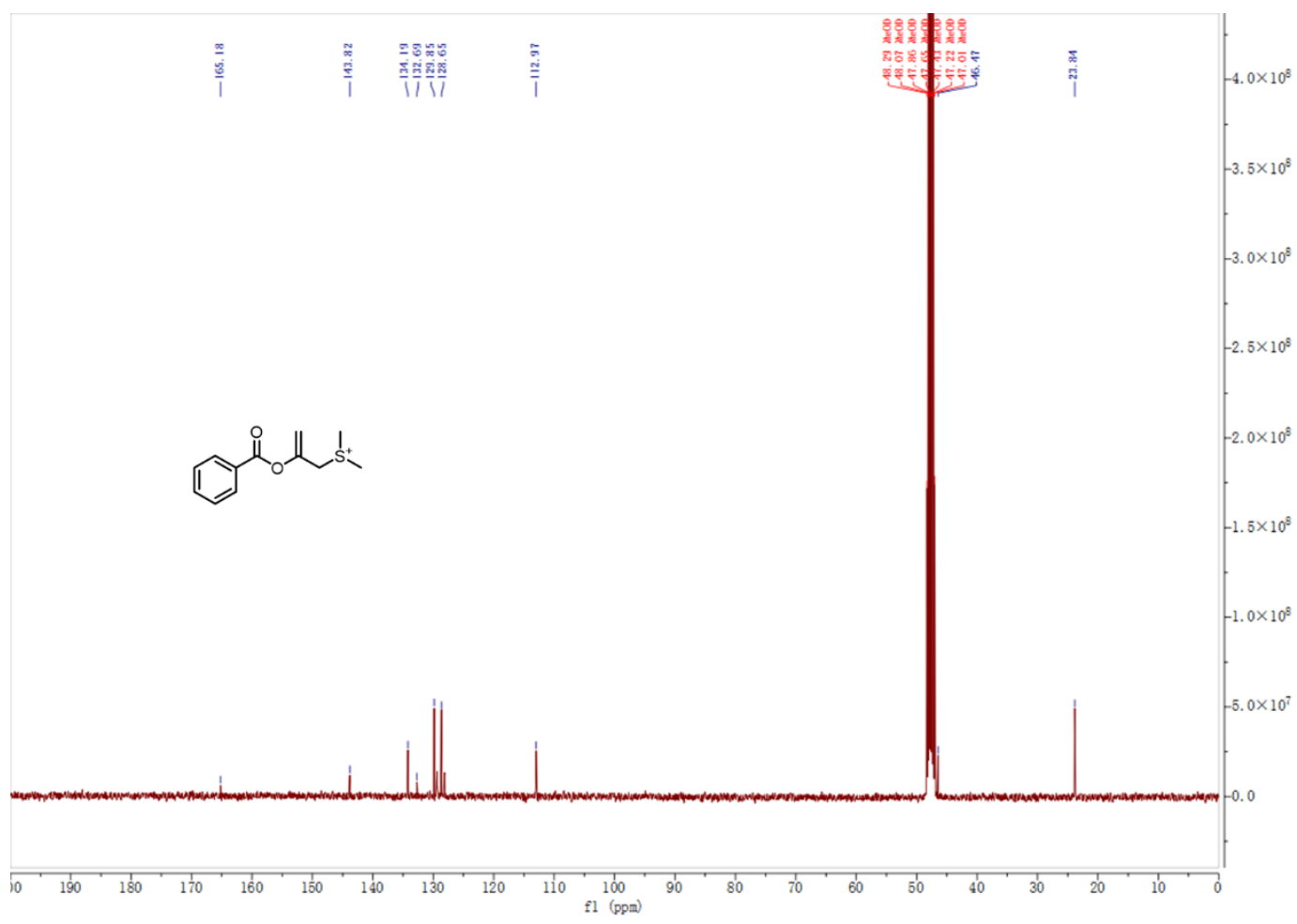

${ }^{13} \mathrm{C}$ NMR (101 MHz, Methanol- $d_{4}$ ) spectrum of $\mathbf{S 1}$ 


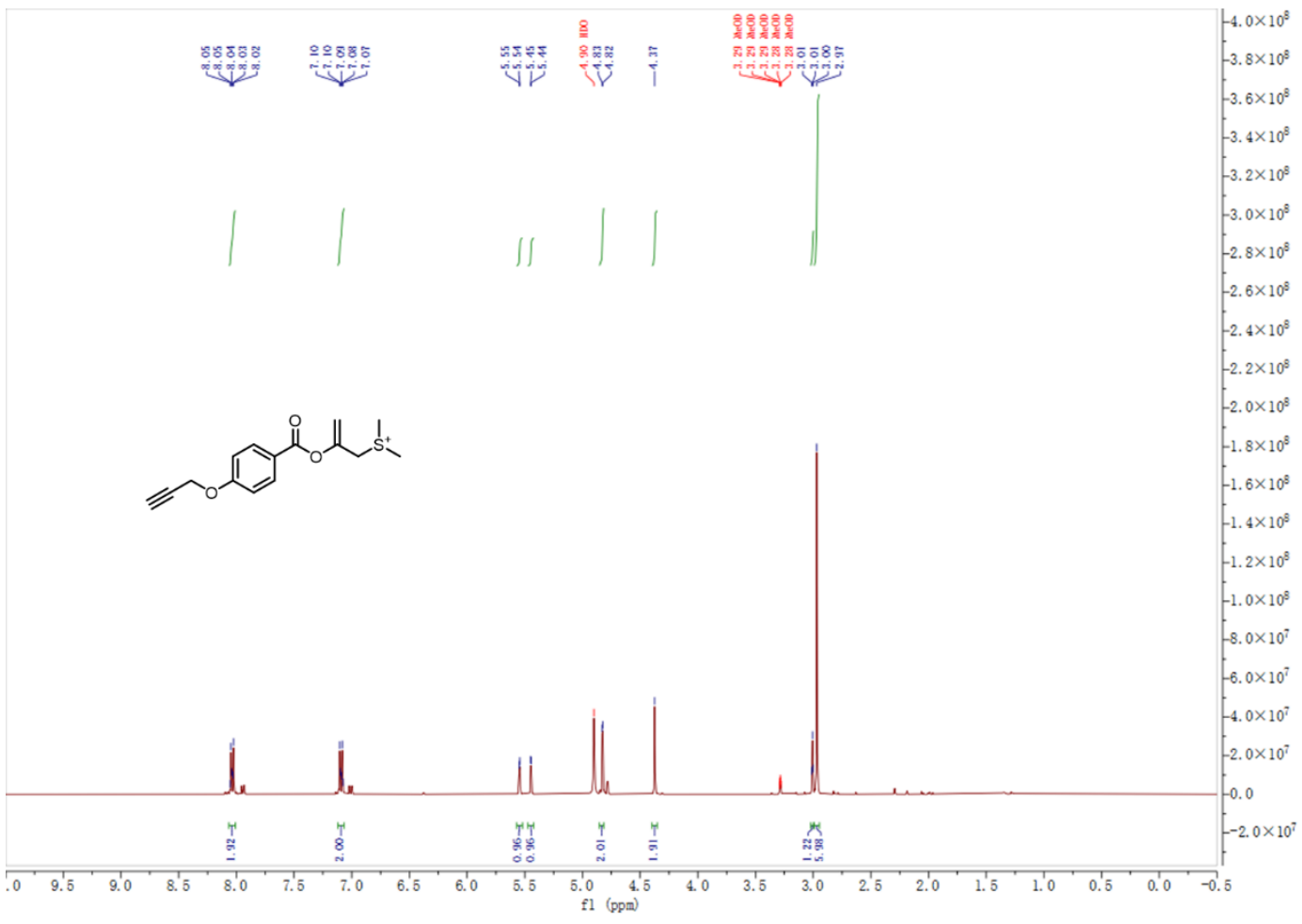

${ }^{1} \mathrm{H}$ NMR (400 MHz, Methanol- $d_{4}$ ) spectrum of P3

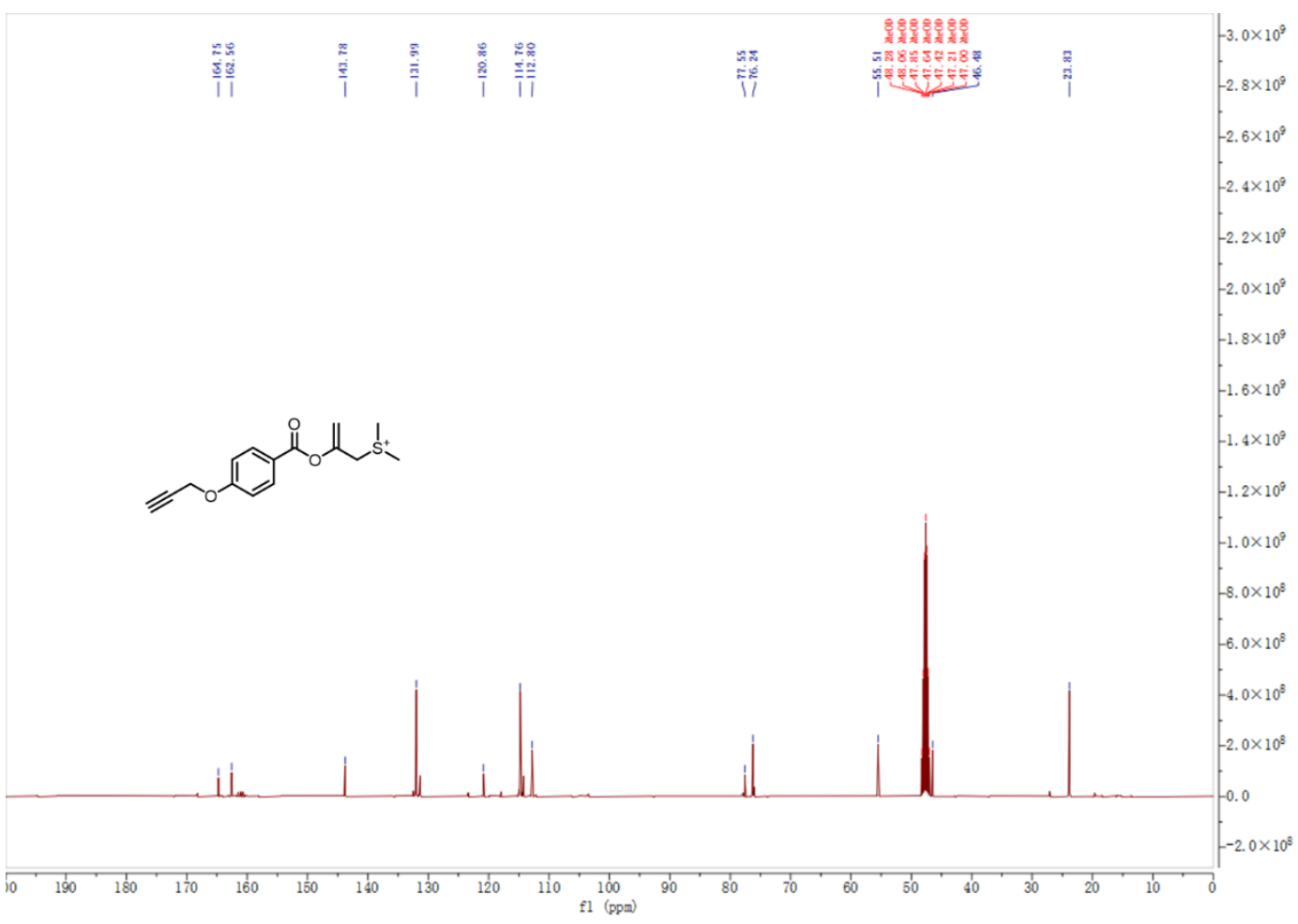

${ }^{13} \mathrm{C}$ NMR (101 MHz, Methanol- $d_{4}$ ) spectrum of $\mathbf{P 3}$ 


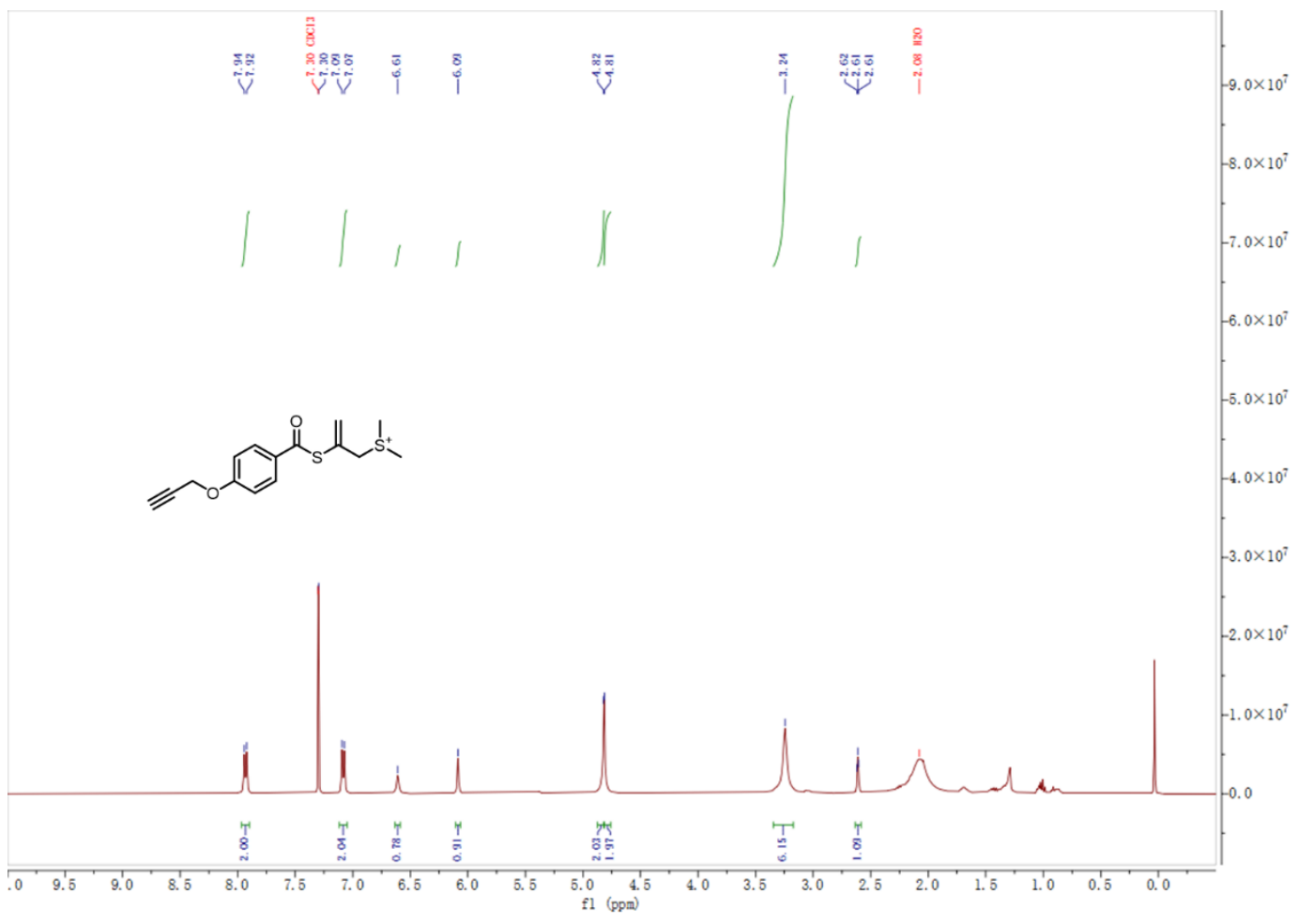

${ }^{1} \mathrm{H}$ NMR (400 MHz, $\mathrm{CDCl}_{3}$ ) spectrum of $\mathbf{P 4}$

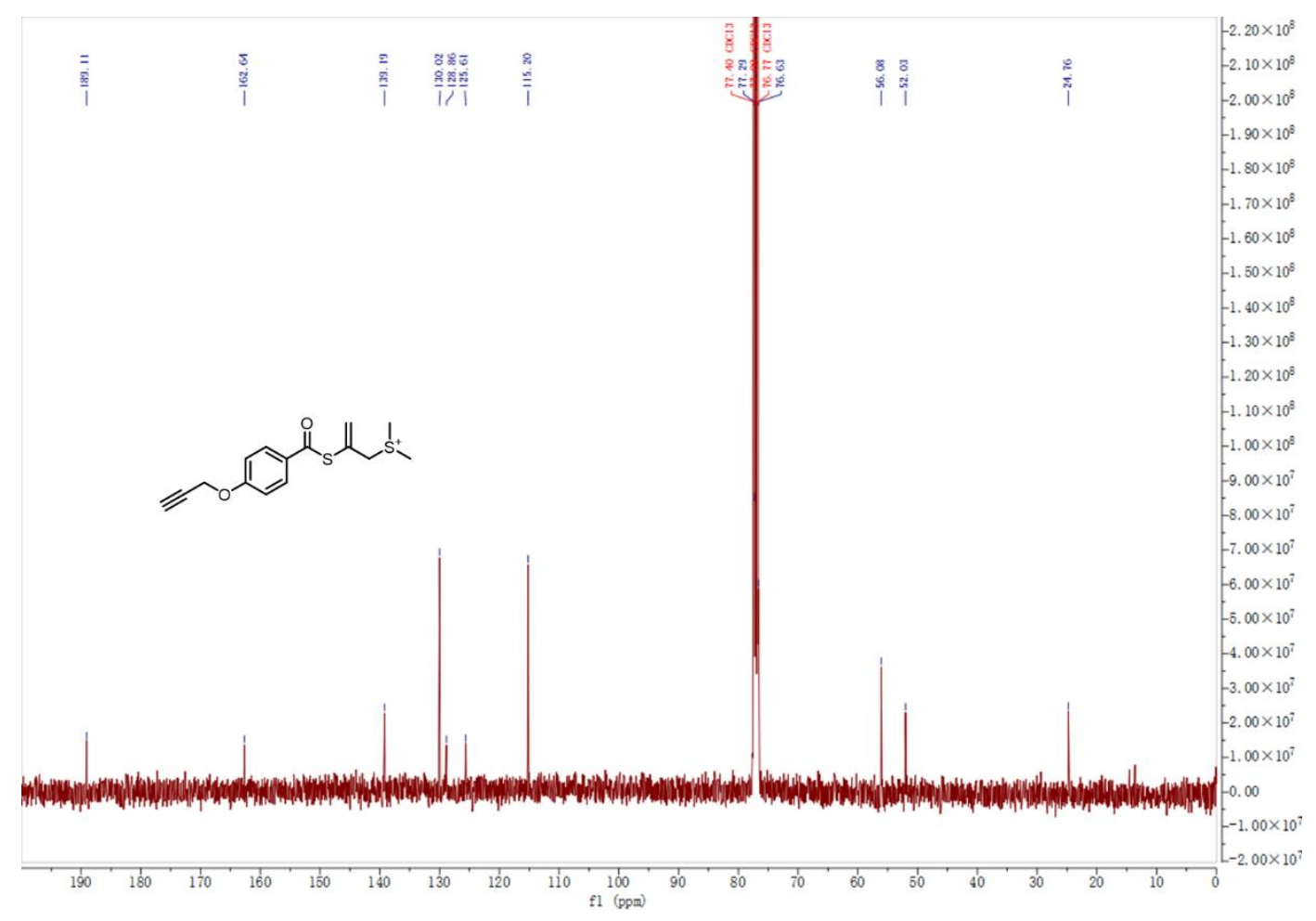

${ }^{13} \mathrm{C}$ NMR (101 MHz, $\mathrm{CDCl}_{3}$ ) spectrum of $\mathbf{P 4}$ 


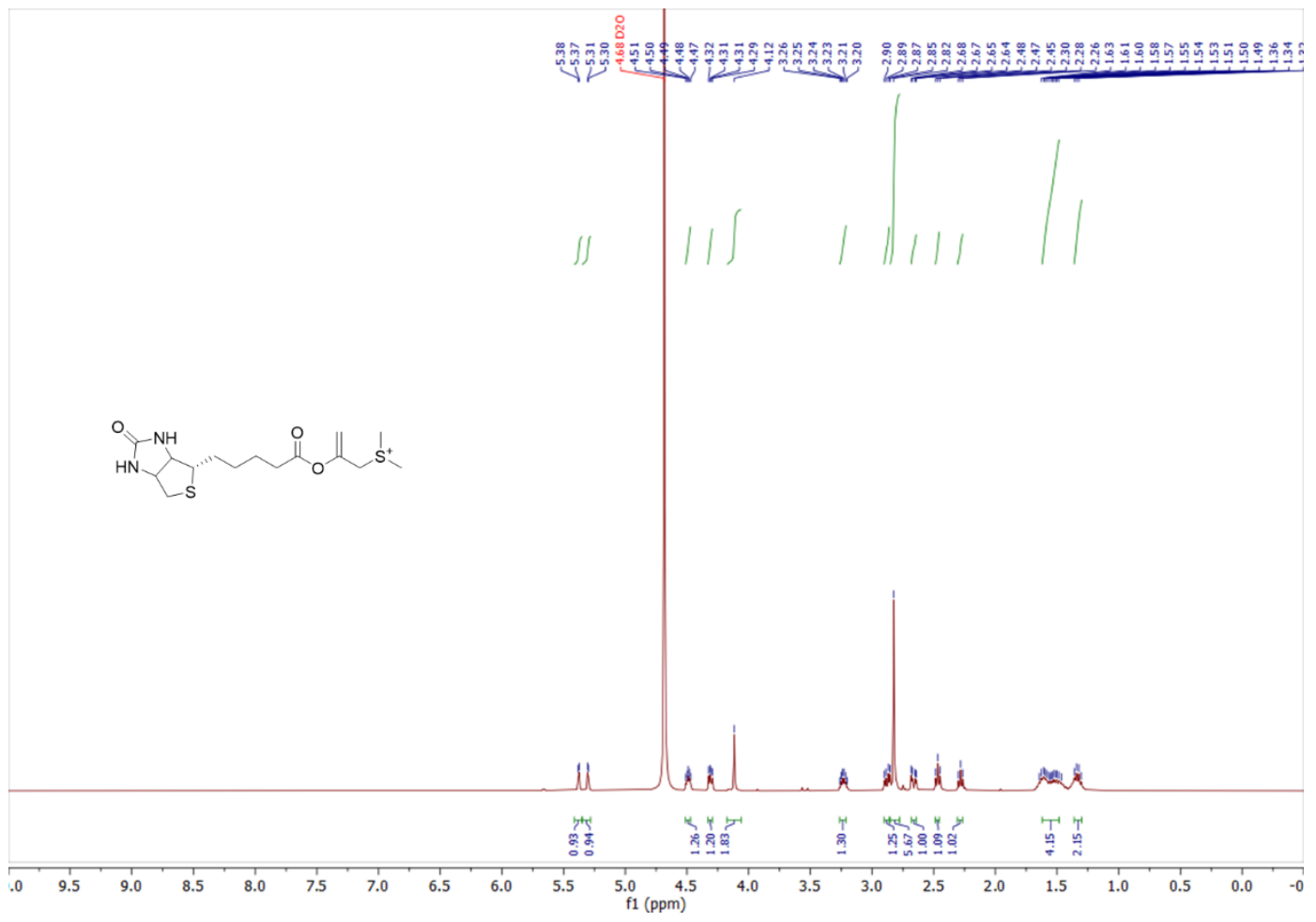

${ }^{1} \mathrm{H}$ NMR (400 MHz, $\mathrm{D}_{2} \mathrm{O}$ ) spectrum of $\mathbf{P 5}$

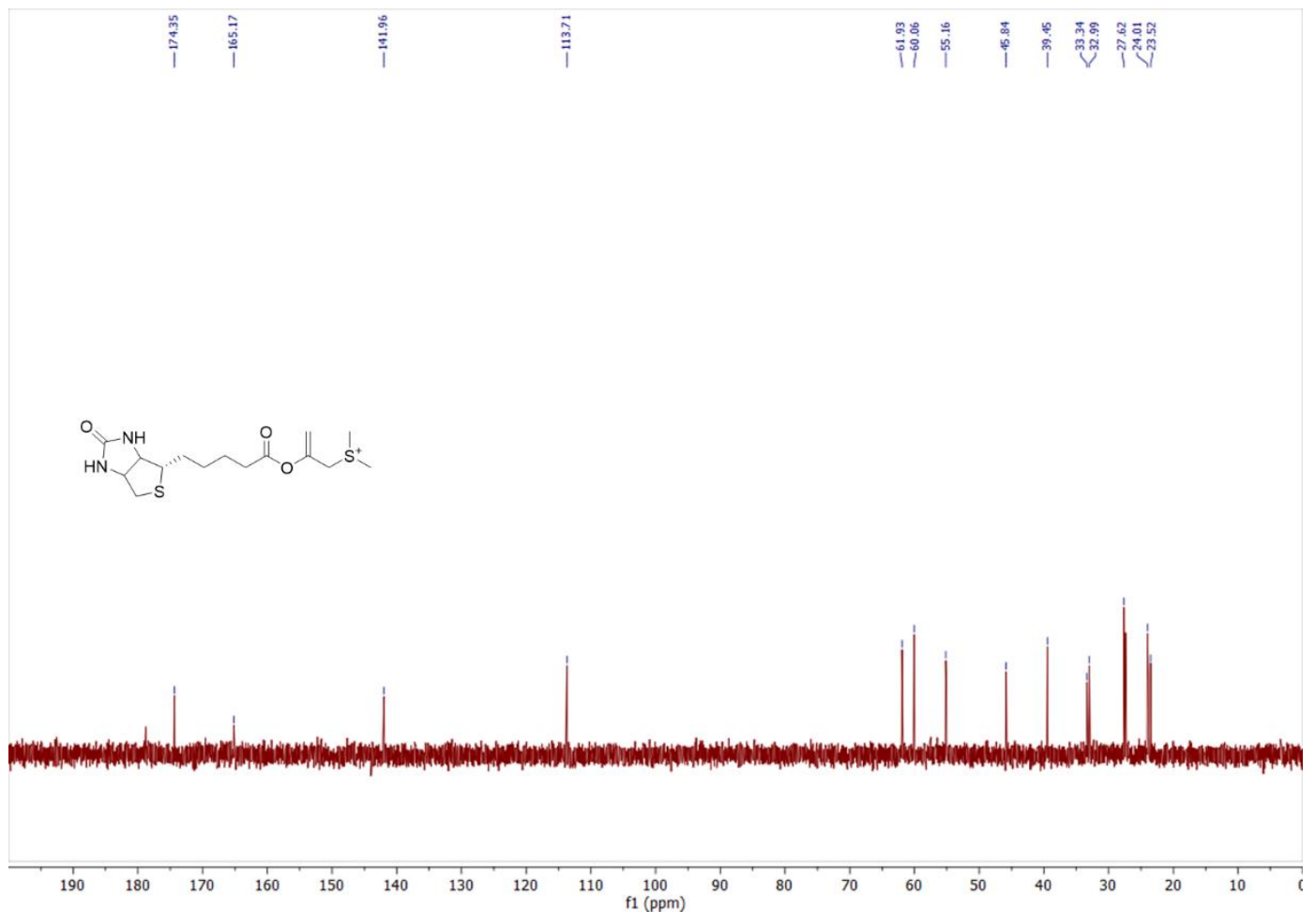

${ }^{13} \mathrm{C}$ NMR (101 MHz, $\mathrm{D}_{2} \mathrm{O}$ ) spectrum of $\mathbf{P 5}$ 


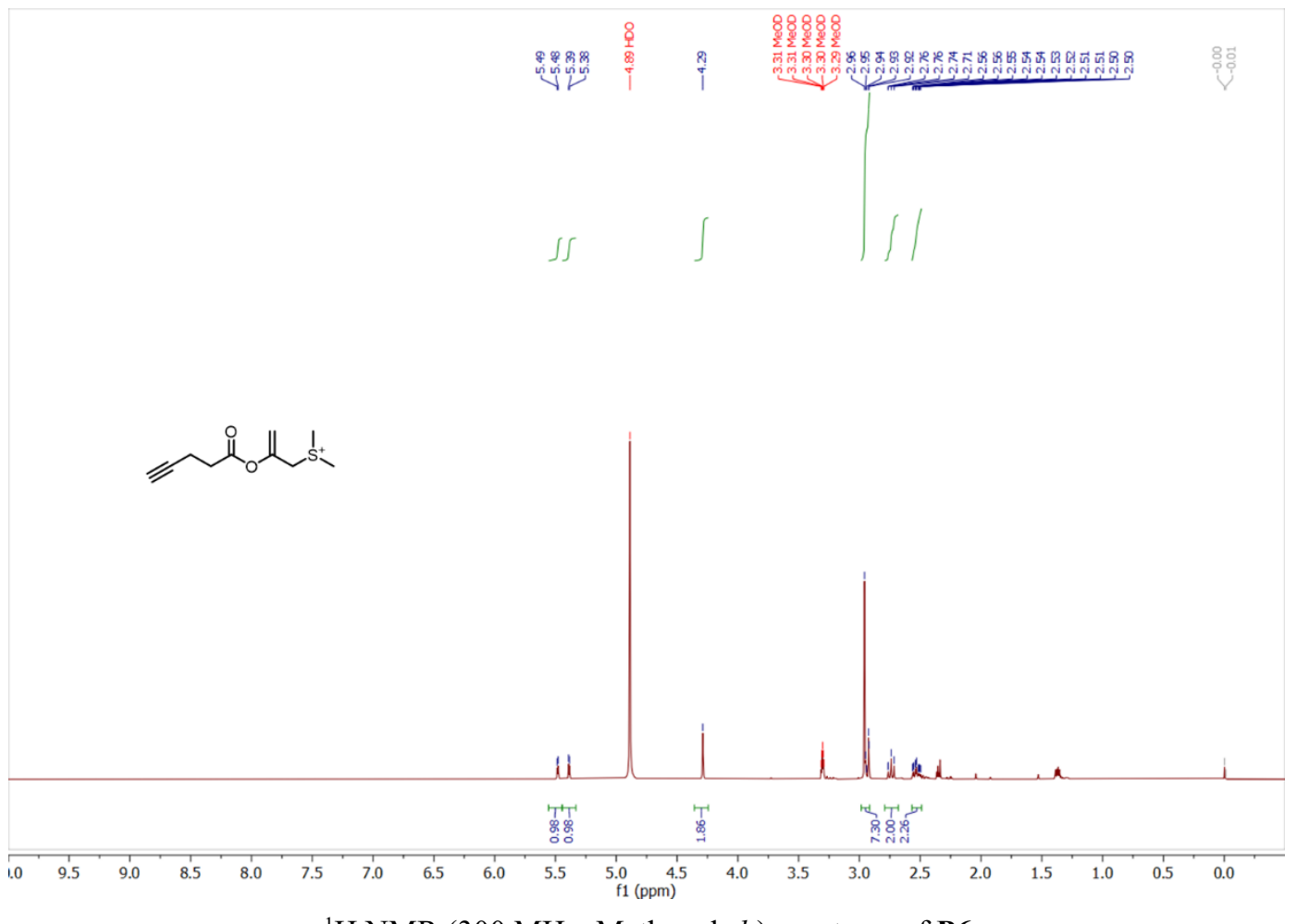

${ }^{1} \mathrm{H}$ NMR (300 MHz, Methanol- $d_{4}$ ) spectrum of $\mathbf{P 6}$

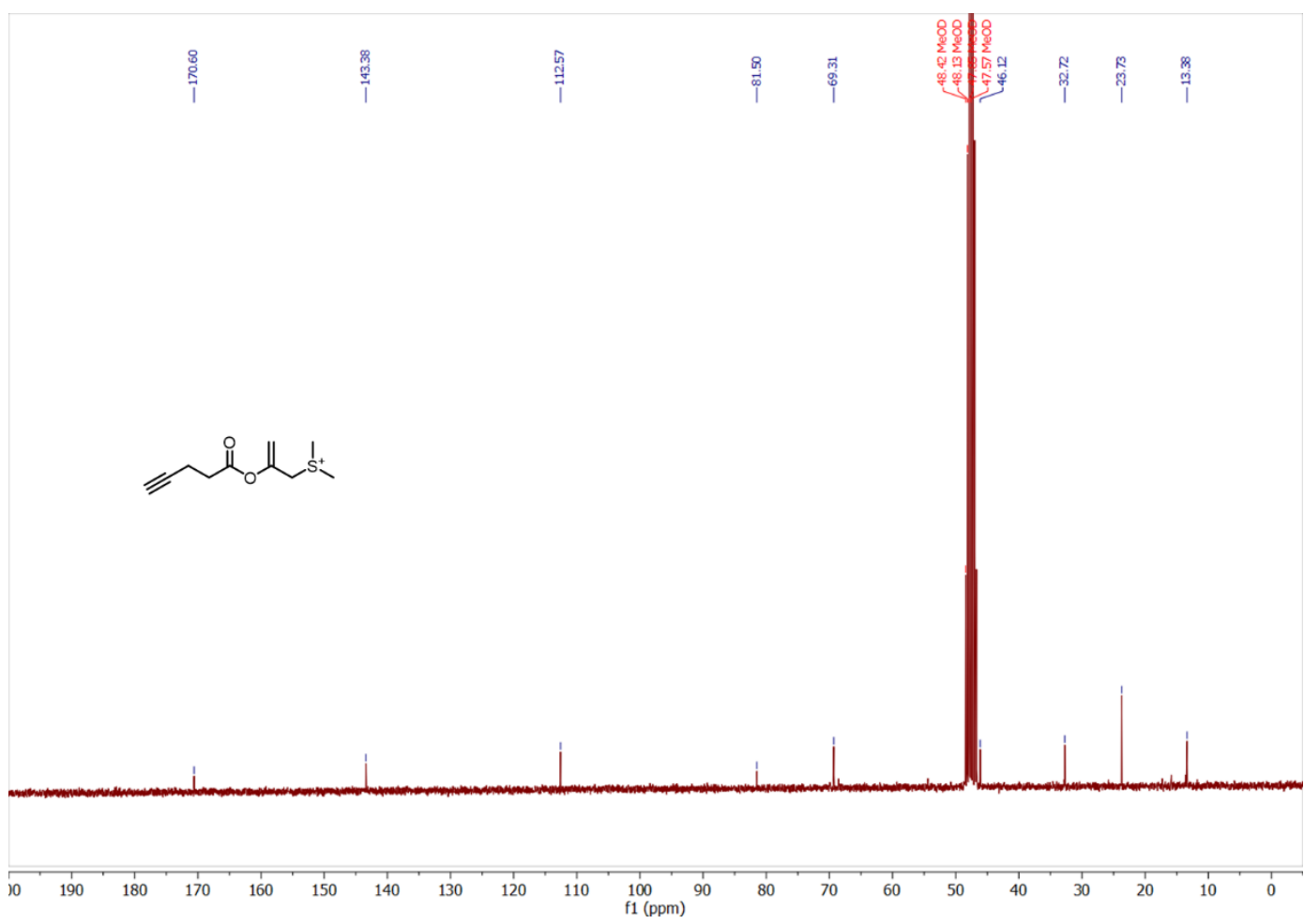

${ }^{13} \mathrm{C}$ NMR (75 MHz, Methanol- $d_{4}$ ) spectrum of $\mathbf{P 6}$ 


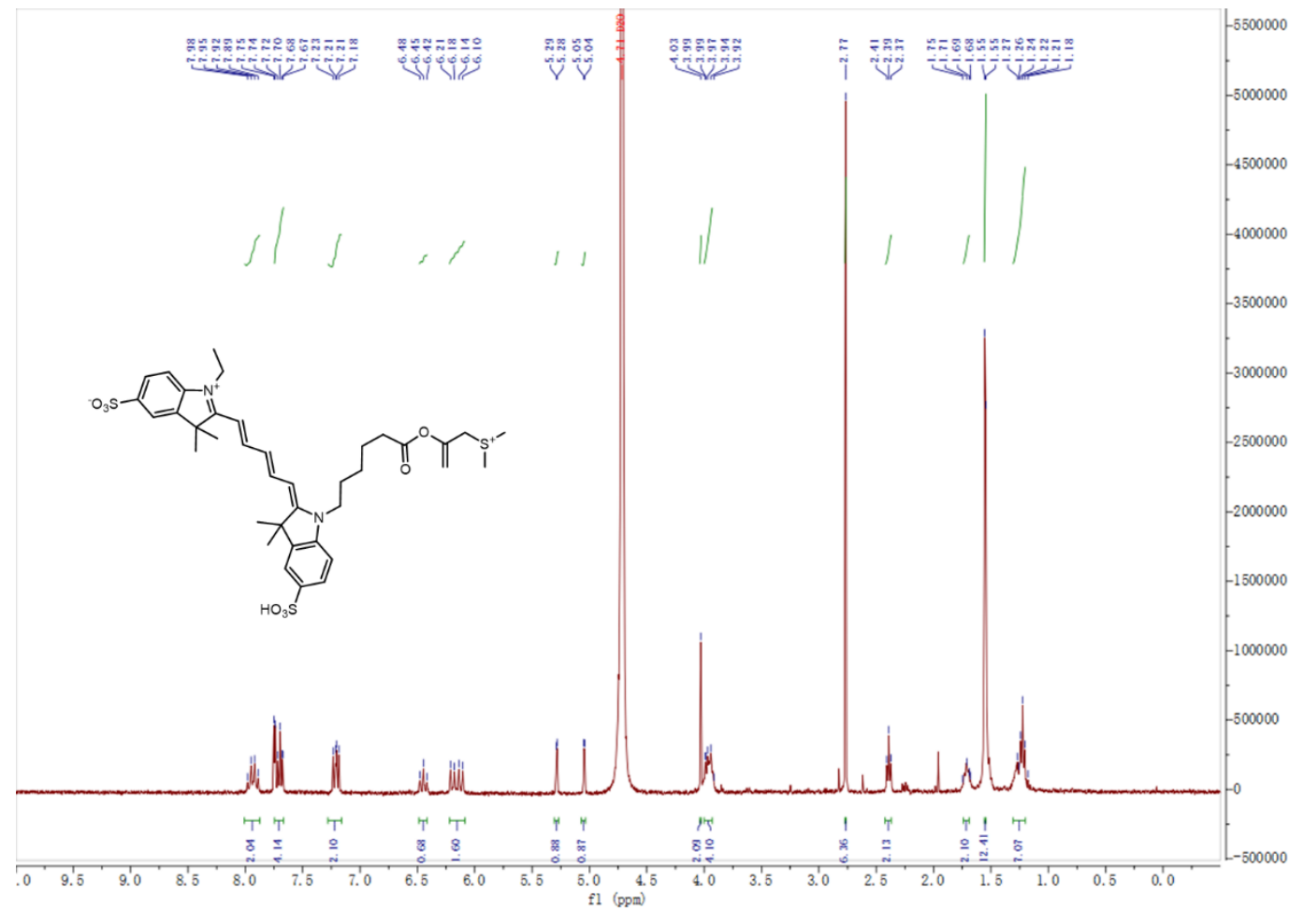

${ }^{1} \mathrm{H}$ NMR (400 MHz, $\left.\mathrm{D}_{2} \mathrm{O}\right)$ spectrum of $\mathbf{P} 7$

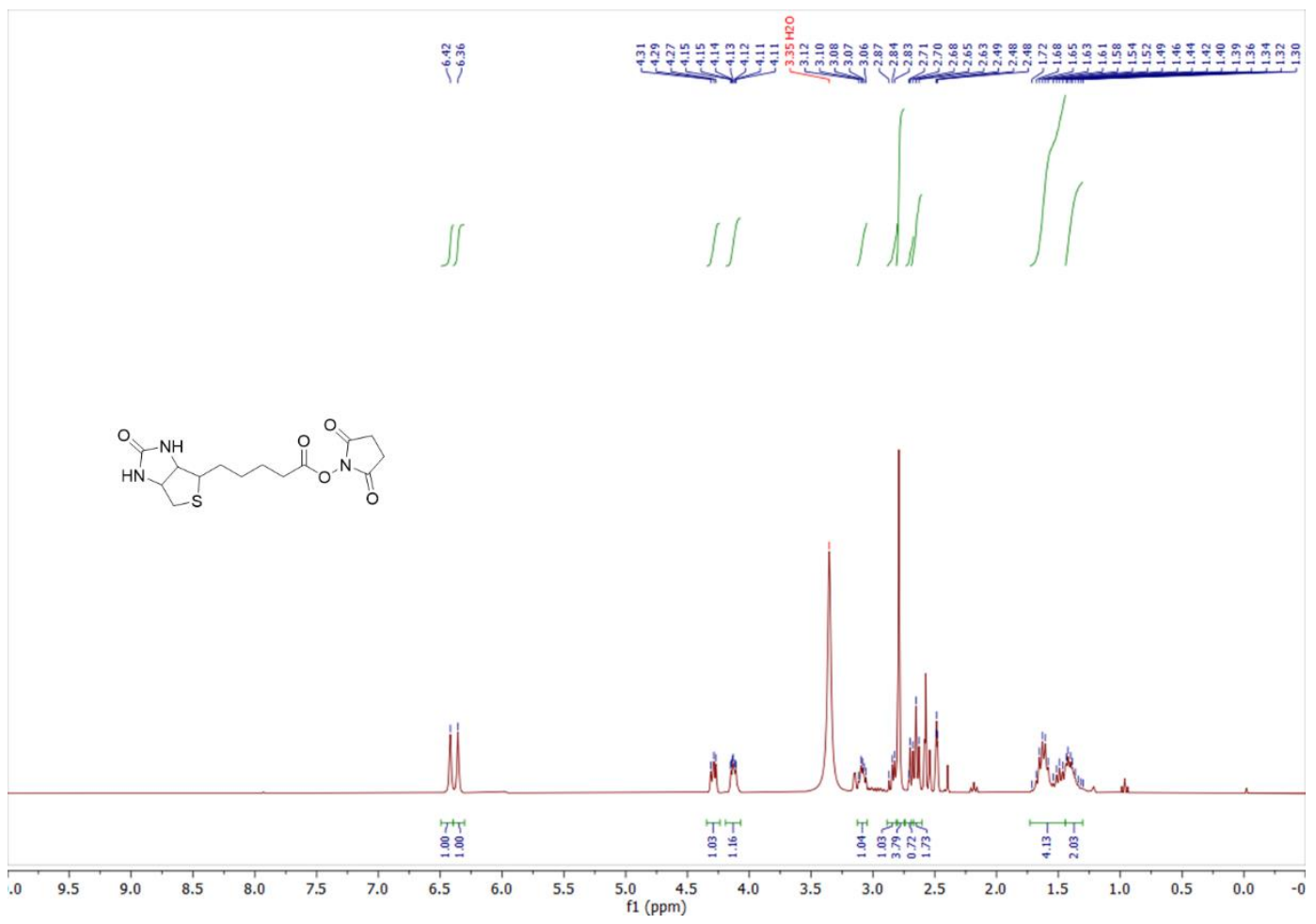

${ }^{1} \mathrm{H}$ NMR (300 MHz, DMSO- $d_{6}$ ) spectrum of $\mathbf{P 8}$ 

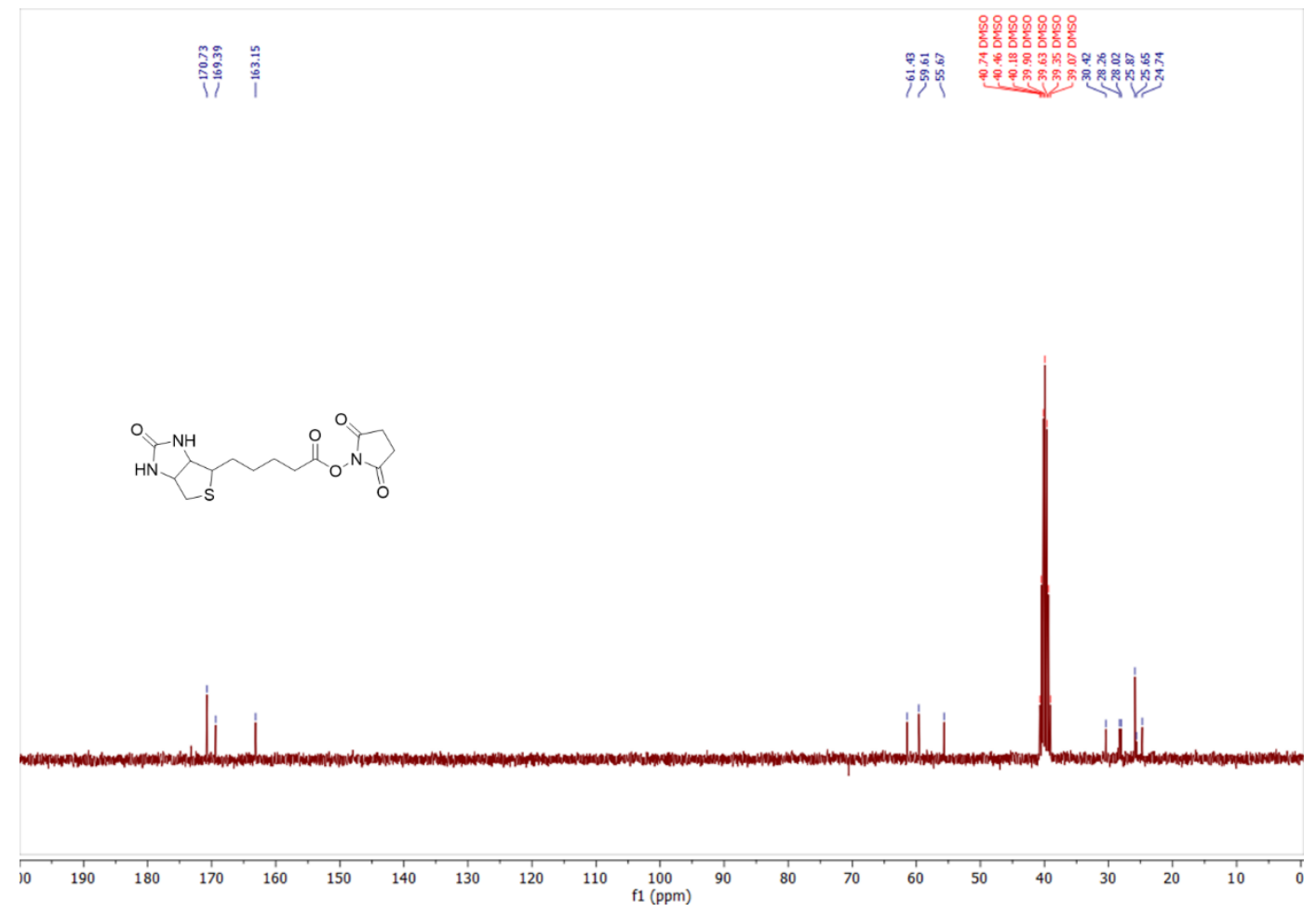

${ }^{13} \mathrm{C}$ NMR (75 MHz, DMSO- $d_{6}$ ) spectrum of $\mathbf{P 8}$

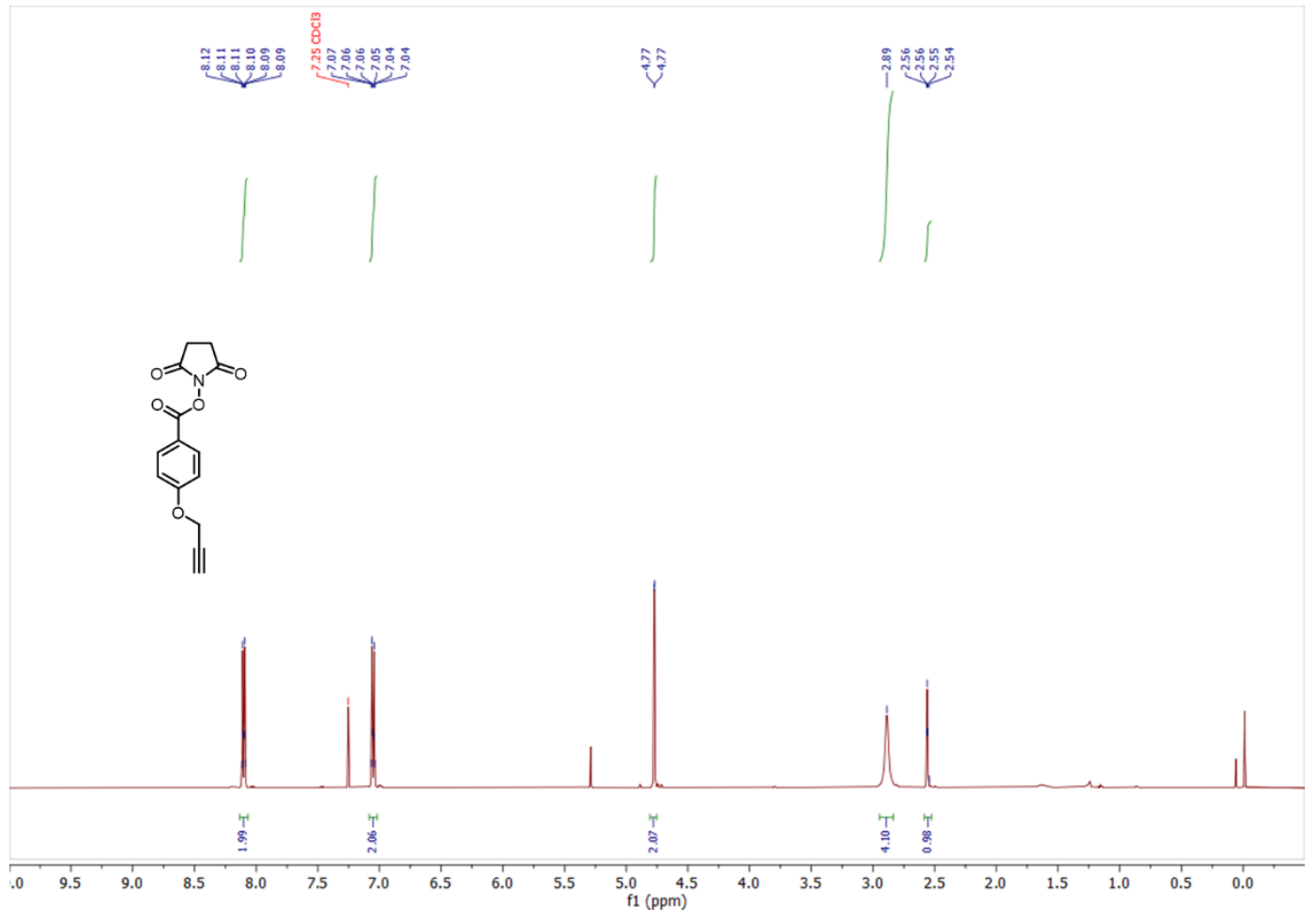

${ }^{1} \mathrm{H}$ NMR $\left(500 \mathrm{MHz}, \mathrm{CDCl}_{3}\right.$ ) spectrum of $\mathbf{P 9}$ 


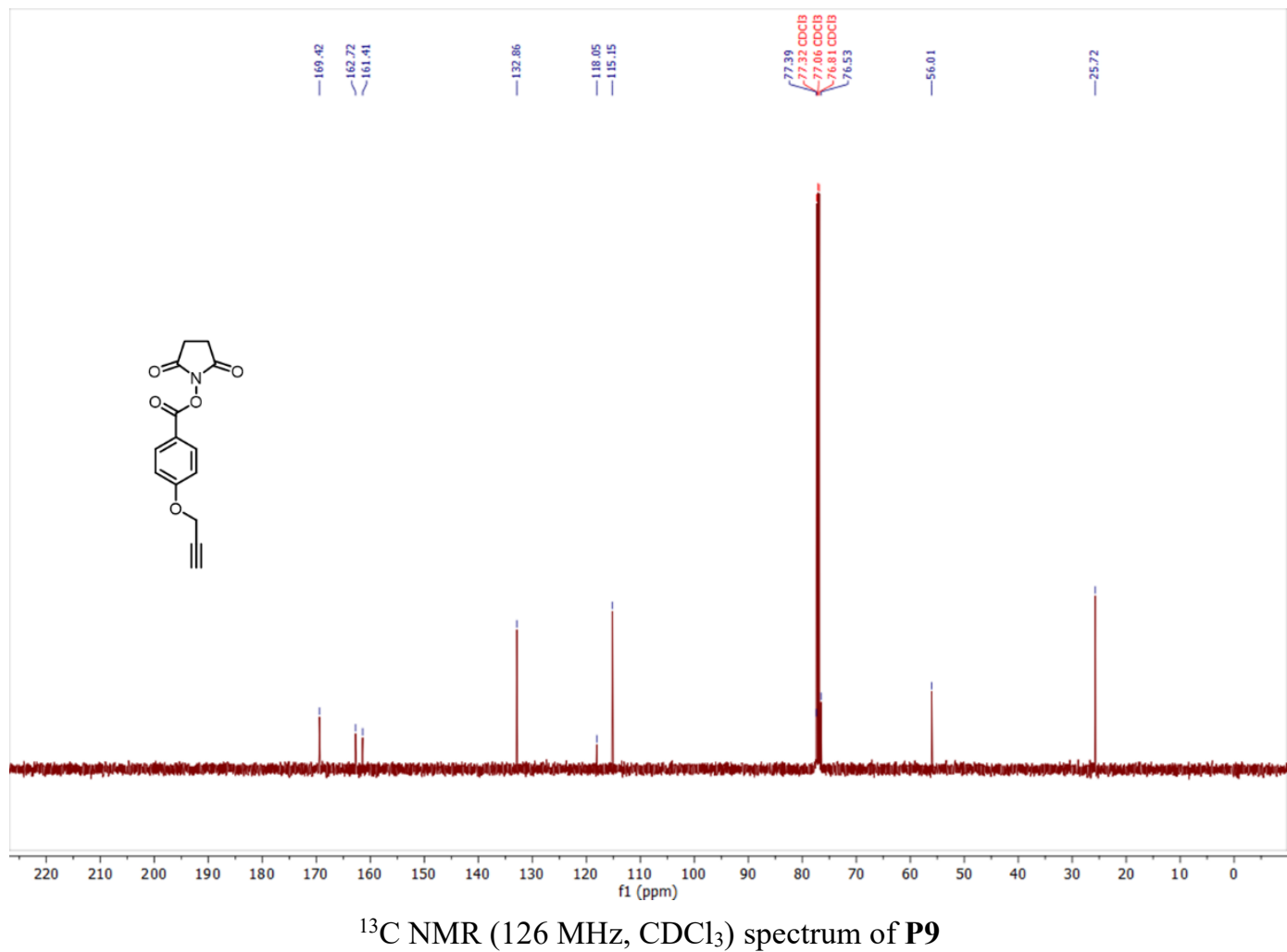


6a, Sequence: Fmoc-GD-NH

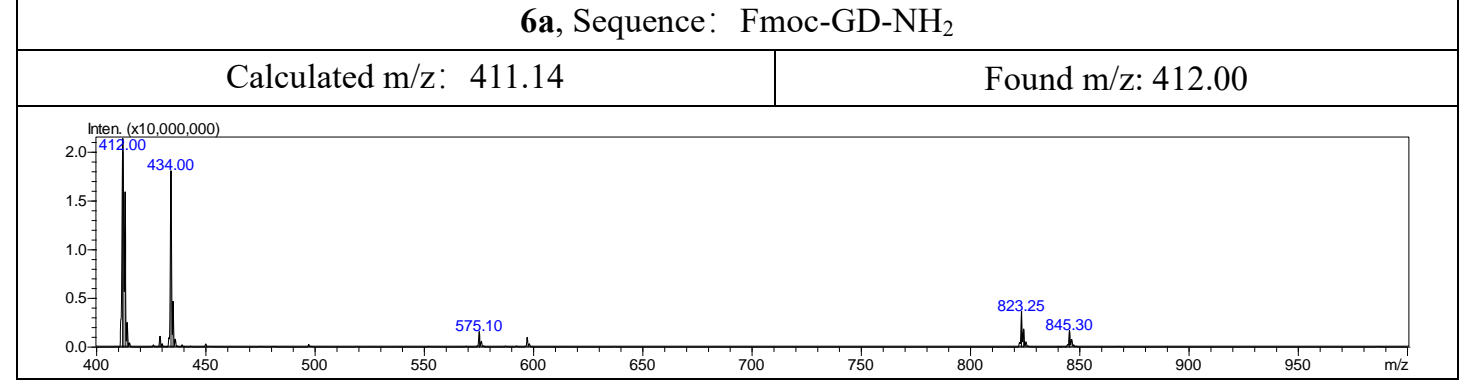

6b, Sequence: Fmoc-WA-NH 2
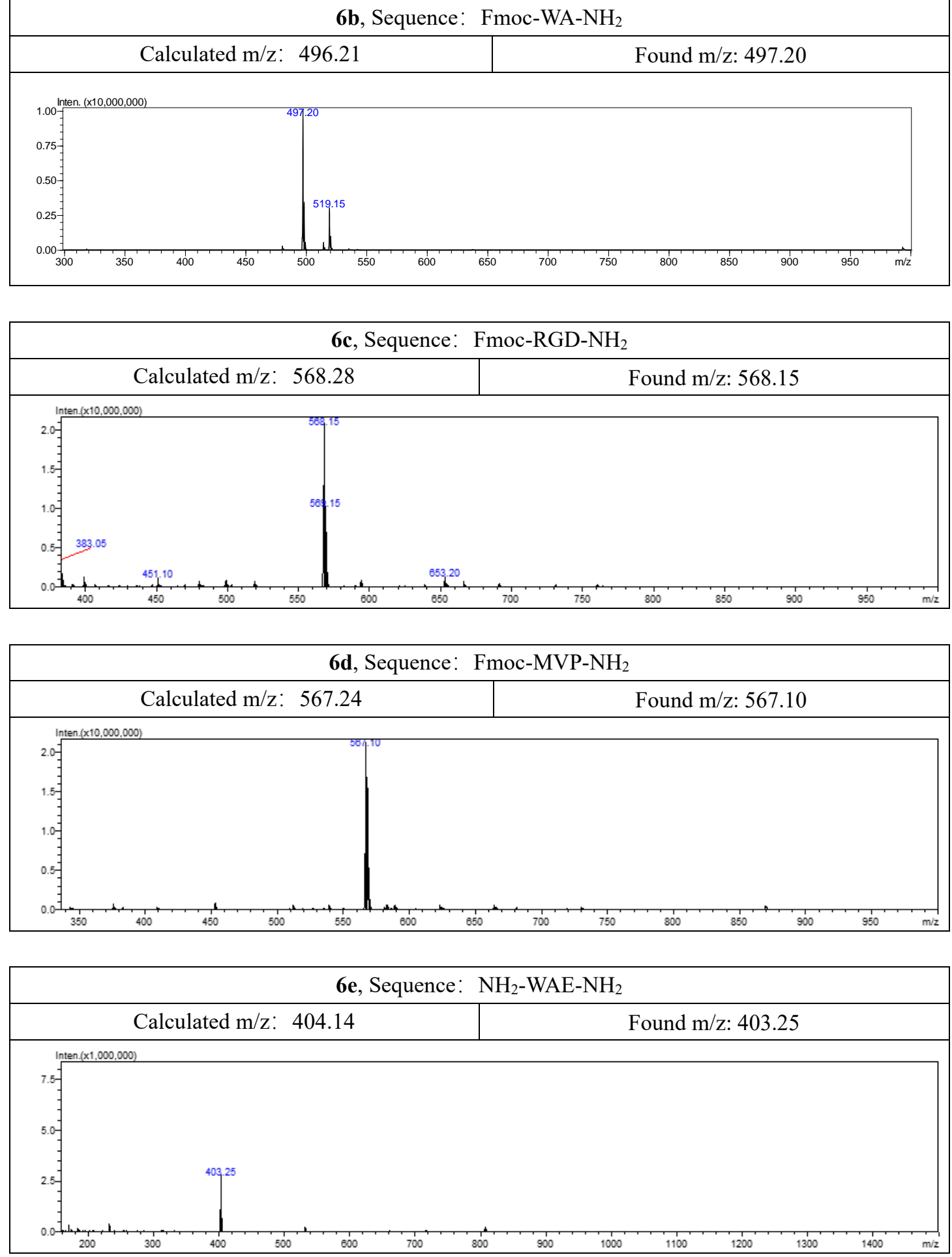

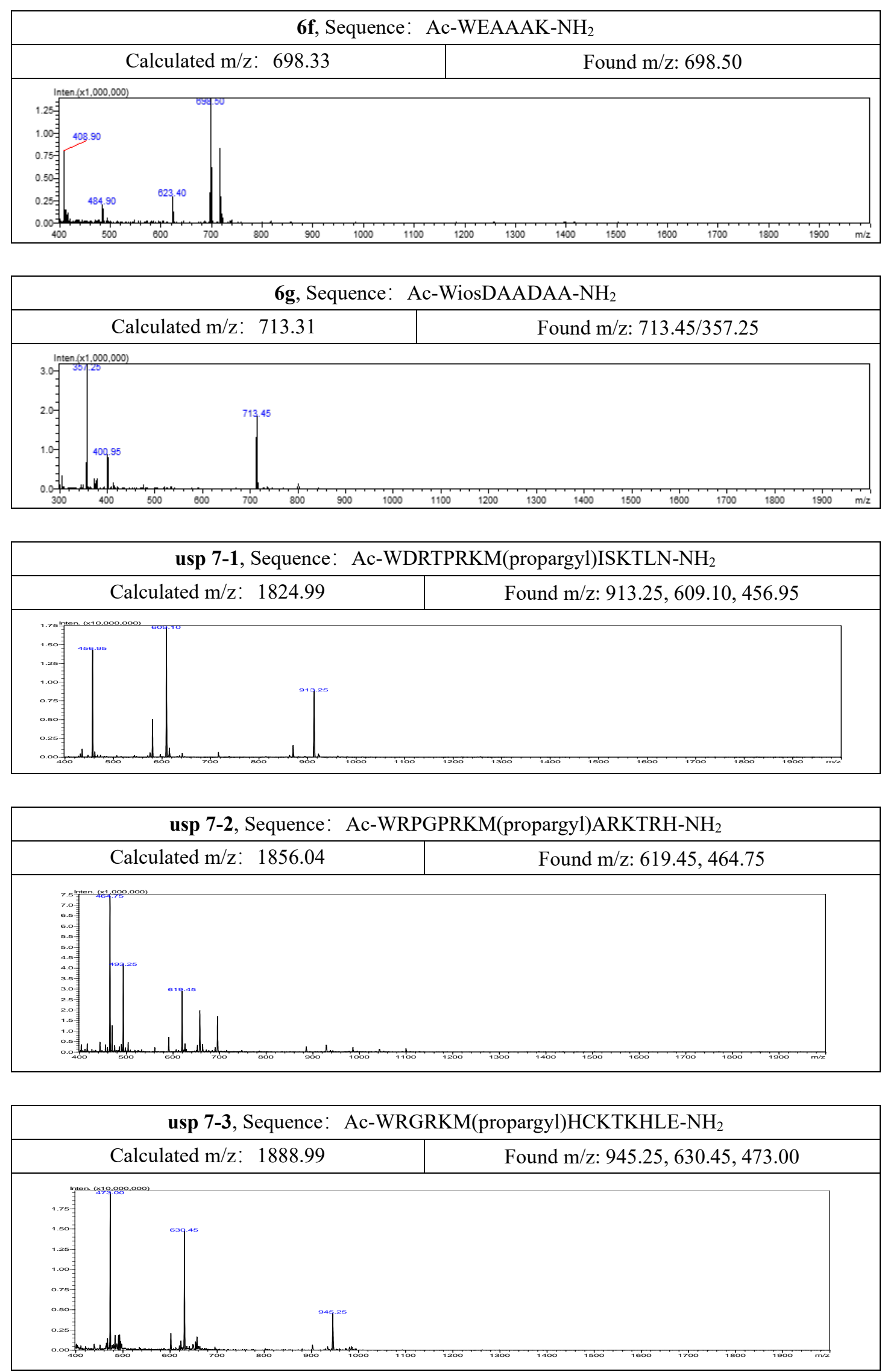

usp 7-4, Sequence: Ac-WRPGPRKM(propargyl-4-pentynoic acid)ARKTRH-NH 


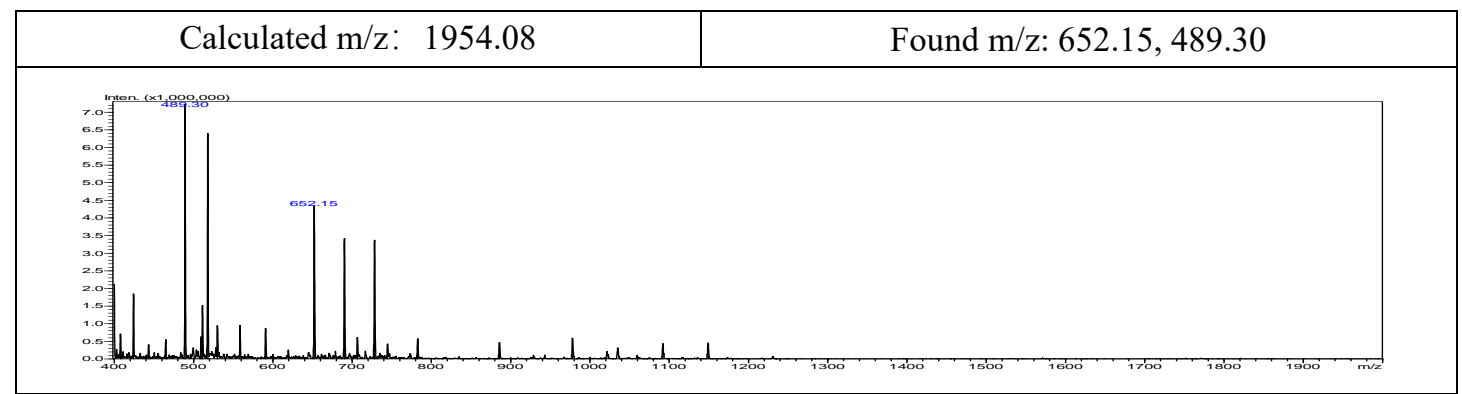

